\title{
SIMILARITY LAWS \\ FOR TURBULENT BOUNDARY LAYERS \\ WITH SUCTION OR INJECTION
}

\section{PROEFSCHRIFT}

TER VERKRIJGING VAN DE GRAAD VAN DOCTOR IN DE TECHNISCHE WETENSCHAPPEN AAN DE TECHNISCHE HOGESCHOOL TE DELFT, OP GEZAG VAN DE RECTOR MAGNIFICUS IR. H. J. DE WIJS, HOOGLERAAR IN DE AFDELING DER MIJNBOUWKUNDE, TE VERDEDIGEN OP WOENSDAG 16 DECEMBER 1964, DES NAMIDDAGS TE 4 UUR

door

HENDRIK TENNEKES

vliegtuigbouwkundig ingenieur geboren te Kampen

\section{8}

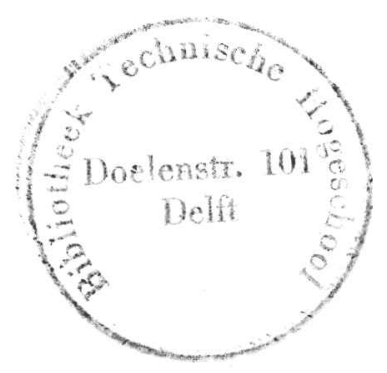


Dit proefschrift is goedgekeurd door de promotor prof. dr. ir. J. A. Steketee 
Aan mijn ouders 



\section{Summary}

The concept of a "law of the wall" and a "velocity defect law", which are related to each other through a common velocity scale and a semilogarithmic mean velocity distribution in the region where they overlap, can be applied succesfully to turbulent boundary layers with suction or injection. The similarity laws proposed in this thesis are supported by experimental data, which were partly obtained by the author in the low turbulence wind tunnel of the Aeronautical Engineering Department at Delft Technological University. For turbulent boundary layers at "moderate" suction rates $\left(0.04<-v_{0} / u_{\tau}<0.10\right)$ the velocity scale is proportional to $\left(u_{\tau}^{2} / v_{0}\right)$. For boundary layers at small suction rates and not too large blowing rates $\left(-0.04<v_{0} / u_{\tau}<0.2\right)$ the empirically determined velocity scale is proportional to $\left(u_{\tau}+9 v_{0}\right)$. 
1. Introduction

1.2. Similarity laws for the mean flow

2. Description of the experiments

2.1. Experimental apparatus

2.2. Scope of the experiments

2.3. Analysis of the experimental data

2.4. Results of the first series of experiments

2.5. Results of the second series of experiments

2.6. Results of the third series of experiments

3. The law of the wall

3.1. The law of the wall for turbulent boundary layers on impervious surfaces

3.2. The limit law of the wall

3.3. The normalized law of the wall

4. The velocity defect law

4.1. The velocity defect law for turbulent boundary layers on impervious surfaces

4.2. The velocity defect law for turbulent asymptotic layers

4.3. The limit velocity defect law 
5. The application of mixing length theory to turbulent

boundary layer flow with suction or injection: a review of the litterature

5.1. Introduction 62

5.2. The bi-logarithmic mean velocity distribution in 65 the inner layer

5.3. Application of the bi-logarithmic law to turbulent 69 equilibrium layers

5.4. Conclusions

6. Conclusions 72

6.1. The similarity laws for the mean flow 72

6.2. The logarithmic velocity scale 74

$\begin{array}{ll}\text { 6.3. Unsolved problems } & 75\end{array}$

$\begin{array}{ll}\text { References } & 77\end{array}$

$\begin{array}{lr}\text { Nederlandse samenvatting } & 83\end{array}$

$\begin{array}{ll}\text { Levensbericht } & 88\end{array}$

Figures 1-30 


\section{SYMBOLS}

a

$A, A^{*}$

b

c

$\mathrm{c}_{\mathrm{f}}$

${ }^{\mathrm{Q}}$

C,

$\mathrm{C}_{\delta}, \mathrm{C}_{\theta}$

d, d

D

$D_{\delta}, D_{\theta}$

f

F

g

G

H

k

$\overline{\mathrm{P}}$

$u_{1}, u_{2}$

$u_{\tau}$

$u_{\tau}^{*}$

$\overline{\mathrm{U}}_{1}, \overline{\mathrm{U}}_{2}$

$\mathrm{U}_{\mathrm{O}}$

$\mathrm{v}_{\mathrm{S}}$

vo

w*

$\mathrm{x}_{1}, \mathrm{x}_{2}$

$\mathrm{Y}_{\mathrm{S}}$

$\alpha^{*}$

$\beta, \beta^{\text {栗 }}$

$r, r^{*}$

$\delta$

$\delta^{*}$ constant in equilibrium analysis

constants in the law of the wall

constant in equilibrium analysis

as above

skin friction coefficient: $\tau_{\mathrm{O}} / \frac{1}{2} \mathrm{OU}_{\mathrm{O}}{ }^{2}$

suction coefficient: $-v_{0} / U_{0}$

constants in formulae for $\mathrm{w}^{\text {* }}$

constants in equilibrium analysis

constants in bi-logarithmic law

constant in velocity defect law

constants in equilibrium analysis

general function for mean velocity, in a law of the wall

same, in a velocity defect law

general function for Reynolds stress, in a law of the wall

same, in a velocity defect law

form parameter: $\delta^{*} / \theta$

mixing length constant

local mean pressure

components of velocity fluctuations, resp. in $x_{1}$ and $\mathrm{x}_{2}$-direction

friction velocity: $\left(\tau_{0} / \rho\right)^{\frac{1}{2}}$

effective friction velocity: $\left(\tau^{*} / \rho\right)^{\frac{1}{2}}$

components of mean velocity, resp.in $x_{1}-$ and $x_{2}$-direction

local mainstream velocity

velocity of spread of the turbulence

suction or blowing velocity (negative in case of suction)

logarithmic velocity scale: $x_{2} \partial \bar{U}_{1} / \partial x_{2}$

coordinates parallel and perpendicular to the surface

function in the bi-logarithmic law

constant in equilibrium analysis

as above

as above

boundary layer thickness

displacement thickness: $-\int_{0}^{\infty}\left\{\left(\bar{U}_{1}-U_{0}\right) / U_{0}\right\} d x_{2}$ 
variable in velocity defect law: $x_{2} / \delta$

$\theta$

$\Lambda$

$\nu$

$\nu_{\mathrm{T}}$

T

p

$\tau_{0}$

$\tau^{*}$

momentum thickness: $-\int_{0}^{\infty}\left\{\bar{U}_{1}\left(\bar{U}_{1}-U_{0}\right) / U_{0}^{2}\right\} d x_{2}$

equilibrium parameter: $\rho v_{0} U_{0} / \tau_{0}$

kinematic viscosity

eddy viscosity: $-\overline{\mathrm{u}_{1} \mathrm{u}_{2}}=\nu_{\mathrm{T}} \partial \overline{\mathrm{U}}_{1} / \partial \mathrm{x}_{2}$

equilibrium parameter: $\delta^{*} \mathrm{~d} \overline{\mathrm{P}} / \tau_{\mathrm{o}} \mathrm{dx}_{1}$

fluid density

skin friction

maximum shear stress within boundary layer 


\section{INTRODUCTION}

\subsection{General}

Distributed suction is applied to turbulent boundary layers with the purpose to delay or prevent separation $[1,2,3]$. For a particular application, a suitable distribution of the suction intensity can be calculated following the methods given by Cornish [3] and by Schlichting and Pechau $[4]$. The accuracy of these methods is limited since in the calculations a skin friction formula for unsucked boundary layers is used. In the litterature no formula is available which incorporates the effects of suction, except a provisional expression given by Sarnecki [5]. A reliable skin friction formula can be obtained if the similarity laws for the mean flow in a turbulent boundary layer are known $[6,7]$. This paper is devoted to a study of the similarity laws valid for turbulent boundary layer flow with suction (or injection). Due to the complexity of the subject and the relatively small number of experimental data, a skin friction formula for sucked boundary layers could not yet be obtained.

\subsection{Similarity laws for the mean flow}

12.01 The present paper is concerned with the similarity laws and the associated properties of turbulent boundary layers. Similarity laws in this context are non-dimensional expressions which relate the mean velocity distribution to a number of independent variables. These laws are primarily used to obtain a simple correlation of experimental data. Their name indicates that in an appropriate non-dimensional plot the mean velocity distributions of different boundary layers exhibit some degree of similarity. To obtain suitable similarity laws for turbulent boundary layers with distributed suction, Clauser's analysis of the behaviour of turbulent boundary layers on impervious walls $[6,7]$ will be generalized. Clauser's analysis is based on widely accepted general properties of turbulent boundary layer flow. Turbulent boundary layers are commonly divided into a thin "inner layer" in the immediate vicinity of the wall and a rather wide "outer layer" which covers almost the 
total momentum defect of the boundary layer. The properties of the flow in the inner and outer layers of turbulent boundary layers without suction will be discussed briefly, since they constitute the foundation of the present research.

12.02 The flow in the inner layer of a turbulent boundary layer is in a state of dynamical equilibrium, which is determined by the conditions at the wall (i.e. skin friction and surface roughness) only. This state of equilibrium of the inner layer flow is not affected by variations of the pressure gradient or the surface roughness in the direction of the main stream and neither by the width of the boundary layer or the mainstream velocity. The similarity law for the mean velocity distribution in the inner layer is appropriately called the "law of the wall". The law of the wall is discussed in the books by Townsend $[8]$ and Hinze [9].

12.03 The outer layer behaves quite differently from the inner layer. The similarity law for the mean flow in the outer layer is called the "velocity defect law". The non-dimensional mean velocity distributions of the outer layer are only similar if the associated "equilibrium parameter" is constant. A suitable equilibrium parameter is the one which represents the relative effects of pressure gradient and skin friction on the gradient of the overall momentum defect relative to the main stream. The mean flow and the energy-containing turbulence in the outer layer are effectively inviscid, so that the velocity defect law does not depend on the Reynolds number of the flow. The behaviour of the outer layer is described in the book by Hinze [9] and in the monographs by Townsend [8] and Rotta [10].

12.04 Experimental evidence has shown that the regimes of validity of the velocity defect law and the law of the wall "overlap" one another in a (sometimes narrow) region within the boundary layer. Also, the velocity scales used in the two similarity laws are equal to each other. Due to these two properties the region of overlap has a semilogarithmic mean velocity distribution. This was proven first by 
Millikan in 1937 [11]. The semi-logarithmic velocity distribution is a characteristic feature of turbulent boundary layers; it is of great importance since a skin friction formula can be derived from it [7].

12.05 In this paper turbulent boundary layer flow with suction (or injection) will be analyzed in a manner like described above for turbulent boundary layers flowing along impermeable walls. In particular, it will be assumed that the flow in the inner layer depends only on the skin friction, the suction intensity and the surface roughness, whereas the flow in the outer layer depends on the main stream velocity, the pressure gradient, the suction intensity and the skin friction. It will be assumed also that the velocity scale for the inner layer is equal to the velocity scale for the outer layer and that in the region of overlap the velocity distribution is semi-logarithmic. The validity of these assumptions is verified by experimental evidence and is supported by theoretical analysis. It will turn out that these concepts yield a simple representation of turbulent boundary layer flow with suction (or injection). A major part of the analysis is concerned with the velocity scale to be used for the two similarity laws; experimental data will show the dependence of the velocity scale on skin friction and suction intensity.

\subsection{Outline of the present research}

13.01 With the background presented in the preceding section, an outline of the present work can now be given. In chapter 2 the results of a group of experiments undertaken in the course of this investigation are presented. These experiments were designed to obtain a series of interrelated data from which the properties of turbulent boundary layers with suction could be studied and to test the validity of the similarity laws proposed in chapters 3 and 4. Some problems of a more general nature, not directly related to the similarity laws, also receive some attention.

13.02 Chapter 3 is devoted to the law of the wall. In section 3.1 a review is given of the established theory of the flow in the inner layer of a turbulent boundary layer without suction. The arguments which lead to 
the formulation of the law of the wall are evaluated. These arguments are generalized in section 3.2 , yielding the so-called "limit law of the wall", which is valid at moderate suction rates.

plotting the experimental evidence available in the litterature and the evidence obtained in the present investigation ( $\mathrm{ch} .2$ ) shows that the expected similarity indeed occurs. A semi-logarithmic region of the velocity distribution is observed in most cases; the slope of this region appears to be independent of the suction rate. In section 3.3 the law of the wall to be used at very small suction rates (also for boundary layers with injection) is developed. This "normalized wall law" covers the range of values of the suction (or blowing) rate at which the "limit law of the wall" is not valid.

13.03 The velocity defect law is discussed in chapter 4 . This chapter begins with a review of the available theory of outer layer flow for boundary layers on impervious surfaces (section 4.1). The velocity defect law for these layers is discussed and the consequences of the overlapping with the law of the wall are pointed out. The equilibrium parameter used by Clauser [7], Townsend $[8,14]$ and Rotta [10] is introduced. After this introductory discussion the flow in turbulent "asymptotic layers" in zero pressure gradient is discussed in section 4.2 . This is considered to be a particularly nice and simple example of turbulent equilibrium flow with distributed suction, for which it may be expected that the mean velocity distributions are similar. The discussion leads to the introduction of the "limit velocity defect law" and an evaluation of its consequences (Section 4.3). A discussion of the velocity defect law related to the normalized law of the wall concludes this chapter (section 4.4 ).

13.04 In chapter 5 a short survey is given of the theoretical work on turbulent boundary layers with suction and injection as available in the litterature. Almost all work has been, based on the mixing length theory for turbulent boundary layers. The results of the application of this theory to sucked and blown boundary layers do not appear to agree in a sufficient degree with the experimental data. In particular, these theories predict a bi-logarithmic region in the mean velocity distribution. 
This "bi-logarithmic law", proposed by Dorrance and Dore [15], Mickley and Davis [16] and Black and Sarnecki [5,17], is shown to be unacceptable since it fails to recognize the nature of the overlapping region between the inner layer and the outer layer of turbulent boundary layers. 
2. DESCRIPTION OF THE EXPERIMENTS

2.1. Experimental apparatus

21.01 The wind tunnel employed for the experiments on turbulent boundary layers with distributed suction is the Low Turbulence Tunnel of the Aeronautical Engineering Department at the Technological University of Delft. The test section is octagonal, $1800 \mathrm{~mm}$ wide and $1250 \mathrm{~mm}$ high. The turbulence level is about $0.04^{\circ} / 0$ at wind velocities in the range 20-60 $\mathrm{m} / \mathrm{sec}$. The wind tunnel has been described in detail elsewhere [18].

21.02 The set-up used for the boundary layer measurements consisted of a porous flat plate (925 mm long and $880 \mathrm{~mm}$ wide), coupled to a suction pump through a manifold. A sketch of the plate and the ducting system is given in fig. 1. In this figure two versions of the plate are indicated; for the first series of test runs the "impervious entry length" in front of the porous surface was $930 \mathrm{~mm}$, whereas the impervious entry length was $100 \mathrm{~mm}$ for the second and third series of test runs. This change was necessary to obtain at least one sucked turbulent boundary layer sufficiently close to asymptotic conditions (constant thickness, velocity distribution independent of $x_{1}$ ). The porous plate was placed vertically in the test section of the wind tunnel. The angle of incidence of the plate was adjusted to obtain zero pressure gradient along the surface. The pressure distribution along the porous surface was measured; deviations from the mean value were observed to be smaller than $0.2^{\circ} / 0$ of the dynamic head of the main stream, not counted somewhat larger disturbances at the edges of the surface. The porous surface consisted of a four-layer sandwich. The innermost layer of this sandwich was a heavy perforated steel plate (open area about $50^{\circ} / 0$ ), which supported the upper layers. To the steel plate an aluminum honeycomb was cemented. The outer surface of the honeycomb was leveled by a high-speed milling device; a nickel screen was stressed over the honeycomb. This screen (VECO 40 W Pure Electrolytic Nickel Screen, manufactured in Eerbeek, Holland) had an open area of $1 \%$; the holes (0.07 mm diameter) were arranged in a triangular pattern of $0.63 \mathrm{~mm}$ pitch ( 40 holes to the inch). 
The screen was covered with a sheet of filtering paper which formed the outermost layer of the porous sandwich. The filtering paper had a rather high specific resistance. This was necessary to improve the uniformity of the suction distribution along the porous surface, since the porosity of the nickel screen was not sufficiently uniform.

1.03 The suction installation consisted of the following major components. The porous plate was supported by a hollow structure which was sealed against leakage. The interior of this structure consisted of ten compartments. Each of these compartments was connected to a suction manifold by means of a $30 \mathrm{~mm}$-wide rubber tube. The ten tubes were equally long; the suction manifold was wide enough to ensure that the airflow through every compartment was nearly the same. The measured variations in the pressure drop through the porous surface at different compartments were at most $5 \%$, not counting a few exceptional cases in which the differences were somewhat larger. The required uniformity of the suction air flow was therefore considered to be obtained. The suction manifold was connected to an airflow measuring device consisting of a smooth brass pipe of circular cross-section (60 $\mathrm{mm}$ interior diameter, $1800 \mathrm{~mm}$ long) which was fitted with static pressure holes and a total head tube at the rear end. The total head tube was carried by a micrometer gear so that the mean velocity distribution of the flow in the pipe could be measured. For most tests however, the total head tube was used as a three-quarter-radius device: it was located such that it measured directly the dynamic head of the mean velocity in the pipe. This location is approximately independent of Reynolds number, so that it can be used for all flow measurements [19]. In one case the velocity distribution in the pipe has been measured to check this method of measurement. It turned out that the total head tube was positioned correctly, so that indeed the mean velocity was measured. The airflow measuring device was connected to a suction pump with a capacity of $0.25 \mathrm{~m}^{3} / \mathrm{sec}$. A sketch of the complete set-up is given in fig. 1 .

1.04 The test runs were carried out at wind velocities of 39 and $55 \mathrm{~m} / \mathrm{sec}$. corresponding to 95 and $190 \mathrm{~kg} / \mathrm{m}^{2}$ dynamic head. Water-filled vertical 
U-tube manometers were used for all pressure measurements. These manometers were read to $0.5 \mathrm{~mm}$ accuracy. For dynamic head readings within the boundary layer a small total-head tube (outer diameter $0.8 \mathrm{~mm}$ ) was used in conjunction with an appropriate static pressure orifice. The total head tube was mounted on a carriage fitted to the side wall of the wind tunnel. This carriage was equipped with a micrometer gear, so that the position of the total head tube relative to the porous surface could be determined with $0.02 \mathrm{~mm}$ accuracy. No corrections for displacement effect and turbulence intensity were applied to the dynamic head readings.

\subsection{Scope of the experiments}

22.01 As pointed out in the Introduction, the present experiments were designed for a study of turbulent boundary layers in zero pressure gradient and with uniformly distributed suction. It was intended to obtain at least one asymptotic layer, which at constant main stream velocity $U_{0}$ and constant suction velocity $-v_{0}$ exhibits a mean velocity distribution independent of $x_{1}$. Measurements of the velocity distribution in an asymptotic layer were needed for correlation with the asymptotic layers investigated by Kay [20] and Dutton [21]. The experiments were further intended to provide data on the flow in the inner part of turbulent boundary layers with distributed suction in order to obtain a check on the similarity law for the inner layer flow proposed in ch. 3 .

22.02 Measurements were restricted to mean velocity distributions. Mean velocity distributions suffice for the investigation of the validity of the proposed similarity laws. They are needed also for the determination of the momentum thickness $\theta$ of the boundary layer at various positions along the porous surface. With the calculated values of $\theta$ and known values of $-v_{0}$ and $U_{0}$ the local skin friction $\tau_{0}$ can be determined if the momentum integral equation for boundary layers is used (sub-section 23.01). Turbulence quantities, like the turbulence intensity and the Reynolds stress, were not measured, since Favre et al [22] recently published a fairly detailed account of measurements of these quantities in turbulent boundary layers with suction. Reynolds stress distributions in turbulent 
boundary layers with injection were measured by Butensky [23].

22.03 The experiments comprised three series of test runs. Each test run is indicated by a serial number and the appropriate value of the suction coefficient $c_{Q}\left(c_{Q}=-v_{0} / U_{0}\right)$. In this way, run $1-306$ indicates series 1 and $c_{Q}=0.00306$. In the first series of runs (at a solid entry length of $930 \mathrm{~mm}$ ) two boundary layers were measured, in series 2 (solid entry length $100 \mathrm{~mm}$ ) nine and in series 3 (solid entry length $100 \mathrm{~mm}$ ) three boundary layers。

22.04 Series one consisted of the runs 1-306 and 1-580. Boundary layer measurements were taken at $100 \mathrm{~mm}$ intervals along the porous surface. Provisional results of these experiments indicated that, whatever value of $c_{Q}$ was chosen, an asymptotic layer could not be attained. It was considered that the "initial" boundary layer at the beginning of the porous surface differed too much from an asymptotic layer to admit a complete conversion from one type of boundary layer to the other within the $925 \mathrm{~mm}$ of porous surface length available. The outer part of the initial boundary layer was much thicker than required for an asymptotic layer. Since it takes a considerable distance in streamwise direction before the flow in an "outer layer" is adjusted to the changed boundary conditions, it was decided to reduce the impervious entry length drastically. This problem was not understood at the time of the construction of the experimental set-up, but it became clear when it was noted that in a similar set-up with about $1000 \mathrm{~mm}$ impervious entry length, Favre et al [22] were unable to obtain any asymptotic layers, although they gathered data over a wide range of values of $c_{Q}$. This problem was investigated also by Dutton [21], who measured the development of turbulent boundary layers with uniform suction over a flat plate with three different impervious entry lengths. The shortest "nose" (100 mm long) was the only one to permit development of an asymptotic layer. Kay [20] used an impervious entry length of $100 \mathrm{~mm}$, whereas Sarnecki [5] used only $6 \mathrm{~mm}$. It was therefore decided to reduce the impervious entry length to $100 \mathrm{~mm}$ for the second series of test runs. Several problems 
remain in this area; e.g.: will the same asymptotic layer result from different initial conditions (at equal $c_{Q}$ ), and: is there an asymptotic layer at every value of $c_{Q}$ ? These problems were considered to reach beyond the scope of the present investigation. An introductory account may be found in the paper by Black and Sarnecki [17] .

22.05 The second series of measurements consisted of nine test runs. In all cases except run 2-430 the short impervious nose was partially covered with a $40 \mathrm{~mm}$ wide sandpaper strip. For run $2-430$ a sandpaper strip of only $10 \mathrm{~mm}$ wide was used. Most test runs were carried out at a wind velocity of $39 \mathrm{~m} / \mathrm{sec}$, except runs 2-292 and 2-273 which were carried out at $55 \mathrm{~m} / \mathrm{sec}$. The first four runs to be carried out were 2-312, 2-382, 2-484 and 2-543. From the provisional results of these test runs the values of $\mathrm{d} \theta / \mathrm{dx}_{1}$ near the trailing edge of the porous surface were calculated. By interpolation the value of $c_{Q}$ was determined at which $\mathrm{d} \theta / \mathrm{dx}_{1}$ would become zero. In this way the asymptotic layer (test run 2-429) was obtained.

After the run in which this asymptotic layer was obtained, four more test runs were carried out. Run 2-292 was taken at the same suction velocity as the asymptotic layer (2-429), but at higher wind velocity. Test runs $2-400$ and $2-273$ also had equal suction velocity but unequal wind velocity. Test run $2-430$ was carried out at the same suction and wind velocities as the asymptotic layer, but with different initial boundary layer (see above). These different conditions were chosen to obtain data on the relation between the inner layer flow and the "suction ratio" $-v_{0} / u_{\tau}\left(u_{\tau}\right.$ is the "friction velocity").

22.06 In the course of the present investigation some doubts arose concerning the validity of the similarity laws at very small values of the suction ratio $\left(-v_{0} / u_{\tau}<0.04\right.$, corresponding to $c_{Q}<0.002$ approximately), whence a third series of experiments was planned and executed. This series consisted of the runs $3-081,3-110$ and 3-157. These three runs were carried out with a wind velocity of $55 \mathrm{~m} / \mathrm{sec}$, to 
obtain small values of $c_{Q}$ at reasonable values of the suction velocity $-v_{0}$. The law of the wall at small values of the suction ratio will be discussed in section 3.3 .

\subsection{Analysis of the experimental data}

23.01 In all test runs mean velocity distribution measurements were taken at $100 \mathrm{~mm}$ intervals along the porous surface, covering nine positions in $\mathrm{x}_{1}$-direction. The measurements were taken along the midchord of the plate, except for some cases in which the two-dimensional character of the boundary layer flow was checked. It was found that over the central $400 \mathrm{~mm}$ of the plate in cross-wise direction the velocity distributions were equal (at same $x_{1}$ ) within experimental accuracy, so that cross-flow must have been negligible.

The mean velocity distributions were integrated graphically in the $\mathrm{x}_{2}-$ direction perpendicular to the wall, to determine $\theta\left(x_{1}\right)$ :

$$
\theta=\int_{0}^{\infty} \frac{\bar{U}_{1}}{U_{0}}\left(1-\frac{\bar{U}_{1}}{U_{0}}\right) d x_{2} .
$$

Through the points in a plot $\theta$ vs $x_{1}$ a smooth curve was drawn. The slope of this curve at the measurement stations was determined numerically from the graph. The values for $\mathrm{d} \theta / \mathrm{dx}_{1}$ obtained in this way were slightly adjusted to obtain a reasonably smooth second derivative. These final values were used to calculate the skin friction coefficient at every measurement station. To this end, the momentum integral equation for boundary layers was used. For boundary layer flow in zero pressure gradient this equation reads $[24]$

$$
\frac{\mathrm{d} \theta}{\mathrm{dx}} \mathrm{x}_{1}=\frac{1}{2} \mathrm{c}_{f}-\mathrm{c}_{\mathrm{Q}}
$$

In this equation, $c_{Q}=-v_{0} / U_{O}$ and $c_{f}$ is the skin friction coefficient, defined by

$$
\frac{1}{2} \quad c_{f}=\frac{\tau_{o}}{\rho U_{o}^{2}}=\left(\frac{u_{\tau}}{U_{o}}\right)
$$


Since $v_{0}$ and $U_{0}$ were known and $d \theta / d x_{1}$ was calculated, $c_{f}$ could be determined and hence, the friction velocity $u_{\tau}$. The friction velocity was needed to plot the velocity distributions according to the appropriate similarity laws.

23.02 Mean velocity distributions may be plotted in several ways. For the flow in the inner layer of turbulent boundary layers on impervious surfaces, velocity distributions are commonly plotted in a graph of $\overline{\mathrm{U}}_{1} / \mathrm{u}_{\tau}$ vs $\ln \mathrm{x}_{2} \mathrm{u}_{\tau} / \nu$. The observed similarity of mean velocity distributions in this semi-logarithmic plot is called the "law of the wall". For turbulent boundary layers with distributed suction no such similarity law was available at the onset of the present investigation. However, the flow in the viscous sub-layer suggests a practical way of non-dimensionalization. The velocity distribution in the viscous sub-layer of a turbulent boundary layer with suction may be written as (see sub-section $32.03)$

$$
\frac{\mathrm{v}_{\mathrm{o}} \overline{\mathrm{U}}_{1}}{\mathrm{u}_{\tau}^{2}}=\exp \left(\frac{\mathrm{v}_{\mathrm{o}} \mathrm{x}_{2}}{\mathcal{V}}\right)-1
$$

It was therefore decided to plot the velocity distributions obtained in the present experiments in graphs of $\mathrm{v}_{0} \overline{\mathrm{U}}_{1} / \mathrm{u}_{\tau}^{2}$ vs $\ln \left(-\mathrm{v}_{\mathrm{o}} \mathrm{x}_{2} / \nu\right)$. This way of plotting proved to be very suitable; it developed into the "limit law of the wall" discussed in section 3.2. Semi-logarithmic graphs were used in analogy with the usual way of plotting the wall law for boundary layers om impervious surfaces.

23.03 Most velocity distributions were observed to exhibit a straight line portion in the semi-logarithmic plot $\mathrm{v}_{\mathrm{o}} \overline{\mathrm{U}}_{1} / \mathrm{u}_{\tau}{ }^{2}$ vs $\ln \left(-\mathrm{v}_{\mathrm{o}} \mathrm{x}_{2} / \nu\right)$. The slope of this semi-logarithmic region was determined from the graphs, at each station of measurement. Choosing a straight line representing the inner portion of a velocity distribution was often rather difficult so that the resulting values of the logarithmic slope exhibited fairly much scatter. The logarithmic slope has the dimensions of a velocity; it will therefore be called the "logarithmic velocity 
scale" (w) (sub-section 32.09$)$. For non-dimensional representation $w^{*}$ is divided by $\mathrm{u}_{\tau}$ :

$$
\frac{1}{u_{\tau}} \frac{\partial \bar{U}_{1}}{\partial \ln x_{2}}=\frac{x_{2}}{u_{\tau}} \frac{\partial \bar{U}_{1}}{\partial x_{2}}=\frac{w^{*}}{u_{\tau}} .
$$

The data on obtained from the experiments were plotted in fig. 23 as a function of the suction ratio $-v_{0} / u_{\tau} \cdot$

\subsection{Results of the first series of experiments}

24.01 The data gathered in test runs $1-306$ and 1-580 were integrated to obtain curves of $\theta$ vs $x_{1}$. These curves are shown in fig. 2. The thickness of these two boundary layers is decreasing, so that $c_{Q}>c_{f} / 2$ according to eqn (23-1). These curves were used to determine the skin friction coefficient and the friction velocity, so that the mean velocity distributions could be replotted in graphs of $v_{0} \bar{U}_{1} / u_{\tau}^{2}$ vs $\ln \left(-v_{0} x_{2} / \nu\right)$. The accuracy of this method for the determination of $c_{f}$ is rather poor, but no other method is available to measure the skin friction on rough porous surfaces more directly or more accurately.

24.02 The data obtained in run 1-306 are plotted in fig. 7 as $v_{0} \bar{U}_{1} / u_{\tau}^{2}$ vs $\ln \left(-v_{0} x_{2} / \nu\right)$. It is observed that these mean velocity distributions have a rather clearly distinguishable semi-logarithmic part, which extends from $-v_{0} x_{2} / \nu=3$ to 60 approximately. The semilogarithmic region therefore is appreciably wider than in Kay's [20] and Dutton's [21] experiments, in which the logarithmic region covers less than a decade. This difference is due to the well-known fact that the width of the logarithmic velocity distribution increases with increasing Reynolds numbers. In the present experiments $\theta_{0} / \nu$ was about 2000 or larger, whereas in Kay's and Dutton's experiments $\theta_{0} / \nu$ was about 600 . With this evidence it is less difficult to conclude that the velocity distribution has a straight part in a semi-logarithmic plot. This feature is of prime importance for the applicability of the proposed similarity laws. 
24.03 The boundary layer measured in run 1-580 behaves quite differently from the preceding one. In fig. 8 it may be observed that the inner layer of this boundary layer approaches the theoretical curve for the viscous sub-layer (given as eqn (32-2) in sub-section 23-02). In particular, it is observed that the slope of the semi-logarithmic region decreases in stream-wise direction, which indicates that in this region the level of turbulent stear stress gradually decreases. It appears therefore that this layer tends to revert to laminar flow.

Favre et al [22] observed similar velocity distributions at sufficiently large values of $c_{Q}$; they even based their estimate of $c_{f}$ on this typical feature. For, at the outer edge of the viscous sub-layer, $v_{0} \bar{U}_{1} / u_{\tau}^{2}=-1$ according to eqn $\left(32-2\right.$ ) (see page 25 ) so that, when $v_{0}$, $U_{0}$ and $\frac{\tau}{U_{1}} / U_{0}$ at this point are known, $u_{\tau}$ can be determined.

Since this boundary layer is in a state of reversal to laminar flow, it cannot be expected that it conforms to the similarity laws for fully developed turbulent flow.

\subsection{Results of the second series of experiments}

25.01 The mean velocity distributions measured in series 2 were integrated to obtain curves of $\theta$ vs $x_{1}$. This was carried out according to the method described in sub-section 23.01 . For the runs at $U_{0}=39 \mathrm{~m} / \mathrm{sec}$ for which the impervious entry length was partially covered with a $40 \mathrm{~mm}$ wide sandpaper strip, the data are given in $\mathrm{fig}$. 3 . For the run at $39 \mathrm{~m} / \mathrm{sec}$ with a $10 \mathrm{~mm}$ wide sandpaper strip (run 2-430), the curve $\theta$ vs $\mathrm{x}_{1}$ is given in fig. 4; for the two runs at $55 \mathrm{~m} / \mathrm{sec}$ these curves are given in fig.5. A certain degree of anomaly is observed between runs 2-382 and 2-400: the run at the higher suction rate has also a larger momentum thickness. This anomaly may partly be due to a change of filtering paper during series 2: test runs $2-312,2-382$ and 2-484 were carried out on the first sheet of paper, and the remaining runs of series 2 (including run 2-400) on a new sheet of filtering paper which may have had slightly different characteristics. Atmosferic conditions (in particular the humidity of the air) may have been another partial cause of this anomaly. 
25.02 The curves of $\theta$ vs $x_{1}$ for the test runs of series 2 were used for the calculation of $u_{\tau}$ according to the method described in sub-section 23.01 . The results were used to replot the velocity distributions as $\mathrm{v}_{\mathrm{o}} \overline{\mathrm{U}}_{1} / \mathrm{u}_{\tau}^{2}$ vs $\ln \left(-\mathrm{v}_{\mathrm{o}} \mathrm{x}_{2} / \nu\right)$. For the nine test runs of series 2 these velocity distributions are given in figs. 9 through 17. Most of these data indicate that the velocity distributions are semi-logarithmic, with approximately equal slope. An exception is the velocity distribution of test run 2-543. From fig. 17 it may be concluded that the boundary layer in this run is in an early state of reversal to laminar flow: the slope of the "logarithmic region" decreases in stream-wise direction, indicating a decreasing turbulence level. The condition of this boundary layer is similar to, but not quite as clearly visible as the condition of the boundary layer in run 1-580. The situation is also clear from fig. 23: the data on the logarithmic slope of run 2-543 fall far below all other data points.

25.03 The boundary layer measured in run 2-429 approached asymptotic conditions very closely: its momentum thickness was independent of $x_{1}$ (see fig. 3 ) whereas its velocity distributions at the stations of measurement $x_{1}=482 \mathrm{~mm}$ and further downstream were practically equal. This layer has been used for a further check of the proposed similarity law for asymptotic layers (section 4.2) and for so-called "equilibrium layers" with suction in general (section 4.3). It should be noted that the boundary layer of run 2-430, for which the initial boundary layer was thinner due to a smaller strip of sandpaper on the impervious entry length, but which had about the same $v_{0} / U_{0}$ and $v_{0} / u_{\tau}$ (see sub-section 22.05 ), exhibits somewhat different velocity distributions than the asymptotic layer (run 2-429). This indicates that the approach to the asymptotic state is rather slow if the initial conditions are not precisely chosen so that the correspondence with the desired asymptotic layer is very close. This very problem has been investigated by Dutton [21] by means of a series of experiments with varying impervious entry lengths. Black and Sarnecki [17] gave a provisional analysis of this and related problems. 


\subsection{Results of the third series of experiments}

26.01 The data obtained in the third series of test runs were subjected to the treatment prescribed in sub-section 23.01 to obtain first the curves $\theta$ vs $x_{1}$ and then the friction velocity $u_{\tau}$ needed for the desired way of plotting the velocity distributions. The growth of the momentum thickness in runs 3-081, 3-110 and 3-157 is given in fig. 6, the velocity distributions are presented in figs. 18 through 20 .

26.02 It is observed that the semi-logarithmic parts of the velocity distributions in figs. 18, 19 and 20 have a much smaller slope than the corresponding semi-logarithmic velocity distributions of the boundary layers in series 1 and 2. This indicates that at very small suction rates (corresponding to $-\mathrm{v}_{\mathrm{o}} / \mathrm{u}_{\tau}<0.04$ approximately) the non-dimensionalization used for the plotting of these velocity distributions is less appropriate. This inadequacy has led to the formulation of the "normalized law of the wall"; cf. section 3.3 . 
THE LAW OF THE WALL

.1. The law of the wall for turbulent boundary layers on impervious surfaces.

1.01 It has been pointed out in the Introduction that the law of the wall is a similarity law which describes the mean velocity distribution in the inner layer of a turbulent boundary layer. In a suitable non-dimensional form it relates the mean velocity $\bar{U}_{1}$ to the distance $x_{2}$ perpendicular to the wall; it states which parameters are involved. The law of the wall for turbulent boundary layers flowing along solid impervious walls may be "derived" in several ways. A derivation in this case is in first instance not much more than a à posteriori justification of the experimentally observed facts. In this review of the theory available in the litterature a few approaches are discussed which are of some value for predicting the law of the wall valid for turbulent boundary layers with suction or blowing. It will be shown that the mean velocity distribution in the viscous sub-layer suggests the proper choice for the law of the wall in a fairly elegant manner. The semi-logarithmic mean velocity distribution in the fully turbulent part of the inner layer will then be derived according to Millikan and according to Rotta. It will be shown finally that the concept of similarity. is compatible with the equations of motion.

31.02 The general expression for the wall law can be derived in the following way. It is proposed that the law of the wall, being a similarity law for the inner layer of turbulent boundary layers, should provide similarity of the flow in the viscous sub-layer. In the viscous sub-layer the Reynolds stress is assumed to be negligible, so that the equations of motion can be solved explicitly. The solution will suggest the proper choice for the functional expression of the law of the wall. The analysis starts with the equations of mean motion in a turbulent boundary layer. The flow is assumed to be incompressible, steady and two-dimensional. The equations of mean motion read, with the usual boundary layer approximations and neglecting the small terms containing the derivatives of the turbulence intensities $w \cdot r \cdot t \cdot x_{1}[8,9]$ 


$$
\begin{aligned}
& \overline{\mathrm{U}}_{1} \frac{\partial \overline{\mathrm{U}}_{1}}{\partial \mathrm{x}_{1}}+\overline{\mathrm{U}}_{2} \frac{\partial \overline{\mathrm{U}}_{1}}{\partial \mathrm{x}_{2}}=\nu \frac{\partial^{2} \overline{\mathrm{U}}_{1}}{\partial \mathrm{x}_{2}{ }^{2}}+\frac{\partial}{\partial \mathrm{x}_{2}}\left(-\overline{\mathrm{u}_{1} \mathrm{u}_{2}}\right)-\frac{1}{\rho} \frac{\mathrm{d} \overline{\mathrm{P}}}{\mathrm{dx} \mathrm{x}_{1}}, \\
& \frac{\partial \overline{\mathrm{U}}_{1}}{\partial \mathrm{x}_{1}}+\frac{\partial \overline{\mathrm{U}}_{2}}{\partial \mathrm{x}_{2}}=0 .
\end{aligned}
$$

In these equations all symbols have the usual meaning, the subscript "1" denoting velocities and distances parallel to, and the subscript "2" denoting those perpendicular to the surface. Close to the wall (in the "inner layer") the mean convection terms and the mean pressure gradient term of eqn (31-1) are small in comparison to the two shear stress gradient terms. This will be discussed further in sub-section 31.08. The equations of motion then reduce to

$$
\nu \frac{\partial^{2} \overline{\mathrm{U}}_{1}}{\partial \mathrm{x}_{2}{ }^{2}}+\frac{\partial}{\partial \mathrm{x}_{2}}\left(-\overline{\mathrm{u}_{1} \mathrm{u}_{2}}\right)=0 \text {. }
$$

In the viscous sub-layer, the Reynolds stress is negligible [9]. In the viscous sub-layer eqn (31-3) thus reduces to

$$
\nu \frac{\partial^{2} \overline{\mathrm{U}}_{1}}{\partial \mathrm{x}_{2}{ }^{2}}=0
$$

For integration of this equation the integration constants can be found from the boundary conditions

$$
\overline{\mathrm{U}}_{1}=0, \nu \frac{\partial \overline{\mathrm{U}}_{1}}{\partial \mathrm{x}_{2}}=\frac{\tau_{\mathrm{o}}}{\rho} \text { at } \mathrm{x}_{2}=0 .
$$

The solution of eqn (31-4) then reads

$$
\overline{\mathrm{U}}_{1}=\frac{\tau_{\mathrm{o}}}{\rho \nu} \mathrm{x}_{2}
$$

If it is desired to write eqn $(31-6)$ in a non-dimensional form, the mean velocity $\bar{U}_{1}$ has to be non-dimensionalized. This is done by dividing it by a quantity having the dimensions of a velocity. Such a quantity may be 
derived from the shear stress by putting

$$
\tau_{\mathrm{o}}=\rho \mathrm{u}_{\tau}^{2}
$$

The velocity $u_{\tau}$ is commonly called the "friction velocity". Substitution of eqn (31-7) into eqn (31-6) yields

$$
\frac{\overline{\mathrm{U}}_{1}}{\mathrm{u}_{\tau}}=\frac{\mathrm{x}_{2} \mathrm{u}_{\tau}}{\nu} \text {. }
$$

This is the desired non-dimensional form of the mean velocity distribution in the viscous sub-layer.

1.03 In eqn (31-8) the quantities $u_{\tau}$ and $\nu$ suffice to obtain a unique nondimensional description of the flow in the viscous sub-layer. Apparently this flow depends only on skin friction and kinematic viscosity, and not on such parameters as the mainstream velocity and

the pressure gradient. It is assumed that these parameters have no effect on the flow throughout the inner layer. If it is now required that similarity of the mean flow in the viscous sub-layer should be included in the law of the wall, this law should have the following general form:

$$
\frac{\overline{\mathrm{U}}_{1}}{\mathrm{u}_{\tau}}=\mathrm{f}\left(\frac{\mathrm{x}_{2} \mathrm{u}_{\tau}}{\nu}\right) \text {. }
$$

This expression has received extensive experimental support $[12,13]$. The evidence has shown that the flow in the inner layer is indeed independent of the following parameters:

$$
\frac{\mathrm{u}_{\tau}}{\mathrm{U}_{\mathrm{o}}}, \frac{\delta^{*} \mathrm{U}_{\mathrm{o}}}{\nu}, \frac{\delta^{*}}{\tau_{\mathrm{o}}} \frac{\mathrm{d} \overline{\mathrm{P}}}{\mathrm{dx}_{1}},
$$

which are non-dimensional representatives of the skin friction coefficient, the "thickness Reynolds number" of the boundary layer and the pressure gradient. The inner layer flow however is affected by surface roughness (if present). The non-dimensional parameter representing the surface roughness is $\mathrm{ku}_{\tau} / \mathcal{\nu}$, in which $\mathrm{k}$ is a characteristic roughness size. 
31.04 The upper part of the inner layer contains fully developed turbulent flow in which the viscous shear stress is negligible compared to the Reynolds stress. The mean velocity distribution in this region can be derived in the way proposed by Millikan [11]. It is assumed that the flow in the fully turbulent part of the inner layer is described not only by the wall law but also by the velocity defect law which is valid in the outer layer of turbulent boundary layers (ch.4). The wall law is given in eqn (31-9); the velocity defect law is (see ch. 4)

$$
\frac{\overline{\mathrm{U}}_{1}-\mathrm{U}_{\mathrm{o}}}{\mathrm{u}_{\tau}}=\mathrm{F}\left(\frac{\mathrm{x}_{2}}{\delta}\right) \text {. }
$$

The so-called "overlapping" of the two laws in the upper part of the inner layer requires that the mean velocity gradient be the same in either similarity law:

$$
\frac{\partial \bar{U}_{1}}{\partial x_{2}}=\frac{u_{\tau}^{2}}{\nu} f^{\prime}\left(\frac{x_{2} u_{\tau}}{\nu}\right)=\frac{u_{\tau}}{\delta} F^{\prime}\left(\frac{x_{2}}{\delta}\right),
$$

in which primes denote differentiation w.r.t. the independent variable. Eqn $(31-11)$ can be rewritten in the form

$$
\frac{\mathrm{x}_{2}}{\delta} \mathrm{F}^{\prime}\left(\frac{\mathrm{x}_{2}}{\delta}\right)=\frac{\mathrm{x}_{2} \mathrm{u}_{\tau}}{\nu} f^{\prime}\left(\frac{\mathrm{x}_{2} \mathrm{u}_{\tau}}{\nu}\right)=\mathrm{C}_{\mathrm{o}} .
$$

Integration yields for the wall law

$$
\frac{\overline{\mathrm{U}}_{1}}{\mathrm{u}_{\tau}}=\mathrm{f}\left(\frac{\mathrm{x}_{2} \mathrm{u}_{\tau}}{\nu}\right)=\mathrm{c}_{\mathrm{o}} \ln \left(\frac{\mathrm{x}_{2} \mathrm{u}_{\tau}}{\nu}\right)+\text { const. }
$$

with a corresponding result for the velocity defect law. The constant $\mathrm{C}_{0}$ can depend only on the parameters occurring in both the wall law and the velocity defect law, since it is a parameter characterizing the overlapping region of the two similarity laws. The wall law parameter is: $\mathrm{k} \mathrm{u}_{\tau} / \mathcal{\nu}$, the defect law parameters are: $\mathrm{u}_{\tau} / \mathrm{U}_{\mathrm{o}}$ and $\Pi$ (a pressure gradient parameter)(cf. ch. 4). Since the two similaritylaws have no common parameters, $\mathrm{C}_{\mathrm{o}}$ is a "universal constant". Experimental evidence supports this conclusion, apart from a slight dependence on Reynolds number [26]. 
1.05 Rotta arrives at the semi-logarithmic mean velocity distribution in a different way $[10]$. He differentiates the law of the wall, eqn (31-9), to obtain

$$
\frac{\partial \overline{\mathrm{U}}_{1}}{\partial \mathrm{x}_{2}}=\frac{\mathrm{u}_{\tau}^{2}}{\nu} \mathrm{f}^{\prime}\left(\frac{\mathrm{x}_{2} \mathrm{u}_{\tau}}{\nu}\right) .
$$

Since in the fully turbulent part of the inner layer the viscosity has a negligible local effect on the flow, Rotta suggests that the mean velocity gradient is independent of viscosity. With a slightly different argumentation: since eqn $(31-14)$ is supposed to be valid also in the lower part of the outer layer, whose mean flow is inviscid (the velocity defect law does not contain the fluid viscosity), the right hand side of this equation should be independent of viscosity. To obtain this independence Rotta estimates that

$$
f^{\prime}\left(\frac{\mathrm{x}_{2} \mathrm{u}_{\tau}}{\nu}\right)=\mathrm{C}_{\mathrm{o}} \frac{\nu}{\mathrm{x}_{2} \mathrm{u}_{\tau}} \text {, }
$$

so that $\frac{\partial \bar{U}_{1}}{\partial x_{2}}=C_{0} \frac{u_{\tau}}{x_{2}}$,

which not only satifies Rotta's requirement but also gives a specific dependence on $x_{2}$. Integration of eqn (31-15) yields eqn (31-13), so that in this way an expression for the mean velocity distribution in the fully turbulent part of the inner layer is obtained. It should be emphasized however that the result is based on a very crude estimate of the velocity gradient.

31.06 Experimental evidence $[12,13]$, has shown that the mean velocity distribution in the inner layer indeed possesses a semi-logarithmic region. Clauser $[7]$ gives

$$
\frac{\overline{\mathrm{U}}_{1}}{\mathrm{u}_{\tau}}=2.44 \ln \left(\frac{\mathrm{x}_{2} \mathrm{u}_{\tau}}{\nu}\right)+4.9+\mathrm{B}\left(\frac{\mathrm{ku}_{\tau}}{\nu}\right) .
$$

The effect of surface roughness is apparently that the logarithmic part of the mean velocity distribution is shifted downward ( $B$ is always 
negative), without change of slope. A semi-logarithmic mean velocity distribution is also predicted by mixing length theory [25,27], but this theory does not seem to produce acceptable results for turbulent boundary layers with suction. A discussion of the application of mixing length theory to turbulent boundary layers with suction is given in ch. 5 .

31.07 The similarity of the mean flow in the inner layer has been discussed in the preceding sections. Now the turbulence proper will be considered, since it is expected that similarity of the mean flow is impossible without simultaneous similarity of the turbulence in the inner layer. It will therefore be necessary to verify if similarity of the mean motion and simultaneous similarity of the Reynolds stress in the inner layer is compatible with the equations of motion. The first need is a similarity law for the Reynolds stress distribution. Integration of eqn (31-3) gives, using the boundary condition that the shear stress at the wall is equal to $\tau_{0}=\rho u_{\tau}{ }^{2}$

$$
\nu \frac{\partial \overline{\mathrm{U}}_{1}}{\partial \mathrm{x}_{2}}+\left(\overline{-\mathrm{u}_{1} \mathrm{u}_{2}}\right)=\mathrm{u}_{\tau}{ }^{2} \text {. }
$$

In the upper part of the inner layer the viscous shear stress is negligible at sufficiently high Reynolds numbers. For this region, eqn (31-17) reduces to:

$$
-\overline{u_{1} u_{2}}=u_{\tau}^{2}
$$

It seems logical to non-dimensionalize the Reynolds stress as follows:

$$
\frac{-\overline{u_{1} u_{2}}}{u_{\tau}^{2}}=g\left(\frac{x_{2} u_{\tau}}{\nu}\right) .
$$

Eqn (31-18) shows that the non-dimensional Reynolds stress in this form has the value unity in the fully turbulent part of the inner layer. The independent variable $\mathrm{x}_{2} \mathrm{u}_{\tau} / \mathcal{V}$ is the parameter employed also in eqn (31-9). 
1.08 The similarity expressions for the mean velocity and the Reynolds stress in the inner layer can be substituted into the equations of motion, eqns (31-1) and (31-2), to check if simultaneous similarity is compatible with these equations. The substitution gives

$$
\frac{\nu}{u_{\tau}{ }^{2}} f^{2} \frac{d u_{\tau}}{d x_{1}}=f^{\prime \prime}+g^{\prime}+\frac{U_{o} \nu}{u_{\tau}{ }^{3}} \frac{d U_{o}}{d x_{1}} .
$$

In this equation, primes denote differentiation w.r.t. $\mathrm{x}_{2} \mathrm{u}_{\tau} / \mathcal{\gamma}$. Also, $\mathrm{d} \overline{\mathrm{P}} / \rho \mathrm{dx} x_{1}$ has been replaced by $-\mathrm{U}_{\mathrm{O}} \mathrm{dU}_{\mathrm{O}} / \mathrm{dx}_{1}$. The order of magnitude of the pressure gradient term is

$$
\left[\frac{\mathrm{u}_{\mathrm{o}} \delta^{*}}{\mathrm{u}_{\tau}^{2}} \frac{\mathrm{du}_{\mathrm{o}}}{\mathrm{dx}_{1}}\right] \cdot\left[\frac{\nu}{\mathrm{u}_{\tau} \delta^{*}}\right]=\sigma(1) \cdot \sigma_{\left(\frac{\nu}{\mathrm{u}_{\tau} \delta^{*}}\right)} .
$$

This is very small compared to the two leading terms ( $f^{\prime \prime}$ and $\left.g^{\prime}\right)$ since the Reynolds number $\delta^{*} u_{\tau} / \nu$ of turbulent boundary layers is generally very large (order of several hundreds). Experiments performed by Clauser $[6]$ have indicated that the parameter

$$
\frac{\mathrm{u}_{\mathrm{o}} \delta^{*}}{\mathrm{u}_{\tau}^{2}} \frac{\mathrm{du}}{\mathrm{dx}_{1}}=-\frac{\delta}{\tau_{\mathrm{o}}} \frac{\mathrm{d} \overline{\mathrm{p}}}{\mathrm{dx}_{1}}=-\prod
$$

is of order unity (see for $\prod$ ch. 4). The 1.h.s. term of eqn (31-20) is of the same order of magnitude as the pressure gradient term, so that this one is also negligible compared to the leading terms. Neglecting the small terms, eqn $(31-20)$ reduces to

$$
f^{\prime \prime}+g^{\prime}=0
$$

which is equivalent to eqn $(31-3)$. It may be concluded that within the approximations used, the simultaneous similarity of mean velocity and shear stress distributions is indeed not prohibited by the equations of motion. 
31.09 In this section it has been shown that the law of the wall can be derived without ambiguity from the condition that it should at least describe the mean flow in the viscous sub-layer. This approach will also be used for the derivation of the law of the wall valid for turbulent boundary layers with suction. The resulting wall law will be seen to agree with the available experimental evidence for "moderate" values of the suction ratio. The theoretical analysis will be complemented with a few other approaches, like Millikan's and Rotta's.

\subsection{The limit law of the wall}

32.01 In this section the law of the wall applicable to turbulent boundary layers with moderate values of the suction ratio $\left(0.04<-v_{0} / u_{\tau}<0.10\right)$ will be discussed. This law will be called the "limit law of the wall" for reasons which will become clear in the course of the discussion. The limit law of the wall will turn out to be not suited to describe the behaviour of turbulent boundary layers with little suction and of those with blowing. The limit wall law will be obtained in the same way as the wall law for turbulent boundary layers on impervious surfaces. In the litterature, a similarity law for sucked turbulent boundary layers is not available. Black and Sarnecki $[5,17]$ constructed a wall law for these layers, but their formulae do not satisfy some basic requirements to be fulfilled by a proper similarity law. Their approach differs so much from the one given here that it is discussed in a separate chapter to prevent confusion (ch. 5).

32.02 The present analysis is based on the hypothesis that the similarity law for the flow in the inner layer should provide at least similarity of the flow in the viscous sub-layer. The mean velocity distribution in the sublayer can be derived directly from the equations of motion. Neglecting small terms, the equations of motion reduce to

$$
v_{\circ} \frac{\partial \bar{U}_{1}}{\partial x_{2}}=\nu \frac{\partial^{2} \bar{U}_{1}}{\partial x_{2}{ }^{2}} \text {. }
$$


In this equation the mean flow convection terms, the pressure gradient term and the Reynolds stress term have been neglected. The Reynolds stress term is negligible in the viscous sub-layer; the pressure gradient term and the mean flow convection terms are of order of magnitude (cf. subsection 31.08$)$

$$
\left[\mathrm{U}_{\mathrm{o}} \frac{\mathrm{dU}}{\mathrm{dx}}\right]=\left[\frac{\tau_{\mathrm{o}}}{\rho \delta^{*}}\right] \cdot\left[\frac{\delta^{*}}{\tau_{\mathrm{o}}} \frac{\mathrm{d} \overline{\mathrm{P}}}{\mathrm{dx}}\right]=\left[\frac{\tau_{\mathrm{o}}}{\rho \delta^{*}}\right] \prod=\left[\frac{\tau_{0}}{\rho \delta^{*}}\right] \cdot \sigma_{(1)} .
$$

The order of magnitude of the two terms in eqn (32-1) is

$$
\left[\frac{v_{0}}{\nu} \frac{\tau_{0}}{\rho}\right]=\left[\frac{\tau_{0}}{\rho \delta^{*}}\right] \cdot\left[\frac{-v_{0} \delta^{*}}{\nu}\right]=\left[\frac{\tau_{0}}{\rho \delta^{*}}\right] \cdot \sigma_{(10)} \text {. }
$$

The Reynolds number $-\mathrm{v}_{\mathrm{O}} \mathrm{O}^{*} / \nu$ is of order 10 or larger for most turbulent boundary layers with moderate suction, as the experiments show $[21,17]$, except possibly for asymptotic and near-asymptotic layers on smooth walls, for which however $\Pi<<1$. It may be concluded then that the approximations involved in writing eqn $(32-1)$ are justified.

32.03 Eqn (32-1) may be integrated twice to obtain the mean velocity distribution in the viscous sub-layer. The result is, using the appropriate boundary conditions

$$
\frac{\mathrm{v}_{\mathrm{o}} \overline{\mathrm{U}}_{1}}{\mathrm{u}_{\tau}^{2}}=\exp \left(\frac{\mathrm{v}_{\mathrm{o}} \mathrm{x}_{2}}{\nu}\right)-1
$$

This is equivalent to the velocity distribution given by Griffith and Meredith $[28]$ for the laminar asymptotic layer. Apparently, the mean velocity distributions in the viscous sub-layers of all turbulent boundary layers coincide if plotted as

$$
\frac{\mathrm{v}_{\mathrm{o}} \overline{\mathrm{U}}_{1}}{\mathrm{u}_{\tau}^{2}}=f\left(\frac{\mathrm{v}_{\mathrm{o}} \mathrm{x}_{2}}{\nu}\right)
$$

This similarity is not only independent of skin friction coefficient, pressure gradient and Reynolds number, but also independent of the 
suction ratio $-v_{0} / u_{\tau}$. This suggests that eqn $(32-3)$ might be a suitable wall law for turbulent boundary layers with suction. For $v_{0}=0$, eqn (32-3) becomes trivial, so that it cannot be expected to be useful at small values of the suction ratio. Therefore it will be referred to as the "limit law of the wall", valid only for sufficiently large suction ratios.

32.04 In fig. 21 the mean velocity distributions of some measured turbulent boundary layers with suction are plotted according to the limit law of the wall. The boundary layers concerned are all asymptotic layers in zero pressure gradient (see ch. 4). For these layers the momentum thickness is independent of $x_{1}$ so that the momentum integral equation reduces to $\mathrm{v}_{\mathrm{O}} \mathrm{U}_{\mathrm{O}}=-\mathrm{u}_{\tau}{ }^{2}$, which renders the experimental determination of $\mathrm{u}_{\tau}$ relatively accurate. In figure 21 the velocity distribution in the viscous sub-layer has been plotted according to eqn (32-2). The overall picture of these velocity distributions shows the following features. First, the viscous sub-layers of Kay's [20] asymptotic layers on a smooth sintered bronze porous surface are relatively thick, extending beyond $-v_{0} x_{2} / \nu=1$. Second, it should be noticed that these curves have a more or less clearly distinguishable semi-logarithmic part; the slope of this region appears to be the same for all boundary layers concerned. This property is exactly analogous to the constant slope of the logarithm in the original law of the wall (sub-sections 31.04 through 31.06); it is considered to be essential for the applicability of a similarity law.

32.05 The velocity distributions of Kay's asymptotic layers have shown that the viscous sub-layer of turbulent boundary layers with sufficient suction may be rather thick. If this is the case, the exponential function in eqn (32-2) cannot be approximated in any way, so that any other way of putting $\mathrm{x}_{2}$ in non-dimensional form will yield a family of sub-layer curves, depending on the suction ratio $-v_{0} / u_{\tau}$. This is considered a disadvantage, since then the sub-layer flows would no longer be similar to each other. Hence, despite the disadvantages of the limit law of the wall for $v_{0} \rightarrow 0$, there is some reason for retaining it at sufficiently large values of the 
suction ratio. For small values of $v_{0} / u_{\tau}$ and for all cases in which the viscous sub-layer is relatively thin (as seems to be the case for all turbulent boundary layers with transpiration), the exponential function in eqn (32-2) may be represented by the series expansions

$$
\begin{aligned}
& \frac{\mathrm{v}_{\mathrm{o}} \overline{\mathrm{U}}_{1}}{\mathrm{u}_{\tau}^{2}}=\frac{\mathrm{v}_{\mathrm{o}} \mathrm{x}_{2}}{\nu}+\frac{1}{2}\left(\frac{\mathrm{v}_{\mathrm{o}} \mathrm{x}_{2}}{\nu}\right)+\ldots, \\
& \frac{\overline{\mathrm{U}}_{1}}{\mathrm{u}_{\tau}}=\frac{\mathrm{u}_{\tau} \mathrm{x}_{2}}{\nu}+\frac{1}{2}\left(\frac{\mathrm{v}_{\mathrm{o}}}{\mathrm{u}_{\tau}}\right)\left(\frac{\mathrm{u}_{\tau} \mathrm{x}_{2}}{\nu}\right)+\ldots .
\end{aligned}
$$

It is concluded that at the outer edge of the viscous sub-layer $-v_{0} x_{2} / \nu$ should be much smaller than one, if the exponential function is to be approximated by the first term of the series expansion. This is the case for all boundary layers with blowing and for those with little suction. For these layers, the original wall law may be used, as eqn (32-5) shows. It will turn out however that the wall law for boundary layers on impervious surfaces has to be generalized to include those cases in a simple manner. This subject is discussed in section 3.3. In sub-section 32.10 the boundaries of the regimes of "little suction" and of "moderate suction" will be discussed.

32.06 The next subject is the mean flow in the fully turbulent part of the inner layer. It is assumed that the "limit law of the wall", eqn (32-3) is valid in this region. It is expected that the suction ratio $-v_{0} / u_{\tau}$, although not appearing in the velocity distribution of the viscous sub-layer, is a parameter in the wall law plot. The inner layer flow is supposed to be independent of skin friction coefficient, pressure gradient and Reynolds number. To obtain an expression for the mean velocity distribution in the fully turbulent part of the inner layer, Millikan's analysis [11] is used. For this analysis, the velocity defect law related to the limit law of the wall is needed. This law reads (sub-section 42.03 )

$$
\frac{\mathrm{v}_{\mathrm{o}}}{\mathrm{u}_{\tau}^{2}}\left(\overline{\mathrm{U}}_{1}-\mathrm{U}_{\mathrm{o}}\right)=\mathrm{F}\left(\frac{\mathrm{x}_{2}}{\delta}\right) \text {. }
$$


The available evidence suggests that the similarity according to this defect law depends on two parameters. These parameters are

$$
\frac{\mathrm{v}_{\mathrm{o}} \mathrm{U}_{\mathrm{o}}}{\mathrm{u}_{\tau}^{2}}=\Lambda, \frac{\delta^{*}}{\tau_{\mathrm{o}}} \frac{\mathrm{d} \overline{\mathrm{P}}}{\mathrm{dx}{ }_{1}}=\prod \text {. }
$$

The defect law does not depend on the suction ratio $-v_{0} / u_{\tau}$ (see section 4.3). In the upper part of the inner layer the limit law of the wall is supposed to overlap with the limit defect law, eqn (32-6). This implies that the mean velocity gradient has to be the same in both expressions. This condition yields

$$
\frac{\partial \overline{\mathrm{U}}_{1}}{\partial \mathrm{x}_{2}}=\frac{\mathrm{u}_{\tau}^{2}}{\nu} \mathrm{f}^{\prime}\left(\frac{\mathrm{v}_{\mathrm{o}} \mathrm{x}_{2}}{\nu}\right)=\frac{\mathrm{u}_{\tau}^{2}}{\mathrm{v}_{\mathrm{o}} \delta^{\mathrm{W}}} \mathrm{F}^{\prime}\left(\frac{\mathrm{x}_{2}}{\delta}\right) .
$$

With some rearrangement

$$
\frac{\mathrm{v}_{\mathrm{o}} \mathrm{x}_{2}}{\nu} \mathrm{f}^{\prime}\left(\frac{\mathrm{v}_{\mathrm{o}} \mathrm{x}_{2}}{\nu}\right)=\frac{\mathrm{x}_{2}}{\delta} \mathrm{F}^{\prime}\left(\frac{\mathrm{x}_{2}}{\delta}\right)=\mathrm{C} .
$$

The two expressions have to be constant since the first depends only on $\mathrm{v}_{\mathrm{o}} \mathrm{x}_{2} / \nu$ and the second only on $\mathrm{x}_{2} / \delta$. Integration of eqn (32-8) yields for the wall law

$$
\mathrm{f}\left(\frac{\mathrm{v}_{\mathrm{o}} \mathrm{x}_{2}}{\nu}\right)=-\mathrm{C} \ln \left(\frac{-\mathrm{v}_{\mathrm{o}} \mathrm{x}_{2}}{\nu}\right)+\text { const. }
$$

The constant $\mathrm{C}$ is expected to be a universal constant since the limit law of the wall and the related velocity defect law have no common parameters. It is especially noteworthy that $\mathrm{C}$ is independent of $-\mathrm{v}_{\mathrm{o}} / \mathrm{u}_{\tau}$ in this analysis. This conclusion is supported by the evidence given in fig.2l.

32.07 The magnitude of the slope of the semi-logarithmic region is a quantity which deserves special attention. The application of Millikan's analysis to the limit law of the wall, as presented in the preceding sub-section, has yielded a constant $\mathrm{C}$ independent of $-\mathrm{v}_{0} / \mathrm{u}_{\tau}$. Two other approaches which will also yield an estimate for the logarithmic slope are now presented. The first of these proceeds as follows. The equation of the mean motion for 
the inner layer reads

$$
v_{0} \frac{\partial \bar{U}_{1}}{\partial x_{2}}=\frac{1}{\rho} \frac{\partial \tau}{\partial x_{2}} .
$$

In eqn $(32-10)$, the sum of the viscous and Reynolds stresses is represented by the symbol $\tau$. The approximations involved in writing eqn (32-10) are the same as those discussed for eqn (32-1). Since the mean velocity gradient near the wall is large, eqn (32-10) indicates that the shear stress has a sharp peak at the wall. This suggests the following estimate

$$
\frac{1}{\rho} \frac{\partial \tau}{\partial \mathrm{x}_{2}}=-\mathrm{C} \frac{\tau_{\mathrm{o}}}{\rho \mathrm{x}_{2}}=-\mathrm{C} \frac{\mathrm{u}_{\tau}^{2}}{\mathrm{x}_{2}} .
$$

Substitution of this expression into eqn (32-10) gives

$$
\frac{\partial \overline{\mathrm{U}}_{1}}{\partial \mathrm{x}_{2}}=-\mathrm{C} \frac{\mathrm{u}_{\tau}^{2}}{\mathrm{v}_{\mathrm{o}} \mathrm{x}_{2}} \text {. }
$$

Integration of eqn (32-12) yields

$$
-\frac{\mathrm{v}_{0} \overline{\mathrm{U}}_{1}}{\mathrm{u}_{\tau}^{2}}=\mathrm{c} \ln \left(\frac{-\mathrm{v}_{\mathrm{o}} \mathrm{x}_{2}}{\nu}\right)+\text { const } \text {. }
$$

This equation is equivalent to eqn (32-9). It should be noted that this estimate is only possible when the suction ratio is not too small; otherwise eqn (32-10) is not a valid approximation of the equations of motion. It should also be observed that no definite argument can be given why $C$ should be independent of $-v_{0} / u_{\tau}$ in this analysis.

32.08 The slope of the semi-logarithmic region can be estimated also with Rotta's [10] method. Assuming the general expression for the limit wall law to be valid, we differentiate eqn (32-3) to obtain

$$
\frac{\partial \overline{\mathrm{U}}_{1}}{\partial \mathrm{x}_{2}}=\frac{\mathrm{u}_{\tau}^{2}}{\nu} \mathrm{f}^{\prime}\left(\frac{\mathrm{v}_{\mathrm{o}} \mathrm{x}_{2}}{\nu}\right) \text {. }
$$


The mean velocity gradient in the fully turbulent part of the inner layer should be independent of viscosity (cf. sub-section 31.05). A suitable estimate for $f^{\prime}$, which satisfies this condition, is:

$$
f^{\prime}\left(\frac{v_{0} x_{2}}{\nu}\right)=\mathrm{C} \frac{\nu}{v_{0} x_{2}} .
$$

Eqn (32-14) is equivalent to eqn (32-12) and yields the same result for the mean velocity distribution. Although the estimate given in eqn (32-14) is the most simple which can be made, it cannot be stated with certainty that $\mathrm{C}$ is independent of $-\mathrm{v}_{0} / \mathrm{u}_{\tau}$, since $\mathrm{f}$ is expected to depend on $-v_{0} / u_{\tau}$ so that $f^{\prime}$ might depend on this ratio too. Nevertheless, the combined evidence of the sub-sections $32.06,32.07$ and 32.08 makes the proposition of constant $\mathrm{C}$ very probable.

32.09 With the theoretical background obtained in the preceding sub-sections the experimental evidence on the logarithmic slope can be evaluated. For easy interpretation of the data the "logarithmic velocity scale" $w$ is defined:

$$
\begin{aligned}
& \mathrm{w}^{*}=\mathrm{x}_{2} \frac{\partial \overline{\mathrm{U}}_{1}}{\partial \mathrm{x}_{2}}, \text { so that } \\
& \overline{\mathrm{U}}_{1}=\mathrm{w}^{*} \ln \mathrm{x}_{2}+\text { const. }
\end{aligned}
$$

The logarithmic velocity scale has the dimensions of a velocity. Rearrangement of eqns $(32-9),(32-12)$ and $(32-14)$ yields

$$
\frac{w^{w}}{u_{\tau}}=-C \frac{u_{\tau}}{v_{o}} \text {. }
$$

For boundary layers on impervious surfaces, the logarithmic velocity scale is given by eqns $(31-13)$ and $(31-15)$ :

$$
\frac{w^{*}}{u_{\tau}}=C_{0} \text {. }
$$

For the mean velocity distributions of sucked and blown turbulent boundary layers given in the litterature, and for those given in chapter 2 of this 
paper, the logarithmic velocity scale has been determined (see subsection 23.03) and has been plotted in figs 22 and 23. It is seen that eqn (32-16) with $\mathrm{C}=0.06$ covers the experimental data quite well provided $-v_{0} / u_{\tau}>0.04$. Straight lines with the prescribed slope have been drawn in fig. 21 , which gives the velocity distributions of some asymptotic suction layers.

\$2.10 At values of the suction ratio larger than about 0.10 , most turbulent boundary layers with suction are either in a state of reversal to laminar flow (for some examples, see sub-sections 24.03 and 25.02) or have so small Reynolds numbers that one cannot speak of fully developed turbulent flow. In these cases it is almost or entirely impossible to discover any semi-logarithmic region in the velocity distribution. The range of validity of the limit law of the wall is therefore restricted to "moderate" values of the suction ratio: $0.04<-v_{0} / u_{\tau}<0.10$. The lower limit is obvious from fig. 23: at small values of $v_{0} / u_{\tau}$ (including all blown boundary layers) the hyperbolic relation $(32-16)$ between $w^{*} / u_{\tau}$ and $-v_{0} / u_{\tau}$ is not valid. For $-v_{o} / u_{\tau}<0.04$ the relation between $w^{*} / u_{\tau}$ and $\mathrm{v}_{\mathrm{o}} / \mathrm{u}_{\tau}$ is well described by the straight line

$$
\frac{w^{*}}{u_{\tau}}=2.3\left(1+9 \frac{\mathrm{v}_{o}}{u_{\tau}}\right) \text {. }
$$

The consequences of this empirical relation are discussed in more detail in section 3.3. It should be noted in advance that, although eqn $(32-18)$ has a far greater range of validity than eqn (32-16), the advantages of the limit law of the wall are so numerous that it will be retained as the appropriate similarity law for boundary layers with moderate suction.

32.11 The experiments have shown that within the range $0.04<-v_{0} / u_{\tau}<0.10$ the slope of the semi-logarithmic mean velocity distribution is independent of the suction ratio, if the velocity distribution is plotted according to the limit law of the wall, eqn (32-3). The only remaining possible effect of $-v_{0} / u_{\tau}$ on the semi-logarithmic velocity distribution is a shift of the logarithm parallel to itself. Unfortunately, 
most porous surfaces are more or less rough, so that the shift due to the suction ratio will be obscured by the shift due to the roughness Reynolds number. The experiments reported in ch. 2 however were all performed on the same porous surface, whose upper surface was filtering paper. The characteristic roughness size of this paper is estimated at about $10^{-4} \mathrm{~m}$, so that the roughness Reynolds number $-v_{0} k / \nu=1$ approximately, at the average value of $-v_{0} / \nu$ that has been used (about $10^{4}$ ). This appears to be large enough to determine the effect of $-v_{o} / u_{\tau}$ by postulating that the surface has been "fully rough". For fully rough surfaces, the viscous sub-layer is absent and the kinematic viscosity cannot be used to nondimensionalize $x_{2}$. In analogy to the corresponding wall law for fully rough impervious surfaces $[7,9]$, the limit law of the wall for rough porous surfaces may be written as follows:

$$
-\frac{\mathrm{v}_{\mathrm{o}} \overline{\mathrm{U}}_{1}}{\mathrm{u}_{\tau}^{2}}=\mathrm{c} \ln \left(\frac{\mathrm{x}_{2}}{\mathrm{k}}\right)+\mathrm{A}\left(\frac{\mathrm{v}_{\mathrm{o}}}{\mathrm{u}_{\tau}}\right) .
$$

It is observed that on a given surface (fixed value of $k$ ) the non-dimensional mean velocity at a fixed value of $x_{2}$ is equal to $A\left(v_{0} / u_{\tau}\right)$, apart from a constant. Hence, plotting of $v_{0} \bar{U}_{1} / u_{\tau}^{2}$ at fixed $x_{2}$ for all mean velocity distributions available will yield a relation between $A$ and $-v_{o} / u_{\tau}$. This has been done in fig. 24 for the boundary layers measured in our laboratory. It is observed that the straight line

$$
A\left(v_{o} / u_{\tau}\right)=11 \frac{v_{o}}{u_{\tau}}+\text { const. }
$$

is a reasonable first approximation for the dependence of the shift of the logarithmic velocity distribution on $-v_{0} / u_{\tau} \cdot$ This approximation is not valid for $-v_{0} / u_{\tau}<0.04$. It is assumed that the dependence of the velocity shift on $-v_{0} / u_{\tau}$ is not changed by surface roughness, so that eqn $(32-20)$ may be used for smooth porous surfaces as well.

32.12 Kay [20] has measured two turbulent asymptotic layers on a porous wall made of sintered bronze. This surface may be considered to be hydrodynamically smooth, since the velocity distributions in these layers join the theoretical viscous sub-layer at about $-v_{0} x_{2} / \nu=1.5$ 
(fig. 21). This gives an opportunity to estimate the constant involved in the velocity shift for turbulent boundary layers with moderate suction on smooth porous walls. For these layers, referring to eqns $(32-3)$, (32-9) and $(32-20)$, the velocity distribution is given by

$$
-\frac{\mathrm{v}_{\mathrm{o}} \overline{\mathrm{U}}_{1}}{\mathrm{u}_{\tau}^{2}}=0.06 \ln \left(\frac{-\mathrm{v}_{\mathrm{o}} \mathrm{x}_{2}}{\nu}\right)-11 \frac{\mathrm{v}_{\mathrm{o}}}{\mathrm{u}_{\tau}}+\mathrm{B} .
$$

At $-v_{o} / u_{\tau}=0.0576$, resp. 0.0548 (average: 0.0562), Kay's experiments give

$$
-11 \frac{v_{0}}{u_{\tau}}+B=0.81
$$

so that $B=0.19$ and, for boundary layers on smooth walls with moderate suction,

$$
-\frac{\mathrm{v}_{\mathrm{o}} \overline{\mathrm{U}}_{1}}{\mathrm{u}_{\tau}^{2}}=0.06 \ln \left(\frac{-\mathrm{v}_{\mathrm{o}} \mathrm{x}_{2}}{\nu}\right)-11 \frac{\mathrm{v}_{\mathrm{o}}}{\mathrm{u}_{\tau}}+0.19 .
$$

The upward shift of the logarithmic velocity distribution due to increasing $-v_{0} / u_{\tau}$ cannot extend to arbitrarity large values of $-v_{o} / u_{\tau}$ since this would give conflicts between the logarithm and the viscous sub-layer, as inspection of fig. 21 shows. It seems impossible that the logarithm would not intersect the viscous sub-layer. This gives a tentative upper bound for $-v_{0} / u_{\tau}$, above which sucked turbulent boundary layer flow on smooth surfaces reverts to laminar flow. This critical value of the suction ratio will be about 0.065 .

32.13 The final part of the analysis is concerned with the equations of motion and the similarity of the Reynolds stress distribution (cf. sub-section 31.08). It is required that simultaneous similarity of the mean velocity and the Reynolds stress be compatible with the equations of motion. If this is not the case, it will be suspected that the similarity laws are incorrect. The similarity expression for the Reynolds stress distribution in the inner layers of turbulent boundary layers with moderate suction is assumed to be

$$
\overline{-u_{1} u_{2}}=u_{\tau}^{2} g\left(\frac{v_{0} x_{2}}{\nu}\right)
$$


In this expression the Reynolds stress, being a shear stress, is nondimensionalized with the shear stress at the wall. The distance $x_{2}$ perpendicular to the wall has been nondimensionalized in the same way as in the similarity law for the mean velocity, eqn (32-3). The equations of motion are, in inner layer approximation,

$$
v_{\circ} \frac{\partial \bar{U}_{1}}{\partial x_{2}}=\nu \frac{\partial^{2} \bar{U}_{1}}{\partial x_{2}{ }^{2}}+\frac{\partial}{\partial x_{2}}\left(-\overline{u_{1} u_{2}}\right) .
$$

This equation is equivalent to eqn (32-10); the approximations involved have been discussed in sub-section 32.02 . Substitution of eqns (32-3) and $(32-23)$ into eqn $(32-24)$ yields

$$
f^{\prime}=f^{\prime \prime}+g^{\prime},
$$

in which primes denote differentiation w.r.t. $v_{0} x_{2} / \nu$. It is concluded that the equations of motion indeed admit the desired simultaneous similarity of mean velocity and Reynolds stress.

32.14 Summarizing the results obtained in this section it may be stated that the limit law of the wall appears to be a suitable similarity law for the velocity distribution at moderate suction ratios: $0.04<-v_{0} / u_{\tau}<0.10$. The limit law however, is not valid for $-v_{0} / u_{\tau}<0.04$, so that the similarity law for turbulent boundary layers with little suction and for those with blowing has yet to be found. The analysis of the situation for $-v_{0} / u_{\tau}<0.04$ will be based on the empirical relation (32-18) for the logarithmic velocity scale; it is presented in the next section.

\subsection{The normalized law of the wall.}

33.01 At small values of the suction ratio and for blown boundary layers $\left(-v_{0} / u_{\tau}<0.04\right)$ the limit law of the wall does not apply. It does not reduce to the original wall law for boundary layers on impervious surfaces if the limit $\mathrm{v}_{\mathrm{o}} \rightarrow 0$ is taken. Moreover, the experimental data have shown that the logarithmic velocity scale does not have the predicted hyperbolic 
dependence on the suction ratio at small values of this ratio. The analysis of the wall law to be used in this regime will be centered around the empirical relation between $w^{*} / u_{\tau}$ and $v_{o} / u_{\tau}$ which has been given in eqn $(32-18)$ :

$$
\frac{w^{*}}{u_{\tau}}=2.3\left(1+9 \frac{v_{o}}{u_{\tau}}\right) \text {. }
$$

The logarithmic velocity scale will be used to construct a wall law in which the mean velocity distributions of all turbulent boundary layers, whether blown, sucked or on impervious walls, have at least the same slope of the semi-logarithmic region. This wall law, in which the logarithmic slope is unity for all turbulent boundary layers, will be called the "normalized law of the wall".

3.02 The theoretical background for eqn (32-18) will be investigated first. Recent investigations by Mickley and Smith [29] of turbulent boundary layers with transpiration result in a tentative interpretation of the nature of the logarithmic velocity scale. Mickley and Smith noted that in their experiments the slope of the semi-logarithmic mean velocity distribution remained equal to the value of the slope for boundary layers without blowing if not the square root of the shear stress at the wall but the square root of the maximum Reynolds stress within the boundary layer is used as friction velocity. This means that

$$
\left(\frac{\tau}{\rho}\right)_{\max }^{\frac{1}{2}}=u_{\tau}^{*},
$$

which will be called the "effective friction velocity", exhibits the very property characteristic for the logarithmic velocity scale, i.e. that it makes the slope of the logarithm independent of the suction ratio. This implies that $w$ and $u_{\tau}$ are proportional to one another, since (see subsection 32.09 )

$$
\frac{\overline{\mathrm{U}}_{1}}{\mathrm{w}}=\ln \mathrm{x}_{2}+\text { const } \text {. }
$$


and in the notation of Mickley and Smith

$$
\frac{\overline{\mathrm{U}}_{1}}{\mathrm{u}_{\tau}^{*}}=2.3 \ln \mathrm{x}_{2}+\text { const },
$$

so that $\quad w^{*}=2.3 u_{\tau}^{*}$.

In this relation, the constant $C_{0}$ in eqn (31-13), which was equal to 2.44 in eqn (31-16), is now taken as 2.3 to obtain agreement with eqn $(32-18)$, since at $v_{0} / u_{\tau}=0, u_{\tau}^{*}=u_{\tau}$. The "representative level of shear stress" in the inner layer is apparently not determined by the shear stress at the wall, but by the maximum of the shear stress within the layer, at least for turbulent boundary layers with blowing. For boundary layers with suction however, the shear stress has a rather sharp peak at the wall and generally no extremum within the boundary layer. The peak at the wall is not directly representative for the level of shear stress in the inner layer. To generalize Mickley and Smith's observations, a suitably chosen average of the shear stress in the inner layer might be used for the definition of the effective friction velocity $u_{\tau}^{\text {* }}$ and the logarithmic velocity scale $w^{\text {. }}$.

33.03 A tentative estimate of the representative level of shear stress, both for blown and for sucked turbulent boundary layers, may be found if a derivation given in a paper by Turcotte [30] is used. Turcotte employs Rannie's [31] estimate of the relation between eddy viscosity $\nu_{t}$ and the distance $\mathrm{x}_{2}$ in the inner layer:

$$
\frac{\nu_{t}}{\nu}=\sinh ^{2}\left(\frac{u_{\tau} x_{2}}{14 \nu}\right)
$$

In eqn (33-3), the eddy viscosity is defined by the relation

$$
\nu_{t} \frac{\partial \bar{U}_{1}}{\partial x_{2}}=-\overline{u_{1} u_{2}} .
$$

Substitution of eqns (33-3) and (33-4) into the equation for the mean motion in the inner layer, eqn (32-24), yields upon integration the 
following shear stress distribution:

$$
\frac{\tau}{\tau_{0}}=\exp \left(14 \frac{\mathrm{v}_{\mathrm{o}}}{\mathrm{u}_{\tau}} \tanh \frac{\mathrm{u}_{\tau} \mathrm{x}_{2}}{14 \nu}\right) .
$$

At sufficiently large values of $x_{2}$, the shear stress approaches a constant value $\tau^{*}$ (Turcotte calls this the "asymptotic" value)

$$
\frac{\tau^{*}}{\tau_{0}}=\exp 14 \frac{\mathrm{v}_{\mathrm{o}}}{\mathrm{u}_{\tau}} .
$$

This "asymptotic value" may be considered as a suitable representative of the average level of shear stress in the inner layer, and will therefore be identified with the square of the effective friction velocity. Since the suction (or blowing) ratio is commonly much smaller than unity, the exponential function may be approximated by the first two terms of a series expansion. Taking the sqare root of eqn (33-6) we obtain then, in first approximation,

$$
\mathrm{u}_{\tau}{ }^{\mathrm{F}}=\mathrm{u}_{\tau}\left(1+7 \frac{\mathrm{v}_{\mathrm{o}}}{\mathrm{u}_{\tau}}\right) \text {. }
$$

Comparison of eqns $(32-18)$ and (33-7) shows that this theoretical approach predicts the dependence of $w^{*}\left(w^{*}=2.3 u_{\tau}^{*}\right)$ on the suction ratio rather well, although not sufficiently accurate. It should be remarked that Rannie's expression for the eddy viscosity appears to be rather artificial. Also, the logarithmic velocity scale associated with the limit law of the wall is not found in this way, so that the applicability of this derivation extends only over a limited range of values of $v_{0} / u_{\tau}$.

33.04 The logarithmic velocity scale, whatever the nature of its dependence on $-v_{0} / u_{\tau}$ may be, suggests the introduction of a modified law of the wall. The mean velocity will be non-dimensionalized by $w^{*}$, as has been indicated in sub-section 32.09 . In this way the slope of the logarithmic velocity distribution is unity, whatever the value of $-v_{0} / u_{\tau}$ may be. The proper nondimensionalization of $x_{2}$ may be found by requiring that the mean velocity distribution in the viscous sub-layer is represented uniquely in the similarity plot. At small values of $-v_{o} / u_{\tau}$ and for all 
blown turbulent boundary layers (for which the sub-layer is supposed to be very thin), the velocity distribution in the sub-layer is given by eqn (31-8) or the first approximation to eqn (32-5), i.e.

$$
\frac{\overline{\mathrm{U}}_{1}}{\mathrm{u}_{\tau}}=\frac{\mathrm{u}_{\tau} \mathrm{x}_{2}}{\nu} .
$$

It is intended to use $w^{*}$ (as yet unspecified) as the velocity scale. The mean velocity distribution in the sub-layer should then be written in the form

$$
\frac{\bar{U}_{1}}{w^{*}}=\frac{u_{\tau}^{2} x_{2}}{\nu w^{*}} .
$$

The nondimensionalization of $\mathrm{x}_{2}$ given in eqn (33-8) will make the velocity distribution in the sub-layer independent of any parameter. This is considered essential for a suitable similarity law, as pointed out in sub-sections 31.02 and 32.03. The general expression for the normalized law of the wall then should be

$$
\frac{\overline{\mathrm{U}}_{1}}{\mathrm{w}^{*}}=f\left(\frac{\mathrm{u}_{\tau}{ }^{2} \mathrm{x}_{2}}{\nu_{\mathrm{w}}^{*}}\right) \text {. }
$$

33.05 The normalized wall law, eqn (33-9), will exhibit a parametric dependence on the suction ratio $-v_{0} / u_{\tau}$. This dependence cannot affect the slope of the semi-logarithmic region of the mean velocity distribution, so that the effect of $-v_{0} / u_{\tau}$ is restricted to a parallel shift of this logarithm. For flow along a smooth wall, the mean velocity distribution in the fully turbulent part of the inner layer is then described by

$$
\frac{\bar{U}_{1}}{w^{w}}=\ln \frac{u_{\tau}^{2} x_{2}}{\nu w^{*}}+A^{*}\left(\frac{v_{o}}{u_{\tau}}\right) .
$$

For boundary layers without suction, $w^{*}=2.3 u_{\tau}$ (or: $w^{*}=2.44 u_{\tau}$, if eqn $(31-16)$ is to be followed). The constant $A^{*^{\tau}}$ can be evaluated on comparison of eqns $(31-16)$ and $(33-10)$ and turns out to be

$$
A^{*}=3.0
$$


For boundary layers satisfying the limit law of the wall: $w^{*}=-0.06 u_{\tau}^{2} / v_{0}$; the constant $A^{*}$ can be derived by comparison of eqns $(32-22)$ and $(33-10)$, which yields

$$
A^{*}=0.33-183 \frac{v_{0}}{u_{\tau}} \text {. }
$$

Eqns (33-11) and (33-12) have been plotted in fig. 25, which shows that at small values of the suction ratio eqn (33-12) cannot be expected to hold. The probable dependence of $A^{*}$ on $-v_{o} / u_{\tau}$ at $-v_{o} / u_{\tau}<0.04$ has been indicated by a broken line. Insufficient data are available to determine the exact shape of this curve. It should be noticed that eqn (33-12), which is based on eqn $(32-22)$, is a provisional relation, which may have to be modified if further evidence becomes available.

3.06 The analysis of the normalized law of the wall will now be completed by an investigation of the effects of this similarity law on the equations of motion. Like in the discussion of sub-sections 31.07 and 32.13 it is desired that the similarity law for the mean velocity and the corresponding similarity law for the Reynolds stress are compatible with the equations of motion. A logical choice for the non-dimensionalization of the Reynolds stress in terms of the normalized wall law is

$$
-\overline{u_{1} u_{2}}=u_{\tau}^{2} g\left(\frac{u_{\tau}^{2} x_{2}}{\nu_{w}^{*}}\right) .
$$

Substitution of eqns (33-9) and (33-13) into the equation for the mean motion, eqn $(32-24)$, yields

$$
\frac{v_{0} w^{*}}{u_{\tau}^{2}} f^{\prime}=f^{\prime \prime}+g^{\prime},
$$

in which primes denote differentiation w.r.t. $\mathrm{u}_{\tau}{ }^{2} \mathrm{x}_{2} / \mathrm{w}^{\mathbb{*}} \nu$. If similarity is to be compatible with the equations of motion, eqn (33-14) shows that either $\mathrm{w}=\mathrm{Cu}_{\tau}^{2} / \mathrm{v}_{\mathrm{O}}$ or the left hand side of this equation has to be small compared to the other terms. It is seen that the limit law of the wall in 
this respect is definitely superior to the normalized wall law with $w^{*}=2.3 u_{\tau}\left(1+9 v_{o} / u_{\tau}\right)$, since it yields the required simultaneous similarity without any restriction on $\mathrm{v}_{\mathrm{o}} / \mathrm{u}_{\tau}$. This has been shown also in sub-section 32.13 . It is observed that with the relation $w^{*}=2.3 u_{\tau}\left(1+9 v_{o} / u_{\tau}\right)$ the desired similarity can only be of an approximate nature. It is not clear how this relation for $w^{*} / u_{\tau}$ can be valid at other than very small blowing rates. Nevertheless, the experimental evidence supports eqn (32-18) up to $\mathrm{v}_{\mathrm{o}} / \mathrm{u}_{\tau}=+0.2$, as fig. 22 shows.

33.07 It is now possible to discuss the question why eqn (32-18) is not accepted beyond $-v_{0} / u_{\tau}=0.04$. Inspection of fig. 23 shows that the difference between eqn $(32-18)$ and eqn $(32-16)$ in the range $0.04<-v_{0} / u_{\tau}<0.10$ is rather small, in any case well within the accuracy of the experimental data. It would seem then that accepting eqn $(32-18)$ as the valid relation between $w^{*} / u_{\tau}$ and $-v_{0} / u_{\tau}$, instead of the hyperbolic relation (32-16), would not make a great difference in the plotting of velocity distributions. However, the introduction of eqn (32-18) prohibits formal similarity of the equations of motion independent of the suction ratio, as has been shown in the preceding sub-section. Further, with eqn (32-18) it is only possible to obtain similarity of the first term in the series expansion of the mean velocity distribution in the viscous sub-layer. This can be illustrated by introducing $\mathrm{w}^{*}$ in the series expansion, eqn (32-5), which yields:

$$
\frac{\overline{\mathrm{U}}_{1}}{\mathrm{w}}=\frac{\mathrm{u}_{\tau}^{2} \mathrm{x}_{2}}{\nu \mathrm{w}}+\frac{1}{2} \frac{\mathrm{v}_{\mathrm{o}}^{\mathrm{w}}}{\mathrm{u}_{\tau}^{2}}\left(\frac{\mathrm{u}_{\tau}{ }^{2} \mathrm{x}_{2}}{\nu \mathrm{w}}\right)+\ldots
$$

Eqn (33-15) indicates that only the hyperbolic relation $w^{*} / u_{\tau}=-0.06 u_{\tau} / v_{0}$ can give the desired similarity throughout the relatively thick viscous sublayer of turbulent boundary layers with moderate suction. Introducing eqn (32-18) in this sub-layer equation gives only approximate similarity, with parametric dependence on $-v_{0} / u_{\tau}$. Finally, the description of turbulent boundary layers in equilibrium states (section 4.2) can proceed elegantly only if the velocity defect law corresponding to the limit law 
of the wall is used. For these reasons the limit law of the wall and the related hyperbolic dependence of $w^{*} / u_{\tau}$ on $-v_{o} / u_{\tau}$ are retained at moderate suction ratios.

3.08 To summarize the results of this section it may be stated that the empirical straight line relating $w^{¥} / u_{\tau}$ to $-v_{o} / u_{\tau}$, which is supported by Turcotte's theoretical analysis, has a rather limited applicability. It is considered to be inferior to the hyperbolic relation between $w / u_{\tau}$ and $-v_{0} / u_{\tau}$ which is related to the limit law of the wall. It will therefore be used only when the limit law of the wall cannot be used, i.e. for $-\mathrm{v}_{\mathrm{o}} / \mathrm{u}_{\tau}<0.04$. The normalized law of the wall nevertheless appears to be a useful concept, which simplifies the interpretation of experimental data since the slope of the logarithmic mean velocity distribution is made independent of $-v_{0} / u_{\tau}$. This law will presumably be used only in conjunction with the empirical relation (32-18) since it reverts to the 1 imit wall law if $\mathrm{w}^{*}=-0.06 \mathrm{u}_{\tau}^{2} / \mathrm{v}_{\mathrm{o}}$ is used. 
4. THE VELOCITY DEFECT LAW

4.1. The velocity defect law for turbulent boundarylayers on impervious surfaces

41.01 In this section the similarity law for the mean velocity distribution in the outer layer of a turbulent boundary layer will be discussed. It will be pointed out in what way this "velocity defect law" is related to the law of the wall. This relation will be useful in deriving the velocity defect law for turbulent boundary layers with suction or blowing. Attention is paid to the equilibrium parameter for pressure gradients used by Clauser, Rotta and Townsend.

41.02 The behaviour of the "outer layer" of a turbulent boundary layer differs distinctly from that of the inner layer $[7,8]$. The flow in the outer layer appears to be independent of the local conditions at the surface, except insofar as these determine the skin friction. Due to the different nature of inner layer flow and outer layer flow separate similarity laws have been developed for the two regimes. The mean velocity distribution in the outer layer (comprising all but the inner 10 procent of the boundary layer thickness) may be represented by

$$
\frac{\bar{U}_{1}-U_{0}}{u_{\tau}}=F\left(\frac{x_{2}}{\delta}\right) .
$$

This expression is called the "velocity defect law" since it is a similarity law for the velocity defect relative to the main stream. For turbulent boundary layers in zero pressure gradient this law correlates the mean velocity distributions with a very slight, almost negligible dependence on the skin friction coefficient (which is assumed to be the representative of the Reynolds number and the surface roughness [7,10]). The velocity defect law was discovered originally for turbulent pipe flow by Darcy [32] in 1858. It was also used by stanton and pannell [33] in 1914 and, according to prandt1 [25], rediscovered by Von Kármán in 1929 [34]. It appears that Schultz Grunow [35] was the first to use the velocity defect law in relation to flat plate boundary layer flow [24]. 
The velocity defect law should be considered as a convenient representation of experimental data; a straightforward derivation cannot be given [9].

1.03 It is observed in eqn (41-1) that the velocity scale for the mean flow in the outer layer is equal to $u_{\tau}$. Comparison with the related wall law, eqn (31-9), shows that the velocity scales for these two laws are equal. This can be made plausible in the following way: the outer layer and the inner layer are supposed to have a certain region in common since it is impossible to conceive a sharp distinction between the regimes of validity of the two similarity laws. In the "overlapping" region a single velocity scale should suffice; this implies that throughout the boundary layer the velocity scale has to be the same. The similarity law for the outer layer flow then has to be a velocity defect law since this is the only way in which similarity at the outer edge of the boundary layer is achieved: at $x_{2}=\delta$, the velocity defect is zero, independent of $u_{\tau} / U_{0}$. An expression not including the velocity defect would cause the conditions at the outer edge of the layer to depend on $u_{\tau} / U_{0} ;$ this would preclude similarity. These considerations suffice for the determination of the velocity defect law; they will be used to derive the velocity defect laws for turbulent boundary layers with suction or blowing (sections 4.3 and 4.4 ).

41.04 Mean velocity distributions of turbulent boundary layers are similar only in very special conditions. If plotted according to eqn (41-1) the mean velocity distributions of all turbulent boundary layers on flat plates in zero pressure gradient collapse into a single curve (sub-section 41.02). This curve is independent of Reynolds number of surface roughness [7,35]; it is valid only for boundary layers which have not been disturbed by sudden changes in surface roughness. In the velocity defect law plot the mean velocity distributions of turbulent boundary layers in non-zero pressure gradients however, do not coincide with the velocity distributions obtained on flat plates. This implies that the velocity distribution in defect law coordinates depends on the pressure gradient. 
Clauser uses the non-dimensional parameter $\prod$ to label the velocity distributions in the defect law plot $[6,7]$ :

$$
\Pi=\frac{\delta^{*}}{\tau_{0}} \frac{\mathrm{d} \overline{\mathrm{P}}}{\mathrm{dx}}=-\frac{\delta^{*} \mathrm{U}_{\mathrm{o}}}{\mathrm{u}_{\tau}^{2}} \frac{\mathrm{dU}_{\mathrm{o}}}{\mathrm{dx} \mathrm{f}_{1}} .
$$

A similar parameter, to be used in turbulent channel flow, was given by Buri $[36]$ and Gruschwitz [37]; according to Prandt $1[25]$ the pressure gradient should be non-dimensionalized by a factor including $\tau_{0}$ in the denominator "to remove the dependence on the Reynolds number". The parameter $\prod$ is used also by Townsend [14] and Rotta [10]. It turns out that mean velocity distributions plotted according to the velocity defect law are similar only for so-called "equilibrium layers", i.e. those which possess a constant value for the parameter $\Pi$ during their flow along a wall $[7,10,14]$. The flow along a flat plate is clearly an example. The parameter $\prod$ occurs also in the momentum integral equation for boundary layers. This equation reads, neglecting the terms with the normal turbulence stresses $[8,24]$

$$
\rho \frac{\mathrm{d}}{\mathrm{dx}_{1}}\left(\theta \mathrm{U}_{\mathrm{o}}^{2}\right)=\tau_{\mathrm{o}}+\delta \frac{\mathrm{d} \overline{\mathrm{P}}}{\mathrm{dx}_{1}} \text {. }
$$

On dividing this equation by $\tau_{0}$, the following relation results:

$$
\frac{\rho}{\tau_{0}} \frac{d}{\mathrm{dx}_{1}}\left({\theta \mathrm{U}_{\mathrm{o}}}^{2}\right)=1+\prod
$$

This occurrence of $\prod$ was first observed by Townsend [14], who states that equilibrium flow is determined by the condition "that the terms in the equation for the momentum integral preserve a constant ratio". The three terms of the momentum integral equation, eqn (41-3), represent the increase of the momentum defect of the boundary layer, the skin friction and the pressure gradient. Equilibrium layers apparently are characterized by constant relative contributions of pressure gradient and skin friction to theincrease of the momentum defect.

41.05 The feasability of the velocity defect law for the description of equilibrium layers has been investigated experimentally by clauser $[6]$, 
who by careful adjustment of the pressure gradient in two cases obtained boundary layers with similar velocity distributions according to the velocity defect law. These two layers were observed to have constant values of $\Pi$. The validity of the description of mean velocity distributions according to the velocity defect law may be investigated also in a formal way. This investigation is carried out by substitution of the velocity defect law and the related similarity expression for the Reynolds stress into the equations of motion for the outer layer. The formal approach will yield an opportunity to evaluate whether or not $\Pi$ is the sole parameter characterizing equilibrium flow. For the analysis a similarity expression for the Reynolds stress distribution is needed. This expression reads, in conformity with the litterature $[7,8,10]$

$$
\frac{-\overline{u_{1} u_{2}}}{u_{\tau}^{2}}=G(\eta),
$$

in which $\eta=x_{2} / \delta$. The equations of motion for the mean flow in the outer layer are, neglecting the viscous shear stress and the normal turbulence stresses $[9]$

$$
\begin{aligned}
& \overrightarrow{\mathrm{U}}_{1} \frac{\partial \overline{\mathrm{U}}_{1}}{\partial \mathrm{x}_{1}}+\mathrm{U}_{2} \frac{\partial \overline{\mathrm{U}}_{1}}{\partial \mathrm{x}_{2}}=\mathrm{U}_{\mathrm{o}} \frac{\mathrm{dU}}{\mathrm{dx_{1 }}}+\frac{\partial}{\partial \mathrm{x}_{2}}\left(-\overline{\mathrm{u}_{1} \mathrm{u}_{2}}\right) ; \\
& \frac{\partial \overline{\mathrm{U}}_{1}}{\partial \mathrm{x}_{1}}+\frac{\partial \overline{\mathrm{U}}_{2}}{\partial \mathrm{x}_{2}}=0 .
\end{aligned}
$$

Substitution of eqns (41-1) and (41-5) into eqns (41-6) and (41-7) yields $[8,10,14]$

$$
\begin{aligned}
G^{\prime} & =\frac{\delta}{u_{\tau}^{2}} \frac{d}{d x_{1}}\left(U_{0} u_{\tau}\right) F-\frac{1}{u_{\tau}} \frac{d}{d x_{1}}\left(\delta U_{0}\right) \eta F^{\prime}+ \\
& +\frac{\delta}{u_{\tau}} \frac{d u_{\tau}}{d x_{1}} F^{2}-\frac{1}{u_{\tau}} \frac{d}{d x_{1}}\left(\delta u_{\tau}\right) F^{\prime} \int_{0}^{\eta} F d \eta \cdot
\end{aligned}
$$

It is assumed that simultaneous similarity of the mean velocity and Reynolds stress distributions is a necessary condition to obtain 
equilibrium flow. Simultaneous similarity should be compatible with the equations of motion. Eqn (4l-8) indicates that, to obtain the required similarity of the Reynolds stress distribution, all coefficients of the terms in this equation should be constant. This condition is satisfied in case

$$
\frac{\mathrm{d} \delta}{\mathrm{dx}_{1}}=\mathrm{a}, \frac{\mathrm{u}_{\tau}}{\mathrm{U}_{\mathrm{o}}}=\mathrm{b}, \frac{\delta}{\mathrm{u}_{\tau}} \frac{\mathrm{dU} \mathrm{o}_{\mathrm{o}}}{\mathrm{dx}_{1}}=\mathrm{c},
$$

where $a, b$ and $c$ are constants $[10]$.

41.06 The momentum integral equation yields a relation for $a$ in terms of $b$ and c. To determine this relation, expressions for the momentum thickness $\theta$ and the displacement thickness $\delta^{*}$ in terms of integrals of the velocity defect function are necessary. These expressions are

$$
\begin{aligned}
& \delta^{*}=\int_{0}^{\infty}\left(1-\frac{\overline{\mathrm{U}}_{1}}{\mathrm{U}_{\mathrm{o}}}\right) \mathrm{dx}_{2}=-\frac{\delta \mathrm{u}_{\tau}}{\mathrm{U}_{\mathrm{o}}} \int_{0}^{\infty} \mathrm{Fd} \eta=\mathrm{C}_{\delta} * \frac{\delta \mathbf{u}_{\tau}}{\mathrm{U}_{\mathrm{o}}}, \\
& \theta=\int_{0}^{\infty} \frac{\bar{U}_{1}}{\mathrm{U}_{0}}\left(1-\frac{\overline{\mathrm{U}}_{1}}{\mathrm{U}_{0}}\right) \mathrm{dx} \mathrm{x}_{2}=-\frac{\delta \mathrm{u}_{\tau}^{2}}{\mathrm{U}_{\mathrm{o}}^{2}} \int_{0}^{\infty} \mathrm{F}^{2} \mathrm{~d} \eta-\frac{\delta \mathrm{u}_{\tau}}{\mathrm{U}_{\mathrm{o}}} \int_{0}^{\infty} \mathrm{Fd} \eta \\
& =\mathrm{C}_{\theta} \frac{\delta u_{\tau}^{2}}{\mathrm{U}_{0}^{2}}+\mathrm{C}_{\delta} \frac{\delta u_{\tau}}{\mathrm{U}_{\mathrm{o}}}
\end{aligned}
$$

We first observe that $\prod$ and $c$ are closely related:

$$
\mathrm{c} \mathrm{C}_{\delta}=\frac{\delta}{\mathrm{u}_{\tau}} \frac{\mathrm{dU}_{\mathrm{o}}}{\mathrm{dx}_{1}} \mathrm{c}_{\delta}=\frac{\delta^{*} \mathrm{U}_{\mathrm{o}}}{\mathrm{u}_{\tau}^{2}} \frac{\mathrm{dU}_{\mathrm{o}}}{\mathrm{dx}_{1}}=-\Pi \text {. }
$$

In this equation, $\mathrm{C}_{\delta}$ is a constant by virtue of the assumed similarity of mean velocity distributions. Apparently, the condition that $c$ be constant may then be replaced by the condition that $\prod$ be constant.

The momentum integral equation becomes, substituting eqns (41-11) and (41-12) into eqn (41-4), using also eqn (4l-9) 


$$
\left(\mathrm{b} \mathrm{c}_{\Theta}+\mathrm{c}_{\delta^{*}}\right) \frac{\mathrm{a}}{\mathrm{b}}=1-3 \mathrm{cc}_{\delta^{*}}-2 \mathrm{bc} \mathrm{c}_{\Theta} \text {. }
$$

Since a can be expressed in terms of $b$ and $c$, a two-parameter description of turbulent equilibrium flow is obtained, in which $u_{\tau} / U_{0}$ and $\prod$ are the pertinent parameters $[7,10]$. However, in most experimental set-ups a slow $x_{1}$-wise variation of $u_{\tau} / U_{0}$ occurs, so that one of the equilibrium parameters is not constant, which prohibits the development of equilibrium flow. Moreover, different boundary layers may have different values of $u_{\tau} / U_{0}$ (even when $u_{\tau} / U_{0}$ is kept constant by proper choice of surface roughness variation [10]), so that two boundary layers with the same value of $\prod$ will not exhibit similar velocity distributions. Notwithstanding these formal complications, the influence of $u_{\tau} / U_{0}$ on the equilibrium state of turbulent boundary layers appears to be only very slight. This has been shown by Clauser's calculations and by Townsend's theory for equilibrium flow. Clauser $[7]$ showed that with a prescribed velocity distribution the shear stress distributions at different values of $u_{\tau} / U_{0}$ are nearly similar, and vice versa. Townsend $[8,14]$ studied turbulent boundary layers at very high Reynolds numbers. His theory is based on the assumption that the velocity defect $u_{\tau} f<<U_{O}$, so that terms containing the square of the velocity defect may be neglected. With this approximation the theory of equilibrium flow is appreciably simplified; one parameter (e.g. T) then suffices to characterize the state of equilibrium. However, for boundary layers at moderate Reynolds numbers (especially in adverse pressure gradients) the velocity defect is generally not small, so that then the approximative theory cannot be used.

Considering this evidence, it is concluded that turbulent equilibrium layers may be represented as a one-parameter family depending on $\prod$ only, with the restriction that the equilibrium state can only be approximate. clauser calls this phenomenon the "near-universality" of the velocity distribution [7]. The approximate nature of the equilibrium prohibits a complete formal analysis of the consequences of the velocity defect law. These problems were recently discussed by Rotta [10], who presented a comprehensive account of the theory of equilibrium layers. 
41.07 The review of turbulent equilibrium flow without suction or injection as presented in this section may be concluded by observing that the experimentally observed similarity of mean velocity distributions in a one-parameter family depending on $\Pi$ only is rather surprising with regard to the theoretical complications involved. The theory has not been settled conclusively yet; the theoretical parts of the analysis given in the next three sections should therefore be considered provisional.

\subsection{The velocity defect law for turbulent asymptotic layers.}

42.01 Experimental investigations of turbulent boundary layers with distributed suction, as reported in the litterature, have been restricted mainly to boundary layers on flat plates at zero pressure gradient. Of special interest is the boundary layer which has a constant thickness and constant properties, so that it is independent of $x_{1}$. This layer is called the "asymptotic (suction) layer" since it is obtained experimentally as the asymptotic limit (for $x_{1} \rightarrow \infty$ ) of a flat plate boundary layer subjected to uniform suction. In this section the velocity defect law for asymptotic layers will be derived. It will be seen that asymptotic layers are equilibrium layers. The state of equilibrium of these layers is different from that of turbulent boundary layers without suction.

42.02 If in a tentative way the properties of unsucked turbulent boundary layers are extrapolated, it may be suggested that asymptotic layers will be equilibrium layers if each of the parameters associated with the momentum integral equation has a unique value. The state of equilibrium will be called "universal" if in the proper non-dimensionalization the velocity distributions are independent of any further parameter. To clarify this point the momentum integral equation is considered. This equation reads $[3,24]$

$$
\rho \frac{\mathrm{d}}{\mathrm{dx}_{1}}\left(\theta \mathrm{U}_{0}^{2}\right)=\tau_{0}+\delta \frac{\mathrm{d} \overline{\mathrm{p}}}{\mathrm{dx} \mathrm{x}_{1}}+\rho \mathrm{v}_{\mathrm{o}} \mathrm{U}_{\mathrm{o}},
$$

or

$$
\frac{\rho}{\tau_{0}} \frac{d}{d x_{1}}\left(\theta U_{0}^{2}\right)=1+\Pi+\Lambda
$$


In this equation, $\prod$ is defined by eqn (41-2) and $\Lambda$ is defined by

$$
\Lambda=\frac{\rho \mathrm{v}_{\mathrm{O}} \mathrm{U}_{\mathrm{o}}}{\tau_{\mathrm{o}}}=\frac{\mathrm{v}_{\mathrm{O}} \mathrm{U}_{\mathrm{o}}}{\mathrm{u}_{\tau}^{2}} .
$$

For asymptotic layers in zero pressure gradient, $\Pi=0$. Also, $\theta$ and $U_{0}$ are independent of $x_{1}$, so that $\Lambda=-1$ by virtue of eqn (42-2). Asymptotic layers apparently are characterized by unique values of $\Pi$ and $\Lambda$ so that it may be expected that they are equilibrium layers. It is not yet clear whether their state of equilibrium will be universal or not.

2.03 It has been shown that asymptotic boundary layer flow is characterized by unique values of $\Pi$ and $\Lambda$. Asymptotic layers will therefore form a class of equilibrium layers if the mean velocity distributions of different asymptotic layers coincide when they are made non-dimensional in a suitable way. A suitable non-dimensionalization of the mean velocity distribution may be found as follows. For asymptotic layers, the equations of motion reduce to

$$
v_{0} \frac{d \bar{U}_{1}}{d x_{2}}=\frac{d}{d x_{2}}\left(-\overline{u_{1} u_{2}}\right),
$$

valid for the inviscid flow in the outer layer. Integration yields

$$
v_{0} \bar{U}_{1}-v_{0} U_{0}=-\overline{u_{1} u_{2}}
$$

It should be noted that the integration has been carried out from the outer edge of the boundary layer inward, since eqn (42-4) is not valid in the direct vicinity of the wall (where viscous shear stress is present), so that it is not allowed to integrate from $x_{2}=0$ outward. Like for the outer layer flow of boundary layers without suction, it may be expected that a state of equilibrium will be physically possible only if similarity of the mean velocity distribution and similarity of the shear stress distribution occur simultaneously. Simultaneous similarity should be compatible with the equations of motion. It appears logical to non-dimensionalize the Reynolds stress by the value of the 
shear stress at the wall. Eqn (42-5) is then transformed into

$$
\frac{v_{0}}{u_{\tau}^{2}}\left(\bar{U}_{1}-U_{0}\right)=\frac{-\overline{u_{1} u_{2}}}{u_{\tau}^{2}}
$$

This equation suggests the following velocity defect law for asymptotic layers:

$$
\frac{\mathrm{v}_{\mathrm{o}}}{\mathrm{u}_{\tau}^{2}}\left(\overline{\mathrm{U}}_{1}-\mathrm{U}_{\mathrm{o}}\right)=\mathrm{F}\left(\frac{\mathrm{x}_{2}}{\delta}\right)
$$

It is noted that this defect law has the same velocity scale as the limit law of the wall, eqn (32-3). It will therefore be called the "limit velocity defect law". A further discussion of this relationship will be given in section 4.3 . It should be noted that eqn (42-7) has a form characteristic for a velocity defect law (cf. sub-section 41.03).

42.04 Since for asymptotic layers $\Lambda=-1$ (i.e. $v_{0} U_{0}=-u_{\tau}^{2}$ ), eqn $(42-7$ ) may be written as follows:

$$
\frac{\overline{\mathrm{U}}_{1}}{\mathrm{U}_{\mathrm{O}}}-1=\mathrm{F}\left(\frac{\mathrm{x}_{2}}{\delta}\right) \text {. }
$$

This equation may then be expected to correlate the mean velocity distributions of all asymptotic layers, irrespective of suction coefficient $\left(c_{Q}=-v_{O} U_{0}\right)$, Reynolds number or surface roughness. This view is substantiated by Dutton's experiments [21] The velocity distributions of two asymptotic layers at widely different values of the suction coefficient $\left(c_{Q}=0.00443\right.$, resp. 0.00730), on surfaces with different roughness were shown to coincide in a plot of $\bar{U}_{1} / \mathrm{U}_{0}$ vs $x_{2}$. This feature has not been explained by Dutton; it can only be accounted for by a velocity defect law like eqn (42-8).

42.05 In figure 26 the mean velocity distributions of some asymptotic layers, including one which has been measured in the laboratory of VTH-Delft, are presented in a plot according to eqn (42-8). It is observed that the mean velocity distributions can be represented by a single curve, 
so that the asymptotic layer is indeed in a state of "universal" equilibrium, with a unique representation of the mean velocity distribution (independent of all parameters, except $\Pi$ and $\Lambda$, which have unique values for asymptotic layers). If these distributions would have shown dependence on Reynolds number, surface roughness or skin friction coefficient, the similarity would have lost its universal character and the applicability of a defect law according to eqns (42-7) or (42-8) would be very restricted. In this context it should be noted that Sarnecki [5] has measured some velocity distributions of an asymptotic layer which deviate somewhat from the curves presented in fig. 26. These data are discussed further in sub-section 52.05.

The presence of a logarithmic part in the mean velocity distribution, which is evident in fig. 26, gives an opportunity to derive a skin friction formula for asymptotic suction layers. The logarithmic region can be expressed numerically as

$$
-\frac{\mathrm{v}_{\mathrm{o}}}{\mathrm{u}_{\tau}^{2}}\left(\overline{\mathrm{U}}_{1}-\mathrm{U}_{0}\right)=0.06 \ln \left(\frac{\mathrm{x}_{2}}{\delta}\right)-0.01 .
$$

In this equation the notation of eqn $(42-7)$ is followed to obtain agreement with the formulation of the limit law of the wall, eqn (32-3). The wall law expression for the logarithmic velocity distribution has been given in section 3.2 ; it reads

$$
-\frac{\mathrm{v}_{\mathrm{o}} \overline{\mathrm{U}}_{1}}{\mathrm{u}_{\tau}^{2}}=0.06 \ln \left(\frac{-\mathrm{v}_{\mathrm{o}} \mathrm{x}_{2}}{\nu}\right)-11 \frac{\mathrm{v}_{\mathrm{o}}}{\mathrm{u}_{\tau}}+0.19 .
$$

It is recalled that this equation is valid for hydrodynamically smooth surfaces only and that the effect of $-v_{0} / u_{\tau}$ is represented in a tentative way, pending more detailed experiments (section 3.2). Subtraction of eqn (32-22) from eqn (42-9) yields (using also $\Lambda=-1$ )

or:

$$
\begin{aligned}
& 0.06 \ln \left(\frac{-v_{0} \delta}{\nu}\right)=11 \frac{v_{o}}{u_{\tau}}+0.80, \\
& 11 \frac{u_{\tau}}{U_{o}}=11\left(\frac{{ }^{c}}{2}\right)=0.80-0.06 \ln \left(\frac{-\delta v_{o}}{\nu}\right) .
\end{aligned}
$$


This is the tentative skin friction formula for asymptotic layers. Note that (by virtue of $\Lambda=-1$ ) $v_{0} / u_{\tau}=-u_{\tau} / U_{0}$ and $v_{0} / U_{0}=-u_{\tau}^{2} / U_{0}^{2}$, i.e. $c_{Q}=c_{f} / 2$.

42.06 It has been discussed in $\mathrm{ch} .2$ that the limit law of the wall is not valid at small values of the suction ratio $\left(-v_{0} / u_{\tau}<0.04\right.$ approximately). Apparently, a unique representation of the velocity distributions of asymptotic layers is not possible at small values of $-v_{0} / u_{\tau}$, since then the inner layer velocity scale $w$ deviates from the velocity scale $-u_{\tau}{ }^{2} / v_{o}$ used in the defect law for asymptotic layers (fig. 26). Within the present framework of similarity laws, either one of two conclusions may be drawn. First, at very small values of $-v_{0} / u_{\tau}$ no asymptotic layers can exist since the velocity scales of the inner and outer layers would be different. Within the present framework of analysis, this would prohibit similarity of the velocity distributions. Second, at small $-v_{o} / u_{\tau}$ asymptotic layers will exhibit a different kind of similarity, based on the logarithmic velocity scale w . However, this would mean that eqn (42-6) would have to be rewritten as

$$
\frac{\bar{U}_{1}-U_{o}}{w^{*}}=\left(\frac{u_{\tau}^{2}}{v_{0} w^{*}}\right) \frac{-\overline{u_{1} u_{2}}}{u_{\tau}{ }^{2}} .
$$

With assumed similarity of $\left(\bar{U}_{1}-U_{0}\right) / w^{*}$, the shear stress distribution only exhibits similarity if the velocity scale is a multiple of $-u_{\tau}^{2} / v_{0}$. This indicates that for $-v_{0} / u_{\tau}<0.04$ (where $w^{*} / u_{\tau}$ is not proportional to $u_{\tau} / v_{0}$ ) indeed no asymptotic layers can exist. This conclusion is supported by experimental data: no asymptotic layers at small suction rates have been reported in the litterature. The result obtained here should however be considered with some caution, since it is based on rather scanty experimental data.

42.07 At the outer edge of a turbulent boundary layer turbulence spreads into the undisturbed fluid above the boundary layer. This process, which is essentially due to the viscous transfer of turbulent vorticity in the "viscous super-layer" [38], is controlled by the turbulence intensity 
in the outer layer. For turbulent boundary layers in zero pressure gradient the rate of spread $v_{S} / U_{O}\left(v_{S}\right.$ is the velocity of spread relative to the ambient fluid) is equal to the rate of growth of the boundary layer thickness $\delta$, minus the slope of the streamlines at the outer edge of the layer [39]:

$$
\frac{\mathrm{v}_{\mathrm{s}}}{\mathrm{U}_{\mathrm{o}}}=\frac{\mathrm{d} \delta}{\mathrm{dx}_{1}}-\frac{\mathrm{d} \delta^{*}}{\mathrm{dx}_{1}}-\frac{\mathrm{v}_{\mathrm{o}}}{\mathrm{U}_{\mathrm{o}}} .
$$

For boundary layers without suction, $\delta$ is approximately 10 times $\theta$, whereas $\delta^{*}$ is about $1.4 \theta$. Since the rate of growth of $\theta$ is equal to $c_{f} / 2$ for unsucked boundary layers in zero pressure gradient, it may be concluded that for these layers $\mathrm{v}_{\mathrm{S}} / \mathrm{U}_{\mathrm{O}}=4.3 \mathrm{c}_{\mathrm{f}}$ approximately. An average value of $c_{f}$ is: $c_{f}=0.003$, so that $v_{s} / U_{o}=0.013$. On the other hand, for asymptotic layers $\mathrm{d} \delta / \mathrm{dx}_{1}$ and $\mathrm{d}^{*} / \mathrm{dx}_{1}$ are zero, so that $\mathrm{v}_{\mathrm{s}}=-\mathrm{v}_{0} \cdot$ With a typical suction coefficient $c_{Q}=-v_{0} / U_{0}=0.005$ there results $\mathrm{v}_{\mathrm{s}} / \mathrm{U}_{\mathrm{O}}=0.005$. It is observed that for asymptotic layers the rate of spread is generally much smaller than for boundary layers on impervious surfaces. An explanation of this difference can be found in a corresponding difference in turbulence intensity, with asymptotic layers apparently at a relatively small turbulence level. This conclusion is in qualitative agreement with observations of Favre et al [22], who report a markedly reduced turbulence level for boundary layers with suction through a porous surface. It should be noted however that the notion of decreasing turbulence level conflicts with the requirement that $v_{S}$ be equal to $v_{0}$ for asymptotic layers. This requirement indicates that $\mathrm{v}_{\mathrm{S}}$ and hence the turbulence intensity should increase with increasing suction rates. One is led towards the hypothesis that on a particular surface an asymptotic layer is possible only at one value of $c_{Q}$. The value of $c_{Q}$ at which a boundary layer can maintain the asymptotic state will increase with increasing turbulence level in the outer layer, i.e. with increasing surface roughness.

12.08 The results of this section may be summarized as follows. Experimental evidence has shown that turbulent asymptotic layers are in a state of exact and universal equilibrium. The similarity law for the outer layer flow of asymptotic layers has been shown to relate to the "limit law of 
the wall", so that it has been called the "limit defect law".

\subsection{The limit velocity defect law.}

43.01 In this section the general expression for the velocity defect law related to the limit law of the wall is discussed. This similarity law, which is the same as the previously introduced "limit velocity defect law", is supposed to be valid at moderate suction ratios $\left(0.04<-v_{0} / u_{\tau}<0.10\right)$ only. The similarity expressions for the mean velocity and the Reynolds stress will be substituted into the equations of motion to obtain a formal analysis of the equilibrium states of the boundary layers concerned. It will be seen that $\Pi$ and $\Lambda$ suffice to determine the equilibrium states, so that an exact two-parameter description appears to be feasible.

43.02 The limit velocity defect law may be obtained according to the rules given in section 4.1. However, the defect law for asymptotic layers given in section 4.2 appears to be suitable. It reads

$$
\frac{\mathrm{v}_{\mathrm{o}}}{\mathrm{u}_{\tau}^{2}}\left(\overline{\mathrm{U}}_{1}-\mathrm{U}_{\mathrm{o}}\right)=\mathrm{F}\left(\frac{\mathrm{x}_{2}}{\delta}\right) .
$$

This expression satisfies the requirements to be met by a general velocity defect law associated with the limit law of the wall, since the velocity scale is equal to the velocity scale used in the limit law of the wall and since the conditions at the outer edge of the boundary layer are represented in such a way that similarity of these conditions is ascertained $\left(\bar{U}_{1}-U_{0}=0\right.$ at $x_{2} / \delta=1$, independent of the velocity scale). The equality of the velocity scales for the inner layer and the outer layer (in analogy with section 4.1) is a necessary condition for the existence of a "overlapping" region, in which only one velocity scale is present. This overlapping region should have a semi-logarithmic mean velocity distribution (sub-section 32.06); such a distribution is indeed observed in most experiments (ch. 2). 
3.03 The similarity of mean velocity distributions of turbulent equilibrium layers is assumed to depend on the equilibrium parameters $\Pi$ and $\Lambda$ occurring in the equation for the momentum integral, eqn (42-2) but not on parameters like $v_{0} / u_{\tau}, u_{\tau} / U_{0}, \delta U_{0} / \nu$ or $\mathrm{ku}_{\tau} / \nu$. The available experimental evidence has shown that this assumption is valid for asymptotic layers, which at $\Pi=0$ and $\Lambda=-1$ do not exhibit any dependence on other parameters (section 4.2). In the litterature however, insufficient data are available to verify this point of view for other equilibrium layers. The data collected in the course of the present investigation (ch. 2) are neither suitable to investigate the equilibrium behaviour of boundary layers with suction, since with the available experimental equipment the equilibrium parameter $\Lambda$ could not be maintained constant along the surface of the flat plate. It is only permissible to use these data insofar as the inner layer flow is concerned, since this flow adjusts much more rapidly to the imposed constraints [7]. Although little is known about sucked equilibrium layers, the semi-logarithmic part of the mean velocity distribution is established as an integral part of the theory (sub-sections 32.06 and 43.02). In a plot according to the limit defect law the semi-logarithmic velocity distribution should depend on $\Pi$ and $\Lambda$ only, so that the following tentative formula can be given:

$$
-\frac{\mathrm{v}_{\mathrm{o}}}{\mathrm{u}_{\tau}{ }^{2}}\left(\overline{\mathrm{U}}_{1}-\mathrm{U}_{\mathrm{o}}\right)=0.06 \ln \left(\frac{\mathrm{x}_{2}}{\delta}\right)+\mathrm{D}(\Pi, \Lambda) .
$$

43.04 In the remaining part of the present section the limit velocity defect law and the related similarity expression for the Reynolds stress distribution in the outer layer will be substituted into the equations of motion to study the formal consequences of the similarity law. It is assumed that the similarity law for the mean velocity depends on $\prod$ and $\Lambda$ only. It is further assumed that the viscous shear stress is negligible in the outer layer, and that the velocity defect of the inner layer is negligible so that it is allowed to take $x_{2}=0$ as lower bound for the integrals occurring in the evaluation of the equations of motion. The similarity expression for the mean velocity is the limit defect law, eqn (42-7); the similarity law for the Reynolds stress is 


$$
\frac{-\overline{u_{1} u_{2}}}{u_{\tau}^{2}}=G\left(\frac{x_{2}}{\delta}\right)
$$

This non-dimensionalization is suggested by eqns (4l-5) and (42-6), which are based on the consideration that it appears plausible to non-dimensionalize the Reynolds stress by the value of the shear stress at the wall. Substitution of eqns $(42-7)$ and (43-2) into the equations of motion for the outer layer flow, eqns (41-6) and (4l-7), yields

$$
\begin{aligned}
G^{\prime}=F^{\prime}- & \frac{1}{v_{0}} \frac{d}{d x_{1}}\left(\frac{u_{\tau}^{2} \delta}{v_{0}}\right) F^{\prime} \int_{0}^{\eta} F d \eta+\frac{\delta}{u_{\tau}^{2}} \frac{d}{d x_{1}}\left(\frac{u_{\tau}^{2} U_{o}}{v_{0}}\right) F+ \\
& +\frac{\delta}{v_{0}} \frac{d}{d x_{1}}\left(\frac{u_{\tau}^{2}}{v_{0}}\right) F^{2}-\frac{1}{v_{0}} \frac{d}{d x_{1}}\left(\delta U_{0}\right) \eta F^{\prime} .
\end{aligned}
$$

In this equation $\eta=x_{2} / \delta$; primes denote differentiation w.r.t. $\eta$. For asymptotic layers all terms with $\mathrm{d} / \mathrm{dx}_{1}$ in their coefficient are zero so that then $G^{\prime}=F^{\prime}$, which is equivalent to eqn $(42-6)$. Since the coefficients of $\mathrm{F}^{\prime}$ and $\mathrm{G}^{\prime}$ are unity, the coefficients of the other terms in eqn (43-3) should be constant to obtain simultaneous similarity of mean velocity and Reynolds stress distributions. This condition can be satisfied by putting

$$
\frac{\mathrm{v}_{\mathrm{o}} \mathrm{U}_{\mathrm{o}}}{\mathrm{u}_{\tau}{ }^{2}}=\bigwedge, \frac{\delta}{\mathrm{v}_{\mathrm{o}}} \frac{\mathrm{dU} \mathrm{U}_{\mathrm{o}}}{\mathrm{dx_{1 }}}=\beta, \frac{\mathrm{U}_{\mathrm{o}}}{\mathrm{v}_{\mathrm{o}}} \frac{\mathrm{d} \delta}{\mathrm{dx}_{1}}=\gamma,
$$

with $\Lambda, \beta$ and $\gamma$ constant. It should be noted that the equilibrium parameter $\Lambda$ occurs here before the coefficients of eqn (43-3) have been related to the momentum integral equation; this supports the use of $\Lambda$ in preference to other parameters representing the suction intensity.

43.05 The analysis cannot be continued before the expressions for $\theta$ and $\delta^{*}$ in terms of the limit defect law are given. These are 


$$
\begin{aligned}
& \delta=\frac{1}{U_{0}} \int_{0}^{\infty}\left(U_{0}-\bar{U}_{1}\right) d x_{2}=-\frac{u_{\tau}^{2} \delta}{v_{0} U_{0}} \int_{0}^{\infty} F d \eta=D_{\delta} * \frac{\delta}{\Lambda}, \\
& \theta=\frac{1}{U_{0}^{2}} \int_{0}^{\infty} \bar{U}_{1}\left(U_{0}-\bar{U}_{1}\right) d x_{2}=-\frac{u_{\tau}^{2} \delta}{v_{0} U_{0}} \int_{0}^{\infty} F d \eta-\frac{u_{\tau}{ }^{4} \delta}{v_{0}{ }^{2} U_{0}^{2}} \int_{0}^{\infty} F^{2} d \eta= \\
& =\left(D_{\delta} *+\frac{D_{\theta}}{\Lambda}\right) \frac{\delta}{\Lambda}
\end{aligned}
$$

The quantities $D_{\delta}$ and $D_{\Theta}$ are constants which depend on $\Pi$ and $\Lambda$ only since the mean velocity distribution is assumed to depend on $\Pi$ and $\Lambda$ only. It should be noted that for turbulent equilibrium layers which satisfy the limit defect law the form parameter $H=\delta^{*} / \theta$ is constant:

$$
\mathrm{H}=\frac{\delta^{*}}{\theta}=\frac{\Lambda \mathrm{D}_{\delta}}{\Lambda^{\mathrm{D}^{*}}+\mathrm{D}_{\Theta}} .
$$

It is clear that $\mathrm{H}$ will depend on $\prod$ and $\Lambda$ only, so that it is constant in equilibrium flow. This situation is not similar to the one for unsucked equilibrium layers [7].

The equilibrium parameter $\prod$ can be expressed in terms of the constant $\beta$ in eqn (43-4). Substitution of eqn (43-5) yields

$$
\beta=\frac{\delta}{v_{0}} \frac{d U_{0}}{d x_{1}}=\frac{1}{D_{\delta}{ }^{*}} \frac{\delta^{*} U_{o}}{u_{\tau}^{2}} \frac{d_{0}}{d_{x_{1}}}=-\frac{\Pi}{D_{\delta}} .
$$

Since $D_{\delta}$ is supposed to be a function of $\prod$ and $\Lambda$ only, $\beta$ is constant in equilibrium flow by virtue of the assumption that $\Pi$ and $\Lambda$ are constant in equilibrium flow. Conversely, since $\beta$ has to be constant to obtain similarity solutions of the equations of motion, eqn (43-8) shows that $\prod$ is a proper equilibrium parameter.

43.06 This provisional analysis of turbulent equilibrium layers with moderate suction can now be completed with the introduction of the momentum integral equation. This equation has been presented as eqn (42-2); upon 
substitution of eqns (43-4), (43-6) and (43-8) and after some rearrangement it becomes

$$
r=\frac{\Lambda_{+} \Pi \Lambda_{+} \Lambda^{2}}{D_{\delta} \Lambda+D_{\theta}}+2 \frac{\Pi}{D_{\delta}}
$$

This expression indicates that $\gamma$ is constant in equilibrium flow since it is a function of $\Pi$ and $\Lambda$ only. It follows that the three parameters $\Lambda, \beta$ and $\gamma$ which had to be constant to admit similarity solutions (sub-section 43.04), are indeed constant in equilibrium flow, since they are functions of the constants $\Pi$ and $\bigwedge$ only. A two-parameter description of turbulent equilibrium flow at moderate suction rates appears therefore to be feasible; the available experimental evidence is however insufficient to settle this problem conclusively. It may be expected that equilibrium flow at moderate suction rates is "exact" (if $\Pi$ and $\bigwedge$ are constant, all coefficients of eqn (43-3) are constant) and "universal" (the coefficients of eqn (43-3) do not depend on any parameter other than $\prod$ and $\Lambda$ ).

43.07 A more detailed discussion of the equilibrium of turbulent boundary layers with moderate suction rates requires a skin friction formula. Such a formula can be incorporated into the analysis following the ideas put forward by Townsend $[8]$ and Rotta $[10]$. The skin friction formula is obtained as a consequence of the "overlapping" of related wall and defect laws $[7]$. Combination of eqns $(32-21)$ and $(43-1)$ yields, when the effect of surface roughness is included

$$
\Lambda=-0.06 \ln \left(\frac{-\mathrm{v}_{\mathrm{o}} \delta}{\nu}\right)+11 \frac{\mathrm{v}_{\mathrm{o}}}{\mathrm{u}_{\tau}}+\mathrm{E}\left(\frac{\mathrm{v}_{\mathrm{o}}^{\mathrm{k}}}{\nu}, \Pi, \Lambda\right)
$$

This equation is related to eqn (42-10) for asymptotic layers on smooth surfaces. At constant $\Pi, \Lambda$ and $v_{0} k / \nu$ it follows that

$$
-0.06 \ln \left(\frac{-\mathrm{v}_{\mathrm{o}} \delta}{\nu}\right)+11 \frac{\mathrm{v}_{\mathrm{o}}}{\mathrm{u}_{\tau}}=\text { const } .
$$

Equilibrium flow is expected to occur only if the main stream velocity $U_{0}$ varies as some fixed power of $x_{1}[8,10,14]$. At constant $\Pi$ and $\Lambda$ 
this implies that $v_{0}, u_{\tau}$ and $\delta$ also are proportional to some power of $x_{1}$. It is clear then that $\ln \left(-\mathrm{v}_{0} \delta / \nu\right)$ would not be proportional to a fixed power of $x_{1}$. This implies that in equilibrium flow with constant $\mathrm{v}_{\mathrm{o}} \mathrm{k} / \mathcal{\nu}$ both $v_{0} / u_{\tau}$ and $-v_{0} \delta / \nu$ have to be constant to satisfy eqn (43-10). The condition of constant $v_{0} / u_{\tau}$ would constitute a rather stringent restriction on the number of equilibrium layers which are physically possible. However, at the present state of the theory, with only very scarce experimental data, it is impossible to evaluate to what extent eqn (43-10) may be violated without upsetting the nature of equilibrium flow with moderate suction.

43.08 The results obtained in this section are necessarily of a somewhat provisional nature since experimental data are lacking, except for asymptotic suction layers. Nevertheless, the formal analysis seems to support the idea that equilibrium states of turbulent boundary layers with moderate suction are defined by the values of $\Pi$ and $\Lambda$ only. The correlation with the related limit law of the wall and the consequences of the resulting skin friction formula could not yet be investigated thoroughly. In the next section, the equilibrium behaviour at small suction ratios will be discussed; it will be seen that generally a state of approximate equilibrium is inevitable.

4.4. The normalized velocity defect law.

44.01 The final subject of this chapter on various velocity defect laws will be the "normalized velocity defect law", which has to be used in conjunction with the normalized law of the wall, section 3.3. The normalized wall law has been chosen in such a way that the slope of the logarithmic part of the mean velocity distributions is unity for all turbulent boundary layers with suction or injection. For small values of the suction ratio, including blown boundary layers $\left(-v_{0} / u_{\tau}<0.04\right)$ the velocity scale was shown to be a linear combination of $u_{\tau}$ and $v_{0}$, i.e.

$$
\frac{w^{*}}{u_{\tau}}=2.3\left(1+9 \frac{v_{o}}{u_{\tau}}\right) \text {. }
$$


The formal consequences of this choice for the equilibrium of the outer layer flow will now be investigated in the usual way, cf. sections 4.1 and 4.3 .

44.02 In analogy to the velocity defect laws for boundary layers with moderate suction and for those on impervious surfaces the velocity defect law relating to the normalized wall law can be written as follows:

$$
\frac{\overline{\mathrm{U}}_{1}-\mathrm{U}_{\mathrm{o}}}{\mathrm{w}^{*}}=\mathrm{F}\left(\frac{\mathrm{x}_{2}}{\delta}\right) \text {. }
$$

The similarity expression for the Reynolds stress is, with reference to eqns $(41-5)$ and $(42-6)$

$$
-\frac{-\overline{u_{1} u_{2}}}{u_{\tau}^{2}}=G\left(\frac{x_{2}}{\delta}\right) \text {. }
$$

Substitution of these similarity expressions into the equations of motion for the outer layer, eqns (41-6) and (41-7), yields

$$
\begin{aligned}
G^{\prime} & =\frac{v_{0} w^{*}}{u_{\tau}^{2}} F^{\prime}+\frac{\delta}{u_{\tau}^{2}} \frac{d}{d x_{1}}\left(U_{0} w^{*}\right) F-\frac{w^{*}}{u_{\tau}^{2}} \frac{d}{d x_{1}}\left(\delta U_{0}\right) \eta F^{\prime}+ \\
& +\frac{\delta w^{*}}{u_{\tau}^{2}} \frac{d w^{*}}{d x_{1}} F^{2}-\frac{w^{*}}{u_{\tau}^{2}} \frac{d}{d x_{1}}\left(w^{*} \delta\right) F^{\prime} \int_{0}^{\eta} F d \eta \cdot
\end{aligned}
$$

To obtain shear stress similarity when the mean velocity distributions are similar, the coefficients of the terms at the r.h.s. of eqn (44-3) must be constant. This is satisfied by introducting

$$
\frac{\mathrm{v}_{\mathrm{O}} \mathrm{U}_{\mathrm{o}}}{\mathrm{u}_{\tau}{ }^{2}}=\Lambda, \frac{\mathrm{w}^{*}}{\mathrm{U}_{\mathrm{O}}}=\alpha^{*}, \frac{\delta \mathrm{w}^{*}}{\mathrm{u}_{\tau}{ }^{2}} \frac{\mathrm{dU}}{\mathrm{dx}_{1}}=\beta^{*},\left(\frac{\mathrm{w}^{*}}{\mathrm{u}_{\tau}}\right) \frac{\mathrm{d} \delta}{\mathrm{dx}_{1}}=\gamma^{*} \cdot(44-4)
$$

where $\alpha^{*}, \beta^{*}, \gamma^{*}$ and $\Lambda$ are constants. Shear stress similarity at constant $\Pi$ and $\Lambda$ is considered to be a necessary condition for a flow to qualify as an equilibrium flow. The state of equilibrium will be universal if the parameters $\alpha^{*}, \beta^{*}$ and $\gamma^{*}$ can be expressed in terms of $\Pi$ and $\bigwedge$ only . 
4.03 The constant $\beta^{*}$ is related to the equilibrium parameter $\Pi$ :

$$
\Pi=-\frac{\delta U_{0}}{u_{\tau}{ }^{2}} \frac{d U_{0}}{d x_{1}}=\frac{\delta w^{2}}{u_{\tau}{ }^{2}} \frac{d U_{o}}{d} \int_{1}^{\infty} F d \eta=\beta^{*} \int_{0}^{\infty} F d \eta
$$

This equation may be compared to eqns (41-12) and (43-8). Assuming that the mean velocity distribution of an equilibrium layer depends on $\Pi$ and $\bigwedge$ only, the integral occurring in eqn (44-5) also depends on $\Pi$ and $\Lambda$ only so that $\beta^{*}$ is determined by the values of these equilibrium parameters. The constant $\gamma^{*}$ may be expressed in terms of $\Pi, \Lambda$ and $w^{*} / U_{0}$ by means of the momentum integral equation (cf. sub-sections 41.06 and 43.06), so that three parameters remain, one more than the two occurring in the momentum integral equation. The occurrence of $\mathrm{w} / \mathrm{U}_{0}$ in the "normalized" equilibrium flow shows a similarity with the presence of $u_{\tau} / U_{0}$ in the analysis of equilibrium flow on impervious surfaces $\left(w^{*} \rightarrow 2.3 u_{\tau}\right.$ for $\left.v_{0} \rightarrow 0\right)$. Since the effect of $u_{\tau} / U_{0}$ on equilibrium flow without suction or blowing is very small (sub-section 41.06), it may be expected that for sucked or blown boundary layers the effect of $\mathrm{w}^{*} / \mathrm{U}_{\mathrm{O}}$ on the state of equilibrium is also small. At constant $\Pi$ and $\Lambda$ "nearly universal" equilibrium flow will then be possible, similar to the equilibrium state of most unsucked turbulent boundary layers (section 4.1 ).

44.04 The results of this section are clearly of a provisional nature. A complete analysis cannot be given due to the lack of a comprehensive theory of equilibrium flow without suction or injection, to which the analysis presented here would be related. The available theory $[8,10,14,40]$ in particular has failed to present a formal analysis of the disturbing effects of the skin friction coefficient at moderate Reynolds numbers. 
5. THE APPLICATION OF MIXING LENGTH THEORY TO TURBULENT BOUNDARY LAYER FLOW WITH SUCTION OR INJECTION: A REVIEW OF THE LITTERATURE

\subsection{Introduction}

51.01 Until recently, mixing length theory has been the basis of all published theoretical work on turbulent boundary layers with distributed suction or injection. The only exception is a short article published by Mickley and Smith in 1963 [29]; see sub-section 54.02. The results of the application of mixing length theory to turbulent boundary layers on a permeable surface will be briefly reviewed in this chapter. This review is presented in a separate chapter to prevent confusion with the approach given in chapters 3 and 4 . These latter chapters were based on a generalization of the similarity laws for turbulent boundary layer flow. The similarity laws are not closely related to the mixing length theory, so that a discussion of this theory is not essential for the understanding of chapters 3 and 4 .

52.02 The mean velocity distribution resulting from the application of mixing length theory to sucked turbulent boundary layers has a bi-logarithmic shape, as will be shown presently. This bi-logarithmic distribution was first derived by Kay [20], who rejected its application however, since the velocity distributions of two asymptotic layers measured by him did not exhibit the required curvature in a semi-logarithmic plot. It seems surprising that, notwithstanding this evidence and the data obtained by Dutton [21], which also gave semi-logarithmic velocity distributions, the bi-logarithmic law has been the basis of all theoretical work for more than ten years. The bi-logarithmic law has been used by Dorrance and Dore [15], Rubesin [41], Clarke et al [42] and by Mickley and Davis [16]. A comprehensive account of the mixing length theory for boundary layers on a permeable surface has been given by Black and Sarnecki [17] and by Sarnecki in his Ph.D. Thesis [5]. The bi-logarithmic law has been used also by Cornish [43] in a paper which incorporated an attempt to construct a "universal description" of the velocity distribution, and by Townsend [40] in a discussion of the flow in the inner layer of turbulent boundary 
layers. The review given in this chapter will be based mainly on the papers by Black and Sarnecki $[5,17]$ since these authors present the consequences of the bi-logarithmic law more carefully and completely than most others.

1.03 The mixing length theory for turbulent boundary layer flow was originated by prandtl $[25]$. The purpose of this theory is to predict a relation between mean velocity gradient and Reynolds stress in the inner layer. This relation should be formally independent of the equations of motion, in order that the unknown Reynolds stress term in the equations of motion can be replaced by a term containing $\overline{\mathrm{U}}_{1}$ and $\mathrm{x}_{2}$ only. The momentum transfer theory, which is one branch of mixing length theory (the other branch is Taylor's vorticity transfer theory [24]), proposes the following expression for the Reynolds stress (the mixing length is assumed here to be proportional to $\mathrm{x}_{2}$ ):

$$
-\overline{u_{1} u_{2}}=k^{2} x_{2}{ }^{2} \stackrel{\partial \bar{U}_{1}}{2} \frac{\left(\frac{1}{\partial x_{2}}\right)}{} \text {. }
$$

This relation is well-known in the theory of turbulent shear flow and has been extensively discussed in the litterature $[9,24,25]$. Eqn (51-1) is used in conjunction with the equations of motion. For the fully turbulent part of the inner layer these equations reduce to eqn (32-24), which may be integrated to obtain

$$
u_{\tau}^{2}+v_{0} \bar{U}_{1}=-\overline{u_{1} u_{2}}
$$

The approximations involved are those which are commonly used for the flow in the inner layer (see sub-sections 31.08 and 32.02 ). Substitution of eqn (51-1) into eqn (51-2) removes the unknown Reynolds stress term. After integration w.r.t. $x_{2}$ this yields for turbulent boundary layers without suction or injection

$$
\overline{\mathrm{U}}_{1}=\frac{\mathrm{u}_{\tau}}{\mathrm{k}} \ln \left(\frac{\mathrm{x}_{2}}{\mathrm{~d}_{\mathrm{o}}}\right) .
$$


Similarly, for boundary layers with suction or injection

$$
\mathrm{u}_{\tau}^{2}+\mathrm{v}_{\mathrm{o}} \overline{\mathrm{U}}_{1}=\left\{\frac{\mathrm{v}_{\mathrm{o}}}{2 \mathrm{k}} \ln \left(\frac{\mathrm{x}_{2}}{\mathrm{~d}}\right)\right\}^{2} \text {. }
$$

Eqn (51-4), the so-called "bi-logarithmic law" by virtue of the presence of a squared logarithm, has been presented by Black and Sarnecki [17] as eqn 3.2.17. In eqns $(51-3)$ and $(51-4), d_{0}$ and $d$ are quantities with dimensions of a length, with an as yet undetermined magnitude.

51.04 It is well-known that eqn (51-3) correctly predicts a semi-logarithmic mean velocity distribution in turbulent boundary layer flow without suction or injection. Due to the arbitrary magnitude of $d_{0}$, eqn (51-3) may either be fitted into the law of the wall or into the velocity defect law. It is commonly adjusted to represent the semi-logarithmic mean velocity distribution in wall law coordinates $\left(\bar{U}_{1} / u_{\tau}\right.$ vs $\left.x_{2} u_{\tau} / \nu\right)$, since its derivation depends on the inner layer approximation to the equations of motion. This adjustment can be made if experimental data are used to determine $d_{0}$. The magnitude of $d_{0}$ can be found also with the following procedure. The viscous sub-layer and the logarithmic part of the boundary layer are supposed to meet at a "transition point". In this point, the mean velocity and the shear stress are continuous, but their derivatives are not. The transition point may be characterized by a critical Reynolds number. If the value of this Reynolds number is known (e.q. by correspondence to the critical Reynolds number of Couette flow), the location of the transition point can be determined. The parameter $d_{0}$ can then be evaluated. This procedure (whose validity has to be proven by experimental evidence) is used by Black and Sarnecki $[5,17]$ for turbulent boundary layers on a permeable surface. The results of this procedure will be discussed in sub-sections 52.02 and 52.03 .

51.05 The mixing length theory is based on a rather crude assumption concerning the relation between Reynolds stress and mean shear, i.e. eqn (51-1). The results of the application of this assumption can be accepted only if they do not contradict with the results of experiments. It is noted that eqn $(51-1)$ is a rather restrictive postulate. The law of the wall however 
is, in its most general form, a result of dimensional analysis only; it does not give a quantitative prescription of the nature of the flow in the inner layer. For boundary layers without suction or injection the law of the wall and the results of mixing length theory agree with one another. However, for boundary layers with suction or injection, the two theories give conflicting results. This will be discussed in sections 5.2 and 5.3 .

\subsection{The bi-logarithmic mean velocity distribution in the inner layer}

52.01 In this section the differences between the bi-logarithmic mean velocity distribution and the similarity laws for the inner layer, as put forward in ch.3, will be compared. Attention will be paid to Black and Sarnecki's method to determine the transition point between the sub-layer and the turbulent flow (sub-section 52.03). Then the velocity distributions predicted by the bi-logarithmic law and those predicted by the limit law of the wall are compared (sub-section 52.03). It will further be seen that the bi-logarithmic law is an semi-empirical law, just like the normalized wall law (sub-section 52.04). The two main arguments opposing the bi-logarithmic law will then be discussed: it does not have a semilogarithmic velocity distribution to yield an overlapping region between the wall law and the related velocity defect law (sub-section 52.05) and it does not include similarity of the flow in the viscous sub-layer (sub-section 52.06 ).

52.02 The major problem associated with the bi-logarithmic law is that it has to be related to some inner layer description in which the parameter d occurring in eqn $(51-4)$ is expressed in terms of the suction ratio $-v_{o} / u_{\tau}$. The value of $d\left(v_{0} / u_{\tau}\right)$ depends on the position of the transition point between the sub-layer and the bi-logarithmic velocity distribution. As already indicated in sub-section 51.04, this transition point is supposed to be characterized by a constant critical value of some typical Reynolds number $[5,17]$. The discussion is now restricted to boundary layer flows along smooth walls. For boundary layers on smooth impervious surfaces the choice of a typical Reynolds number is fairly easy: the value of $d_{0}$ does not depend on any parameter, although the choice of 
Reynolds number may slightly affect the numerical value obtained for $d_{0}$. For turbulent boundary layers on permeable surfaces however, it is not so simple to choose a critical Reynolds number. The parameter $d$ will depend on the suction ratio $-v_{o} / u_{\tau}$. The relation between $d$ and $-v_{o} / u_{\tau}$ is markedly affected by the nature of the critical Reynolds number, as Black and Sarnecki $[5,17]$ have shown.

Sarnecki used the results of his experiments to determine which "transition criterion" should be used and, consequently, which relation between $d$ and $v_{0} / u_{\tau}$ should be accepted. Among twelve others, the curve resulting from postulating that $\left(\mathrm{x}_{2}{ }^{2} \partial \overline{\mathrm{U}}_{1} / \partial \mathrm{x}_{2}\right) / \nu=$ const. at the transition point, was found to correlate the experimental data rather nicely $[5]$. It should be noted however that the use of experimental data in this context is rather dangerous since the relation between $d$ and $v_{0} / u_{\tau}$ is also affected by surface roughness. Sarnecki assumed (without verification) that the blotting paper and nylon surfaces which were used in his experiments were hydrodynamically smooth, but comparison with the limit law of the wall will show that this assumption is probably incorrect (sub-section 52.03 ).

52.03 Mean velocity distributions resulting from the bi-logarithmic law and the transition criterion chosen by Sarnecki have been calculated in terms of the coordinates of the limit law of the wall. These velocity distributions, together with those predicted by the limit wall law, eqn (32-22), are presented in fig. 27 for a few values of $v_{0} / u_{\tau}$. It is observed that in the range of values of $x_{2} v_{0} / \nu$ which is covered by the turbulent part of the inner layer, at least for $-v_{0} x_{2} / \nu<50$, the average slope of the bi-logarithmic velocity distribution is roughly equal to the "universal" slope predicted by the limit law of the wall. This feature is considered to be the background of the often rather accurate estimate of the skin friction coefficient of turbulent boundary layers with suction according to Black and Sarnecki's formulae $[5,17]$. It is also observed that the velocity distributions predicted by Sarnecki fall well below those predicted by the limit law of the wall at the same values of $v_{0} / u_{\tau}$. It will be recalled that the location of the semilogarithmic velocity distribution in the limit law of the law has been 
obtained on basis of the assumption that Kay's porous sintered bronze surface [20] was hydrodynamically smooth (sub-section 32-12). Since velocity distributions are supposed to shift downward due to surface roughness, it may be concluded that Sarnecki's nylon and blotting paper surfaces [5] were not smooth, so that his determination of the relation between $d$ and $-v_{0} / u_{\tau}$ may have been affected by roughness effects of unknown magnitude.

2.04 Black and Sarnecki $[5,17]$ have shown that in the limit $v_{0} / u_{\tau} \rightarrow 0$ the bi-logarithmic law, eqn (51-4), can be transformed into the original logarithmic law, eqn (51-3). In this respect the bi-logarithmic law is superior to the limit law of the wall, which is not valid for $-v_{o} / u_{\tau}<0.04$. The introduction of a normalized wall law (section 3.3) to fill the gap between the original wall law at $v_{0} / u_{\tau}=0$ and the limit law of the wall at $-v_{0} / u_{\tau}>0.04$ is rather artificial. However, the relation between $\mathrm{d}$ and $\mathrm{v}_{0} / \mathrm{u}_{\tau}$ in the bi-logarithmic law, which is needed to determine the velocity distribution, can be determined only by reference to experimental data, so that this representation, just like the normalized wall law, is merely an empirical formula.

52.05 The first and main argument opposing the bi-logarithmic law of course is the absence of a semi-logarithmic mean velocity distribution. As shown in ch.3, a similarity law for the mean flow in the inner layer can join the corresponding law for the outer layer only if the velocity distribution in the region of overlap is semi-logarithmic. Moreover, the existence of a velocity defect law is vital to the proper interpretation of turbulent equilibrium flow (ch. 4). Besides this theoretical argument, it is observed that most experimental data do not support the concept of a bi-logarithmic velocity distribution. Black and Sarnecki however claim that the data do support their theory. For a few velocity distributions obtained by Sarnecki [5] appreciable curvature is indeed observed, as fig. 28, which is a reproduction of the relevant data, shows. However, these velocity distributions were obtained at $-v_{0} / u_{\tau}=$ 0.061 approximately; comparison with some velocity distributions 
obtained in our laboratory on a similar surface at rather large values of the suction ratio, figs 8,16 and 17 , indicate that the boundary layers concerned are probably in the first stage of reversal to laminar flow. It is also possible that in these layers no fully developed turbulence was present. In this context it should be noted that the rather thicker boundary layers measured by Sarnecki on a perforated surface (as opposed to the nylon surface for the above-mentioned layers) exhibit velocity distributions with a clearly recognizable semi-logarithmic part [5]. This is shown by an example which has been replotted in limit wall law coordinates, fig. 29. It is not surprising that Sarnecki commented that he experienced difficulties in the correlation of the velocity distributions of fig. 29 to the bi-logarithmic law $[5]$.

52.06 A second argument against the bi-logarithmic law is that it cannot be generalized to include the velocity distribution in the viscous sublayer. The limit law of the wall on the contrary, gives an elegant description of the flow in the viscous sub-layer. According to the limit law of the wall the velocity distribution in the sub-layer is a single "universal" curve (sub-section 32.03 ):

$$
\frac{\mathrm{v}_{\mathrm{o}} \overline{\mathrm{U}}_{1}}{\mathrm{u}_{\tau}^{2}}=\exp \frac{\mathrm{v}_{\mathrm{o}} \mathrm{x}_{2}}{y}-1 .
$$

Black and Sarnecki plot the bi-logarithmic law commonly as

$$
\frac{\bar{U}_{1}}{U_{0}}+Y_{s}^{2}=f\left(Y_{s}\right) \text {. }
$$

In this equation, $\mathrm{Y}_{\mathrm{S}}$ is defined by

$$
\mathrm{Y}_{\mathrm{S}}=\frac{1}{2 \mathrm{k}}\left(\frac{-\mathrm{v}_{\mathrm{o}}}{\mathrm{U}_{\mathrm{o}}^{\frac{1}{2}}}\right) \ln \frac{\mathrm{U}_{\mathrm{o}} \mathrm{x}_{2}}{\gamma} .
$$

It is obvious that a relation like eqn (52-1) cannot be expected to represent the simple velocity distribution in the viscous sub-layer as a single curve. The bi-logarithmic law is therefore not suitable as a similarity law for the flow in the inner layer. 


\subsection{Application of the bi-logarithmic law to turbulent equilibrium layers}

3.01 In this section the bi-logarithmic law will be applied to turbulent equilibrium layers. A characteristic property of equilibrium layers is that their velocity distributions are similar if plotted according to the appropriate velocity defect law (ch.4). Hence, it is worth while to check if the bi-logarithmic law satisfies this similarity condition. A simple equilibrium layer is the asymptotic layer (section 4.2 ); it will be shown that for this layer the bi-logarithmic velocity distribution does not exhibit similarity in velocity defect law coordinates.

53.02 For asymptotic layers $\Lambda=-1$, so that $\mathrm{v}_{\mathrm{O}} \mathrm{U}_{\mathrm{O}}=-\mathrm{u}_{\tau}^{2}$.

The bi-logarithmic law, eqn (51-4), may then be written as

$$
1-\frac{\overline{\mathrm{U}}_{1}}{\mathrm{U}_{\mathrm{o}}}=\left(\frac{\mathrm{v}_{\mathrm{o}}}{2 \mathrm{u}_{\tau} \mathrm{k}} \ln \frac{\mathrm{x}_{2}}{\mathrm{~d}}\right) .
$$

Sarnecki states that for all asymptotic layers the mean velocity distribution departs only little from the bi-logarithmic law, even in the outermost part of the boundary layer [5], so that up to the outer edge of the asymptotic layer the velocity distribution is considered to be represented by eqn (53-1). It should be noted that Cornish asserts that this may be the case for some asymptotic layers but not for others [43]. This argument however cannot be accepted since it does not take into account that asymptotic layers are equilibrium layers which should have similar velocity distributions. If Sarnecki's assumption is accepted, the parameter d can (for asymptotic layers only) be identified with the boundary layer thickness $\delta$, since according to eqn $(53-1), \bar{U}_{1}=U_{0}$ at $x_{2}=\delta$. Eqn (53-1), which should be compared to the limit defect law for asymptotic layers,eqn $(42-7)$, indicates then that the velocity distribution predicted by the bi-logarithmic law depends on the suction ratio $-v_{0} / u_{\tau} \cdot$ This contradicts with the experimental evidence (section 4.2 , fig. 26) and with the concept of velocity similarity for equilibrium layers. 
53.03 Since the boundary layer thickness $\delta$ is a rather awkward quantity, which is very difficult to determine in experiments, velocity distributions according to the velocity defect law may be compared in a more realistic way if the displacement thickness $\delta^{*}$ is used as the appropriate length scale. For asymptotic layers this is allowed, since a defect law with $\delta$ and the related one with $\delta$ as length scale are equivalent. This is shown as follows. The limit defect law for asymptotic layers reads

$$
\frac{\overline{\mathrm{U}}_{1}}{\mathrm{U}_{\mathrm{O}}}-1=\mathrm{F}\left(\frac{\mathrm{x}_{2}}{\delta}\right)
$$

On integration

$$
\delta^{*}=\int_{0}^{\infty}\left(1-\frac{\bar{U}_{1}}{\mathrm{U}_{0}}\right) d x_{2}=-\delta \int_{0}^{\infty} F \mathrm{~d} \eta,
$$

in which $\eta=x_{2} / \delta$. It is concluded that $\delta$ and $\delta$ are proportional, the proportionality constant being universal since eqn (42-8) gives a universal description of the flow in asymptotic layers (section 4.3 ). Sarnecki's claim that the mean velocity distribution throughout the asymptotic layer is described by the bi-logarithmic law (sub-section 53.02) implies that eqn (53-1) may be used to determine $\delta$. Integration of eqn (53-1) yields a relation between $\delta^{*}$ and $d$ :

$$
\mathrm{U}_{\mathrm{O}} \delta^{\#}=-2 \cdot 793 \mathrm{v} \cdot \mathrm{d}
$$

This relation was derived by Cornish [43], from whom the numerical value of the constant was taken. Eqn (53-3) may be used to substitute for $d$ in eqn (53-1). The velocity distributions obtained in this way still depend on the suction ratio $-v_{0} / u_{\tau}$ however. Three members of this family have been plotted in fig. 30. In this figure the experimental velocity distributions of asymptotic layers have been replotted in the same coordinates $\left(\bar{U}_{1} / \mathrm{U}_{0} \mathrm{vs} \cdot \mathrm{x}_{2} / \delta^{*}\right)$. Comparison of these data and the bi-logarithmic velocity distributions shows that the bi-logarithmic law gives a rather poor representation of the velocity distributions of asymptotic layers and that it cannot account for the apparent 
similarity of the flow in these equilibrium layers. It should be noted however that the asymptotic layer found by Sarnecki on a nylon surface conforms to the bi-logarithmic law rather better than all others. This case however, is considered to be an exception (see also sub-section $52.05)$.

\subsection{Conclusions}

54.01 To conclude the discussion presented in this chapter it may be stated that for two reasons the bi-logarithmic velocity distribution predicted by mixing length theory is not very well suited to represent the behaviour of turbulent boundary layer flow with suction or injection. First, it agrees only moderately with the experimental evidence and it is rather cumbersome to use when plotting velocity distributions. Second, it cannot be related to a description of turbulent boundary layer flow by means of similarity laws for the inner and the outer layer. In particular, the equilibrium flow of asymptotic layers cannot be represented by the bi-logarithmic law.

54.02 With only one exception, all published theoretical work on turbulent boundary layers with suction or injection has been based on mixing length theory. The exception is a recent article by Mickley and Smith [29]. In this article a velocity scale equivalent to the "logarithmic velocity scale" ( $w^{*}$ ) was introduced to obtain a provisional velocity defect law for turbulent boundary layers with injection. This velocity scale was obtained in a purely empirical way; it was not related to the suction ratio $-v_{o} / u_{\tau}$. The measured velocity distributions of two turbulent boundary layers with injection were observed to exhibit semilogarithmic parts with the proper slope if they were plotted according to the velocity defect law with modified velocity scale (see also sub-section 33.02 ).

The relevance of this modified attitude towards the behaviour of turbulent boundary layers with suction or injection has been pointed out by the present author in a short comment to Mickley and Smith's paper [45]. 
6. CONCLUSIONS

6.1. The similarity laws for the mean flow

61.01 It has been shown in this paper that a description of turbulent boundary layer flow based on separate, but closely related similarity laws for the inner layer and the outer layer, can be applied successfully to turbulent boundary layers with suction or injection. The distinction between the inner layer and the outer layer is a prerequisite for a simple and consistent description; the two similarity laws should be related to each other through a common velocity scale and a semi-logarithmic velocity distribution in the region of overlap. The results of experiments carried out for the present research, together with experimental evidence available in the literature, have shown that these concepts are valid for turbulent boundary layer flow with suction or injection.

61.02 The proposed description, which has been generalized from the phenomenological concepts of Clauser $[7]$, Coles $[44]$, Rotta $[10]$, Townsend [8] and others, agrees appreciably better with the experimental data than the results of mixing-length theory. The relation between Reynolds stress and mean rate of strain is not prescribed in the present analysis, so that the equations of motion cannot be solved explicitly. However, it has been possible to obtain appropriate similarity laws, using mainly qualitative considerations. The general expressions for the proposed similarity laws are

$$
\frac{\mathrm{v}_{\mathrm{o}} \overline{\mathrm{U}}_{1}}{\mathrm{U}_{\tau}^{2}}=\mathrm{F}\left(\frac{\mathrm{v}_{\mathrm{o}} \mathrm{x}_{2}}{\nu}\right), \frac{\mathrm{v}_{\mathrm{o}}\left(\overline{\mathrm{U}}_{1}-\mathrm{U}_{\mathrm{O}}\right)}{\mathrm{U}_{\tau}^{2}}=\mathrm{G}\left(\frac{\mathrm{x}_{2}}{\delta}\right)
$$

for moderate suction rates; and

$$
\frac{\overline{\mathrm{U}}_{1}}{\mathrm{w}^{*}}=\mathrm{F}\left(\frac{\mathrm{x}_{2} \mathrm{U}_{\tau}^{2}}{\mathcal{\nu}_{\mathrm{w}}^{*}}\right), \frac{\overline{\mathrm{U}}_{1}-\mathrm{U}_{\mathrm{o}}}{\mathrm{w}^{*}}=\mathrm{G}\left(\frac{\mathrm{x}_{2}}{\delta}\right)
$$

for small suction rates and all blowing rates (if not too large). 
61.03 To support the general expression for the law of the wall, it is usually demonstrated that the flow in the viscous sub-layer exhibits similarity if expressed according to this law. Conversely, similarity of the flow in the viscous sub-layer may be used as a necessary requirement imposed on any wall law. It has been shown in this paper that in this way the appropriate non-dimensional expressions for the mean velocity $\overline{\mathrm{U}}_{1}$ and the distance from the wall $\mathrm{x}_{2}$ can be determined easily. An approach along such lines may be suitable also for the study of other turbulent shear flows, like magneto-hydrodynamic and compressible shear flows with or without heat transfer.

61.04 In the litterature the velocity defect law for turbulent boundary layers on impervious surfaces is commonly subjected to the condition that similarity of the mean velocity distribution and similarity of the Reynolds stress distribution should occur simultaneously. This condition is also applied here since it is considered necessary for obtaining a physically possible state of equilibrium. The condition is supposed to be satisfied when simultaneous similarity is compatible with the equations of motion. In the present paper this treatment has been applied not only to all velocity defect laws but also to the various forms of the law of the wall. The limit law of the wall satisfies the condition of simultaneous similarity, but in the normalized wall law it is formally impossible. Therefore, the limit similarity laws should be preferred above the normalized similarity laws.

61.05 The present analysis provides a simple description of the flow in turbulent asymptotic layers. It has been shown that the velocity distributions of asymptotic layers coincide if plotted according to the limit velocity defect law. This supports the proposed description of turbulent boundary layer flow with suction or injection. It has been shown that mixing length theory is unable to recognize the unique character of asymptotic layers. The velocity distributions of asymptotic layers do not depend on any parameter. This agrees with the proposal to use 


$$
\Pi=\frac{\delta^{*}}{\tau_{0}} \frac{\mathrm{d} \overline{\mathrm{P}}}{\mathrm{dx} \mathrm{x}_{1}}, \Lambda=\frac{\rho \mathrm{v}_{\mathrm{o}} \mathrm{U}_{\mathrm{o}}}{\tau_{\mathrm{o}}}
$$

as equilibrium parameters, since these parameters have unique values for asymptotic flow ( $\Pi=0, \Lambda=-1)$.

\subsection{The logarithmic velocity scale}

62.01 The proposed similarity laws for sucked and blown turbulent boundary layers have led to the introduction of the logarithmic velocity scale $\mathrm{w}^{*}$. If the mean velocity is non-dimensionalized by $\mathrm{w}^{*}$, the slope of the semi-logarithmic part of the velocity distribution is unity, whatever the value of the suction ration $-v_{0} / u_{\tau}$ (which is the pertinent parameter). At moderate suction rates $\left(0.04<-v_{0} / u_{\tau}<0.10\right)$

$$
\frac{w^{*}}{u_{\tau}}=-0.06 \frac{u_{\tau}}{v_{o}} \text {, }
$$

whereas at small suction rates and all blowing rates (if not too large)

$$
\frac{w^{w}}{u_{\tau}}=2 \cdot 3\left(1+9 \frac{\mathrm{v}_{\mathrm{o}}}{\mathrm{u}_{\tau}}\right) .
$$

62.02 The logarithmic velocity scale is related to the representative level of turbulent shear stress. This is evident for turbulent boundary layers on impervious walls, for which $\mathrm{w}^{*}=c\left(\tau_{0} / \rho\right)^{\frac{1}{2}}=\mathrm{cu}_{\tau}$. For boundary layers with blowing, the logarithmic velocity scale relates to the maximum Reynolds stress within the boundary layer, as Mickley and Smith [29] have shown. For boundary layers with suction the relation between

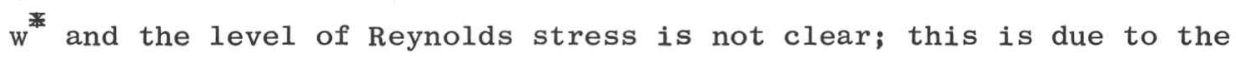
absence of a suitable estimate of the level of Reynolds stress in those layers.

62.03 The concept of a logarithmic velocity scale simplifies the description of turbulent boundary layers with mass transfer. It may very well be that this concept is powerful enough to be applicable also to 
compressible or magnetohydrodynamic turbulent boundary layers with or without heat transfer. It will be relatively easy to determine w empirically from measured velocity distributions; qualitative considerations will presumably suffice to determine on which parameters $w^{*} / u_{\tau}$ depends.

\subsection{Unsolved Problems}

63.01 A very disturbing problem in the theory of similar velocity distributions concerns the parameters to be used in equilibrium flow. In this paper the parameters $\Pi$ and $\Lambda$ associated with the momentum integral equation have been used. However, other non-dimensional groups are also constant in equilibrium flow; it is not clear which are most suited to describe the nature of the equilibrium. The effect of the parameters $u_{\tau} / U_{0}$ and $\mathrm{w}^{*} / \mathrm{U}_{\mathrm{O}}$ in boundary layer flows without and with suction respectively, has been shown to be rather obscure.

63.02 The linear dependence between the logarithmic velocity scale $w^{*}$ and the suction ratio $-v_{o} / u_{\tau}$ at small values of the latter has not been explained in a satisfactory way. The only theoretical background is Turcotte's [30] analysis, which is based on a rather speculative estimate of the distribution of the eddy viscosity in the inner layer. On the other hand, the linear relation between $\mathrm{w}^{*} / \mathrm{u}_{\tau}$ and $-\mathrm{v}_{\mathrm{o}} / \mathrm{u}_{\tau}$ is not surprising in view of the fact that a parameter with very small values is concerned.

63.03 At other than relatively small injection rates the normalized wall law with the linear relationship between $w^{*} / u_{\tau}$ and $-v_{o} / u_{\tau}$ is not expected to be valid. Especially cases with zero or negative effective wall shear [17] will need special attention. In this paper, however, the main emphasis has been on turbulent boundary layers with suction, so that blown boundary layers could not be treated in much detail.

63.04 At the present state of the art it appears to be impossible to tackle the problem of surface roughness. Surface roughness is a major source 
of complication for porous walls, since most porous walls not only are rough but also have a not strictly homogeneous suction distribution (e.g. perforations). The limit and normalized walls laws reduce the effect of surface roughness to a parallel shift of the mean velocity distribution, but as yet not sufficient data are available to determine the relation between the magnitude of the velocity shift and some appropriate roughness Reynolds number. Therefore, it has been impossible to give a skin friction formula needed for the calculation of boundary layer growth. 


\section{REFERENCES}

1. Lachmann, G.V. (editor)

2. Moon, I Man

3. Cornish, J.J.

4. Schlichting, $\mathrm{H}$. Pechau, W.

5. Sarnecki, A.J.

6. Clauser, F.H。

7. Clauser, F.H.

\section{"Boundary Layer and Flow Control" \\ (2 volumes) Pergamon Press, Oxford (1961).}

"Distributed Suction Boundary Layer

Control on Conical Diffusers".

Aeroph.Dept., Miss. State College,

Research Rept. 17 (1958).

"A Simplified Procedure for Calculating Boundary Layer Control Systems for Unflapped Airfoils".

Aeroph. Dept., Miss. State

College,

Research Rep. 15 (1958).

"Auftriebserhơhung von Tragflugeln durch kontinuierlich verteilte Absaugung". Zeitschr. fur Flugwiss. VII, 5, p.113-119 (1959).

"The Turbulent Boundary Layer on a Permeable Surface".

Ph.D. thesis, Cambridge (1959).

"Turbulent Boundary Layers in Adverse Pressure Gradients". Journ. Aero. Sci. 21 , p. 91-108 (1954).

"The Turbulent Boundary Layer". Advances in Applied Mechanics, vol. IV, p. 1-51, Academic Press, New York (1956). 
8. Townsend, A.A.

9. Hinze, J.O.

10. Rotta, J.C.

11. Millikan, C.B.

12. Nikuradse, J.

13. Ludwieg, $\mathrm{H}$. Tillmann, W.

14. Townsend, A.A.

15. Dorrance, W.H. Dore, F.J.
"The Structure of Turbulent Shear Flow". Cambridge Univ. Press (1956).

"Turbulence".

McGraw-Hill Book Co., New York (1959).

"Turbulent Boundary Layers in

Incompressible Flow".

Progress in Aero.Sci., vol. 2,

p. 1-219, Pergamon Press, Oxford (1962).

"A Critical Discussion of Turbulent

Flows in Channels and Circular Tubes".

Proc. Vth Intern.Congr.Appl.Mech.,

Cambridge, Mass., p. 386-392 (1938).

"Gesetzmassigkeiten der turbulenten

Stromung in glatten Rohren".

Forschungsheft Ver. deutscher Ing.,

$\mathrm{nr} .356$ (1932).

"Investigations of the wall Shearing Stress in Turbulent Boundary Layers". NACA TM 1285 (1950)

"The properties of Equilibrium Boundary Layers".

Journ. F1. Mech., 1, p. 561-573 (1956).

"The Effect of Mass Transfer on the Compressible Turbulent Boundary Layer Skin Friction and Heat Transfer". Journ.Aero.Sci., 21, p.404-410 (1954). 
16. Mickley, H.S.

Davis, R.S.

17. Black, T.J.

Sarnecki, A.J.

18. Dobbinga, E.

Van Ghesel Grothe, J.A.

19. Eck, Br.

20. Kay, J.M.

21. Dutton, R.A.

22. Favre, A.

Dumas, $R$.

Verollet, E.

23. Butensky, M.S.
"Momentum Transfer over a Flat Plate with Blowing".

NACA TN 4017 (1957).

"The Turbulent Boundary Layer with Suction or Injection".

ARC 20,501, (FM 2745), (1958).

"De lage-snelheids Windtunnel van de subafdeling Vliegtuigbouwkunde der Technische Hogeschool".

Aeron.Eng.Dept., Technological University Delft, Rep.77 (Reprint from: de Ingenieur $67,38,1955)$.

"Technische Stromungslehre".

4th ed, Springer Verlag, Berlin (1954).

"Boundary Layer Flow with Uniform Suction". ARC R and M 2628 (1948).

"The Effects of Distributed Suction on the Development of Turbulent Boundary Layers". ARC 20,036 (FM 2671) (1958). Also:

$\mathrm{R}$ and M 3155 (1960).

"Couche Limite sur Paroi Plane Poreuse avec Aspiration".

Publ.Sci.Techn.du Min. de l'Air, no. 377 (1961).

"The Transpired Turbulent Boundary Layer on a Flat Plate".

Sc.D. thesis, Mass. Inst.Techn., Cambridge, Mass. (1963). 
24. Schlichting, $\mathrm{H}$.

25. Prandtl, L.

26. Hinze, J.O。

27. Prandt1, L. Tietjens, 0 .

28. Griffith, A.A. Meredith, F.W.

29. Mickley, H.S. Smith, K.A.

30. Turcotte, D.L.
"Boundary Layer Theory".

Pergamon Press, London (1955).

"The Mechanics of Viscous Fluids".

Section G, p. 34-208, in: W.F.Durand, Aerodynamic Theory, vol. III, Springer, Berlin (1935).

"Turbulent Pipe Flow".

Mécanique de la Turbulence, p. 129-165, Editions du Centre de la Récherche Scientifique, Paris (1962).

"Hydro- und Aeromechanik".
Springer Verlag, Berlin (1929).

"Possible Improvement in Aircraft

Performance due to Use of Boundary Layer Suction".

ARC 2315 (1936).

"Velocity Defect Law for a Transpired Turbulent Boundary Layer".

AIAA Journal, 1, p. 1685 (1963).

"A Sub-layer Theory for Fluid Injection into the Incompressible Turbulent Boundary Layer" .

Journ. Aero/Space Sci., 27, p. 675-678 (1960).

"Heat Transfer in Turbulent Shear Flow". Journ.Aero.Sci., 25, p. 485-489 (1956). 
32. Darcy, H.

33. Stanton, T.E. Pannell, J.R.

34. Von Karman, Th.

35. Schultz-Grunow, F.

36. Buri, A.

37. Gruschwitz, E.

38. Corrsin, S. Kistler, A.L.

39. Head, M.R.
"Récherches Expérimentales Relatives aux Mouvements de l'Eau dans les Tuyaux". Mem. Pres. à l'Acad.Sci.de l'Inst. Imp. de France, 15, p. 141, (1858)。

"Similarity of Motion in Relation to the Surface Friction of Fluids".

Phil. Trans. Royal Soc. A, 214, p. 199(1914).

"Mechanische Aehnlichkeit und Turbulenz". Nachr. Ges. Wiss. Gottingen, Math.-Phys. Klasse, p. 58-68 (1930).

"Neues Reibungswiderstandsgesetz fitr glatte platten".

Luftfahrtforsch. 17, p. 239-246 (1940).

"Eine Berechnungsgrundlage fur die turbulente Grenzschicht bei beschleunigter und verzøgerte Strømung." Thesis, Zurich (1931).

"Die turbulente Reibungsschicht in ebener Stromung bei Druckabfall und Druckanstieg". Ing Archiv, 2, p. 321-346 (1931).

"The Free-Stream Boundaries of Turbulent Flows".

NACA TN 3133 (1954).

"Entrainment in the Turbulent Boundary Layer".

ARC R and M 3152 (1960). 
40. Townsend, A.A.

41. Rubesin, M.W.

42. Clarke, J.H. Menkes, H.R. Libby, P.A.

43. Cornish, J.J.

44. Coles, D.

45. Tennekes, H.
"Equilibrium Layers and Wall Turbulence". Journ. Fl. Mech. 11, p.97-120 (1961).

"An Analytical Estimation of the Effect of Transpiration Cooling on the HeatTransfer and Skin-Friction Characteristics of a Compressible Turbulent Boundary Layer" • NACA TN 3341 (1954).

"A Provisional Analysis of Turbulent Boundary Layers with Injection". Journ • Aero.Sci. 22, p. 255-260 (1955),

"A Universal Description of Turbulent Boundary Layer Flow with or without Transpiration".

Aeroph.Dept., Miss.State College, Res. Rept. 29 (1960).

"The Law of the Wake in the Turbulent Boundary Layer". Journ.F1.Mech. 1, p. 191-226 (1956).

"Comment on: Velocity Defect Law for a Transpired Turbulent Boundary Layer". A IAA Journ. 2, 2, p. 414-415 (1964). 


\section{Samenvatting}

De wandwet en de snelheidsverlieswet voor onsamendrukbare turbulente grenslagen op niet-doorlatende vaste wanden worden, zoals algemeen bekend is, gekenmerkt door een gemeenschappelijke snelheidsschaal (de "wrijvingssnelheid", $u_{\tau}$ ) en een logarithmisch snelheidsprofiel in het gebied waar beide geldig zijn. In dit proefschrift: "Gelijkvormigheidswetten voor turbulente grenslagen met afzuiging of aanblazing" wordt aangetoond dat het mogelijk is, ook voor deze grenslagen gelijkvormigheidswetten te formuleren die door deze eigenschappen worden gekenmerkt. Hierdoor wordt een betrekkelijk eenvoudige beschrijving van het gedrag van afgezogen en aangeblazen turbulente grenslagen verkregen.

Ten behoeve van het in dit proefschrift beschreven onderzoek werden in de lage-turbulentie windtunnel van de onderafdeling vliegtuigbouwkunde een aantal metingen verricht. De resultaten van deze metingen worden besproken in hoofdstuk 2. De metingen betroffen snelheidsprofielen van een 14-tal turbulente grenslagen op een vlakke plaat zonder drukgradient en met uniforme afzuiging. De schuifspanning aan de wand werd bepaald door grafische differentiatie van het verloop van de impulsverliesdikte in stromingsrichting. Met behulp van de op deze wijze bepalde wrijvingssnelheid werden de gemeten snelheidsprofielen uitgezet als $v_{0} \bar{U}_{1} / u_{\tau}{ }^{2}$ tegen $\mathrm{v}_{\mathrm{o}} \mathrm{x}_{2} / \nu$. Het nut van deze beschrijving is in te zien door het snelheidsprofiel in de visceuze onderlaag van afgezogen turbulente grenslagen te beschouwen. Dit snelheidsprofiel wordt gegeven door

$$
\frac{\mathrm{v}_{\mathrm{o}} \overline{\mathrm{U}}_{1}}{\mathrm{u}_{\tau}}=\exp \left(\frac{\mathrm{v}_{\mathrm{o}} \mathrm{x}_{2}}{\nu}\right)-1 \text {. }
$$

Het is duidelijk dat deze kromme op de meest eenvoudige wijze wordt weergegeven door op de corrdinaatassen $v_{0} \bar{U}_{1} / u_{\tau}^{2}$ en $v_{0} x_{2} / \nu$ uit te zetten. In overeenkomst met de wijze waarop snelheidsprofielen van turbulente grenslagen gewoonlijk worden uitgezet, werd voor $v_{0} x_{2} / \nu$ in de figuren 
7 t/m 20 een logarithmische schaal gebruikt. Door deze figuren wordt aangetoond dat in vrijwel alle gevallen er een logarithmisch gebied in het snelheidsprofiel is te herkennen; de helling van de logarithme is in het merendeel van de gevallen dezelfde. Deze resultaten stemmen overeen met enkele gegevens uit de literatuur, wanneer deze op overeenkomstige wijze worden uitgezet (zie fig. 21).

De beschikbare experimentele gegevens steunen de theoretische overwegingen die leiden tot het formuleren van een tweetal gelijkvormigheidswetten voor afgezogen grenslagen, die in dit proefschrift worden aangeduid als "grenstoestand-gelijkvormigheidswetten" (limit similarity laws):

$$
\begin{aligned}
& \frac{\mathrm{v}_{\mathrm{O}} \overline{\mathrm{U}}_{1}}{\mathrm{u}_{\tau}^{2}}=\mathrm{f}\left(\frac{\mathrm{v}_{\mathrm{o}} \mathrm{x}_{2}}{\nu}\right), \\
& \frac{\mathrm{v}_{\mathrm{o}}\left(\overline{\mathrm{U}}_{1}-\mathrm{U}_{\mathrm{o}}\right)}{\mathrm{u}_{\tau}^{2}}=\mathrm{F}\left(\frac{\mathrm{x}_{2}}{\delta}\right) .
\end{aligned}
$$

De wandwet, verg. (32-3), wordt besproken in sectie 3.2 ; hij is afhanke$1 i j \mathrm{k}$ van de parameters $\mathrm{v}_{0} / \mathrm{u}_{\tau}$ en $\mathrm{k}_{\mathrm{o}} / \nu$. Op voorlopige wijze werd uit de meetresultaten de invloed van $v_{0} / u_{\tau}$ op de wandwet bepaald (zie subsecties 32.11 en 32.12 ); de grootte van de invloed van de oppervlakteruwheid $\left(v_{0} k / \nu\right)$ kon nog niet worden vastgesteld.

De grenstoestand-snelheidsverlieswet, verg. (42-7), die wordt besproken in secties 4.2 en 4.3 , hangt af van de "evenwichtsparameters"

$$
\Pi=\frac{\delta^{*}}{\tau_{\mathrm{o}}} \frac{\mathrm{d} \overline{\mathrm{P}}}{\mathrm{dx}{ }_{1}}, \Lambda=\frac{\rho \mathrm{v}_{\mathrm{o}} \mathrm{U}_{\mathrm{o}}}{\tau_{\mathrm{o}}},
$$

waarvan de eerste ook voorkomt in het werk van Clauser [6,7] en Rotta [10]. De snelheidsdefectwet is alleen geldig wanneer de evenwichtsparameters een constante waarde hebben voor de betrokken grenslaag. Zulk een grenslaag wordt een "evenwichtsgrenslaag" $[7,8,10]$ genoemd. Asymptotische grenslagen in een stroming zonder drukgradient worden uitgesproken voorbeelden van evenwichtsgrenslagen geacht. Voor deze grenslagen is de 
impulsverliesdikte $\theta$ constant; het snelheidsprofiel verandert niet in stromingsrichting. Uit de impuls(integraal)vergelijking, die voor afgezogen en aangeblazen grenslagen als volgt kan worden geschreven:

$$
\frac{\rho}{\tau_{0}} \frac{{\mathrm{d} \theta \mathrm{U}_{\mathrm{o}}^{2}}^{2}}{\mathrm{dx}_{1}}=1+\Pi+\Lambda \text {, }
$$

blijkt dat voor asymptotische grenslagen $\Pi=0, \Lambda=-1$. Dit versterkt het vermoeden dat asymptotische grenslagen evenwichtsgrenslagen zijn. De snelheidsprofielen van verschillende asymptotische grenslagen blijken inderdaad samen te vallen indien zij worden uitgezet volgens de grenstoestand-snelheidsverlieswet (zie fig. 26). Door deze resultaten wordt de bruikbaarheid van de voorgestelde gelijkvormigheidswetten duidelijk aangetoond.

In de beide grenstoestand-gelijkvormigheidswetten wordt de gemiddelde snelheid in de grenslaag $\left(\bar{U}_{1}\right)$ dimensieloos gemaakt door vermenigvuldiging met $v_{0} / u_{\tau}^{2}$. Voor grenslagen die voldoen aan deze wetten is de snelheidsschaal dus evenredig aan $u_{\tau}^{2} / v_{0}$. Door de procedure van Millikan [11] over te nemen, kan worden aangetoond dat in het snelheidsprofiel dan een logarithmisch gedeelte kan worden verwacht. Dit logarithmisch snelheidsprofiel wordt beschreven door

$$
-\frac{\mathrm{v}_{\mathrm{o}} \overline{\mathrm{U}}_{1}}{\mathrm{u}_{\tau}^{2}}=\mathrm{c} \ln \left(\frac{-\mathrm{v}_{\mathrm{o}} \mathrm{x}_{2}}{\nu}\right)+\text { const. }
$$

Uit de gemeten snelheidsprofielen van een aantal afgezogen turbulente grenslagen blijkt, zoals reeds is opgemerkt, dat in het merendeel van de gevallen inderdaad een logarithmisch snelheidsprofiel met dezelfde helling optreedt (figuren $7 \mathrm{t} / \mathrm{m} \mathrm{21}$ ). Bij zeer kleine waarden van de afzuigintensiteit wordt de helling echter geringer naarmate de afzuigintensiteit afneemt (figuren 18, 19 en 20). Om dit afwijkend gedrag verder te onderzoeken werd de grootte van de snelheidsschaal experimenteel bepald voor een groot aantal turbulente grenslagen met afzuiging of aanblazing, waarvan snelheidsprofielen bekend waren. Daartoe werd de "logarithmische snelheidsschaal" ( $w^{*}$ ) gedefinieerd: 


$$
w^{*}=x_{2} \frac{\partial \bar{U}_{1}}{\partial x_{2}},
$$

d.w.z.

$$
\overline{\mathrm{U}}_{1}=\mathrm{w}^{*} \ln \mathrm{x}_{2}+\text { const. }
$$

De verkregen gegevens werden uitgezet als $w^{*} / u_{\tau}$ tegen $v_{o} / u_{\tau}$ (figuren 22 en 23). Uit deze figuren blijkt dat alléén voor $0.04<-v_{0} / u_{\tau}<0.10$ de snelheidsschaal kan worden weergegeven door

$$
\frac{w^{*}}{u_{\tau}}=-C \frac{u_{\tau}}{v_{o}},
$$

aansluitend bij de grenstoestand-gelijkvormigheidswetten (zie verg.32-12). Deze wetten zijn dus alleen geldig voor $0.04<-v_{0} / u_{\tau}<0.10$. Indien natuurlijke logarithmen worden gebruikt, geldt: $C=0.06$; bij gebruik van decimale logarithmen geldt: $C=0.138$. Voor $-v_{0} / u_{\tau}<0.04$ (met insluiting van alle aangeblazen grenslagen) blijkt verg. (32-16) echter niet bruikbaar te zijn; het verband tussen $w^{*} / u_{\tau}$ en $v_{0} / u_{\tau}$ blijkt dan goed weergegeven te worden door

$$
\frac{w^{*}}{u_{\tau}}=2 \cdot 3\left(1+9 \frac{v_{o}}{u_{\tau}}\right) .
$$

Op grond van deze resultaten werd een tweetal "genormaliseerde gelijkvormigheidswetten" geformuleerd, die gebruikt kunnen worden wanneer de grenstoestand-gelijkvormigheidswetten niet geldig zijn (secties 3,3 en 4.4).

De beschouwingen in dit proefschrift worden afgesloten met een bespreking van de in de literatuur gegeven theoriern (hoofdstuk 5). Het blijkt dat in het algemeen wordt uitgegaan van de mengwegtheorie van Prandt1. Dit leidt tot een dubbel-logarithmisch snelheidsprofiel $[5,17]$, dat niet in overeenstemming is te brengen met de hier voorgestelde gelijkvormigheidswetten. 
In de slotbeschouwingen (hoofdstuk 6) wordt onder meer aanbevolen de in dit proefschrift gegeneraliseerde gelijkvormigheidsbeschouwingen toe te passen op turbulente grenslagen in samendrukbare stromingen met of zonder warmte-overdracht en op magneto-hydrodynamische turbulente kanaalstromingen. 


\section{Levensbericht}

Hendrik Tennekes werd op 13 december 1936 te Kampen geboren. Aan het Christelijk Lyceum te Almelo behaalde hij in 1954 het diploma H.B.S.-B. Van 1954 tot 1960 studeerde hij vliegtuigbouwkunde aan de Technische Hogeschool te Delft; deze studie werd op 25 maart 1960 afgesloten met het ingenieursdiploma. In het cursusjaar 1958-1959 was hij studentassistent aan het Aeronautics Department van The Johns Hopkins University te Baltimore. Sinds 1 april 1960 is hij als wetenschappelijk ambtenaar in dienst van de onderafdeling der vliegtuigbouwkunde aan de Technische Hogeschool te Delft. 


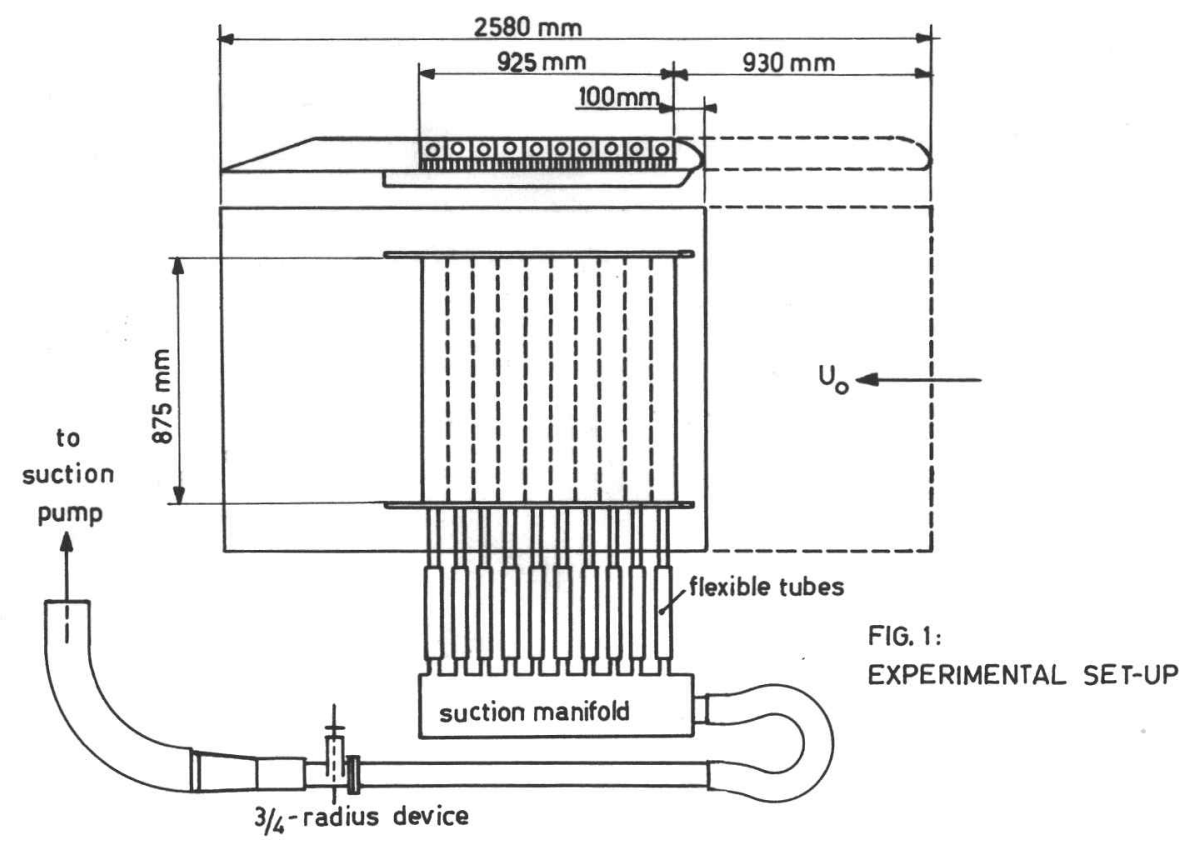

FIG. 2: MOMENTUM THICKNESS, SERIES 1

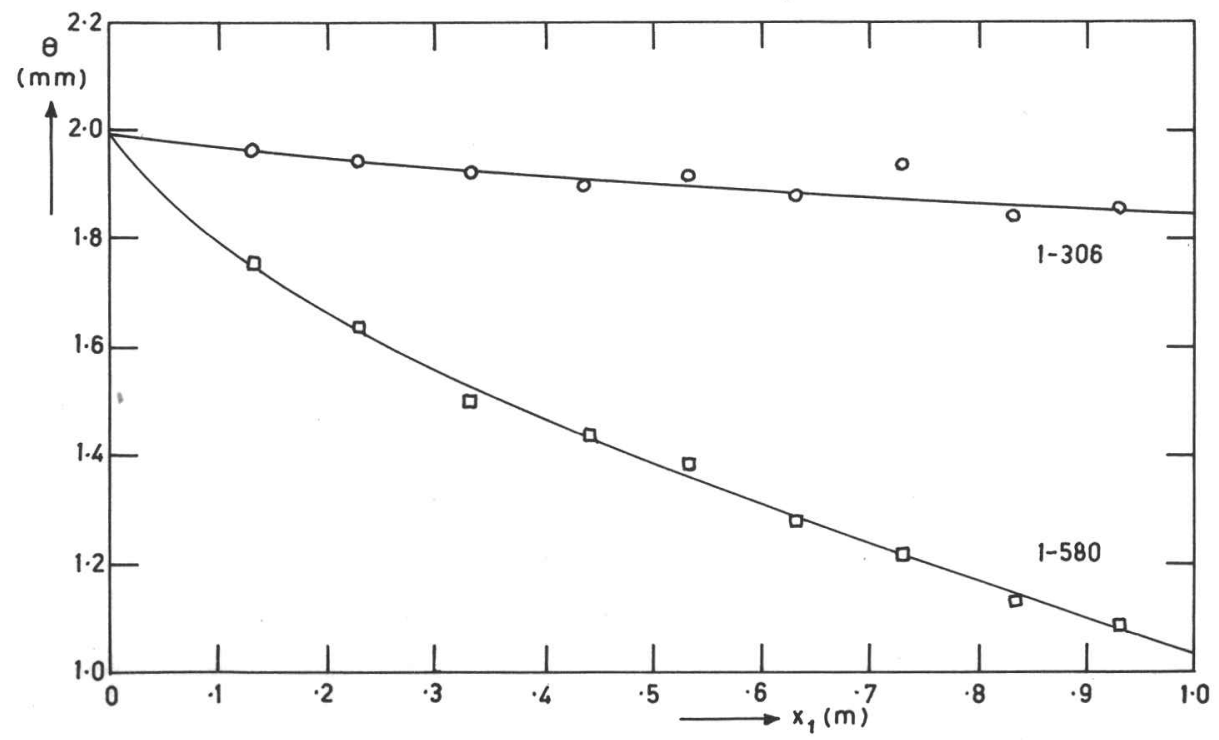


FIG. 3: MOMENTUM THICKNESS, SERIES 2

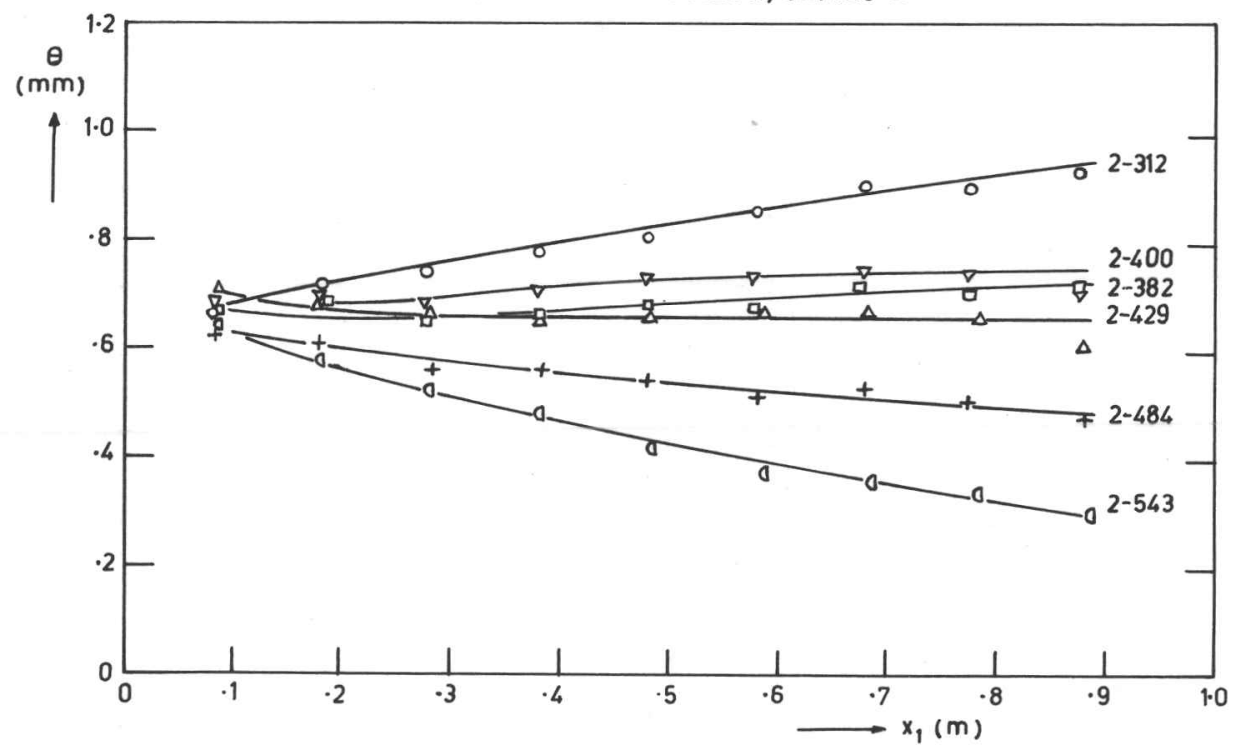

FIG. 4: MOMENTUM THICKNESS, RUN 2-430

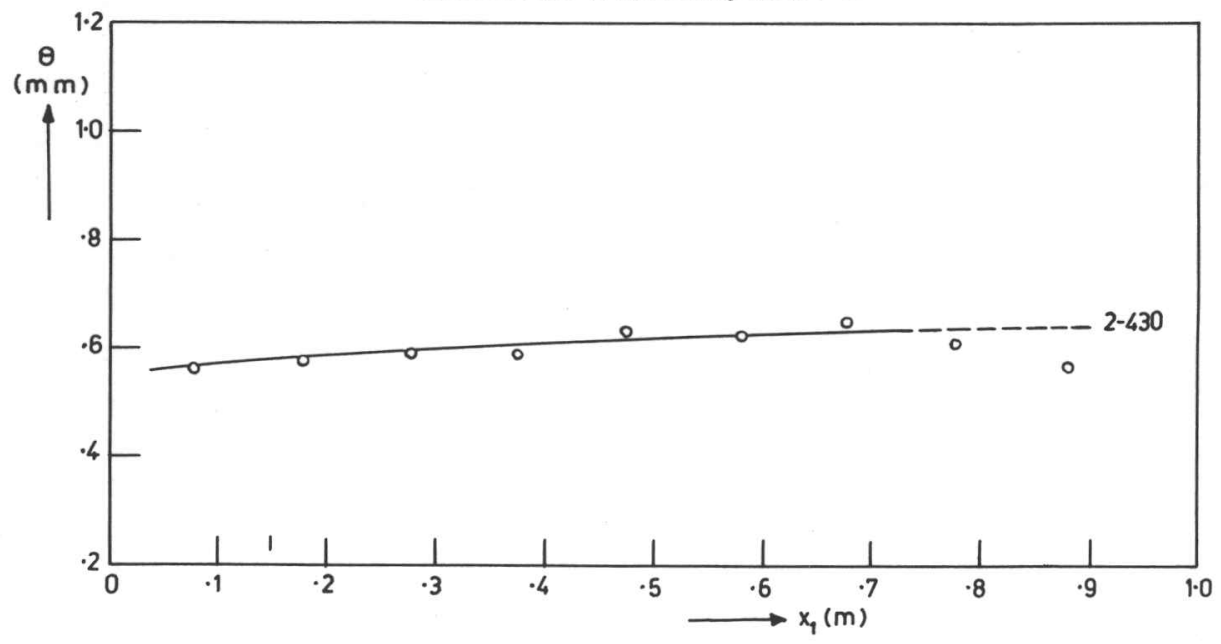


FIG. 5: MOMENTUM THICKNESS, SERIES 2

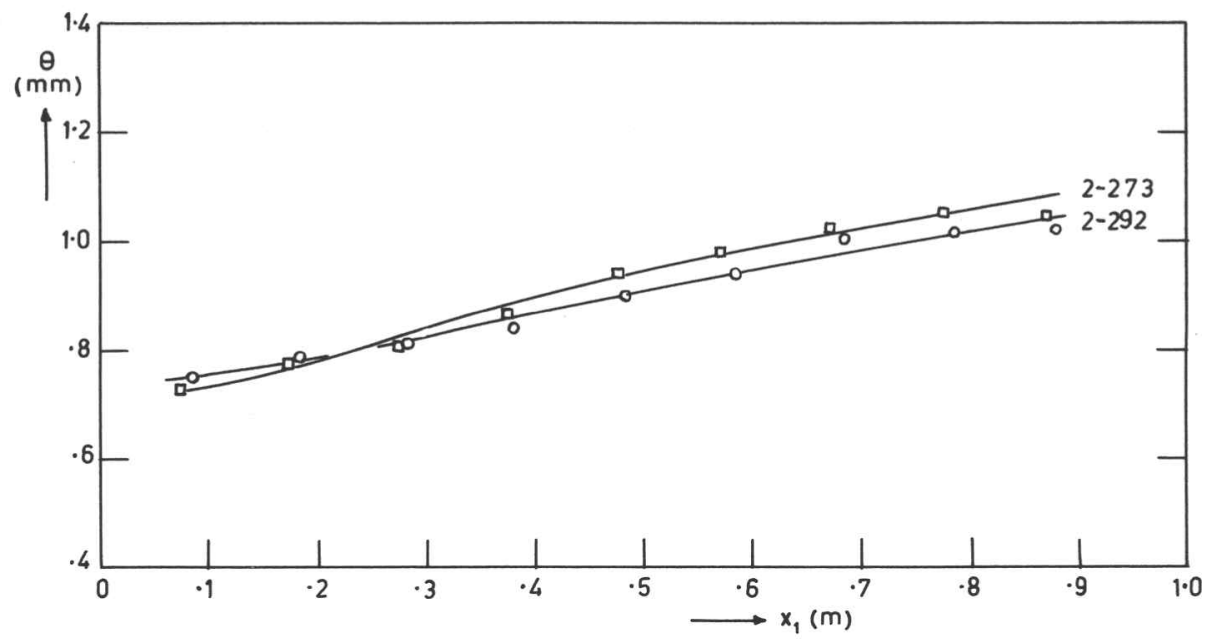

FIG.6: MOMENTUM THICKNESS, SERIES 3

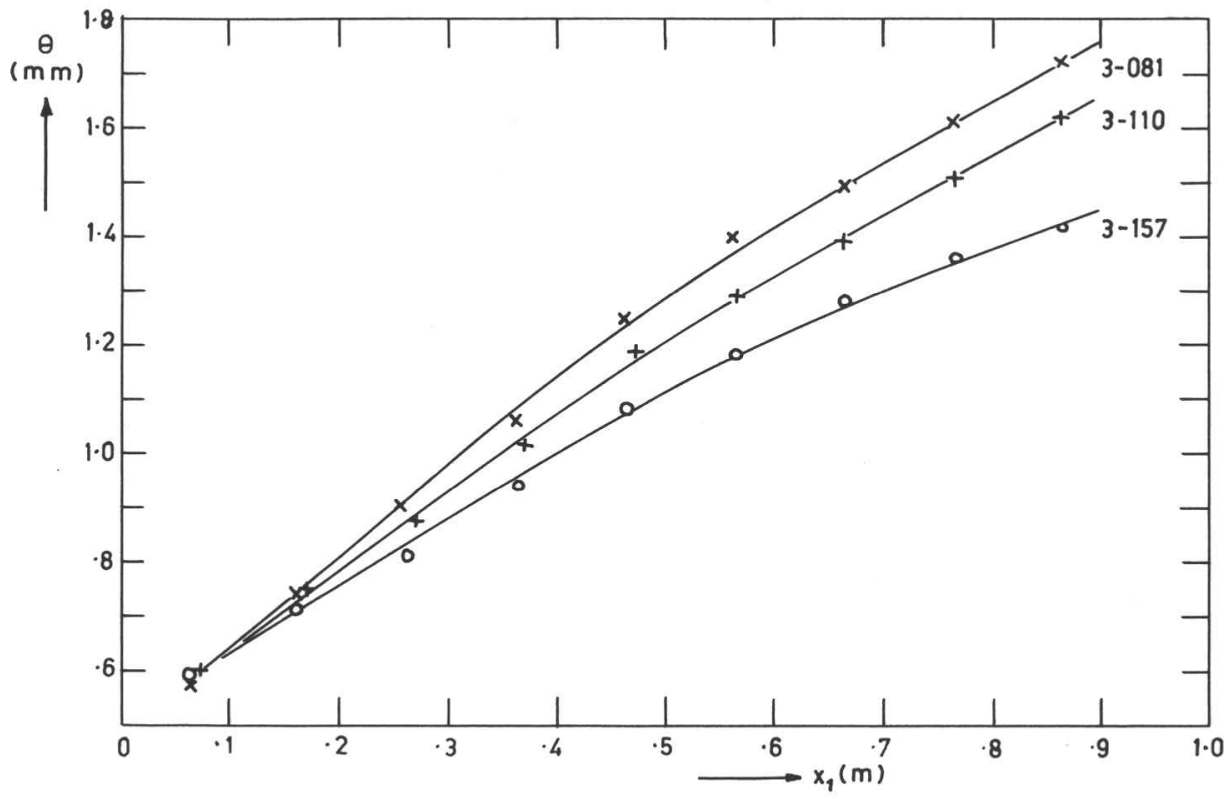


FIG.7: VELOCITY DISTRIBUTIONS, RUN 1-306

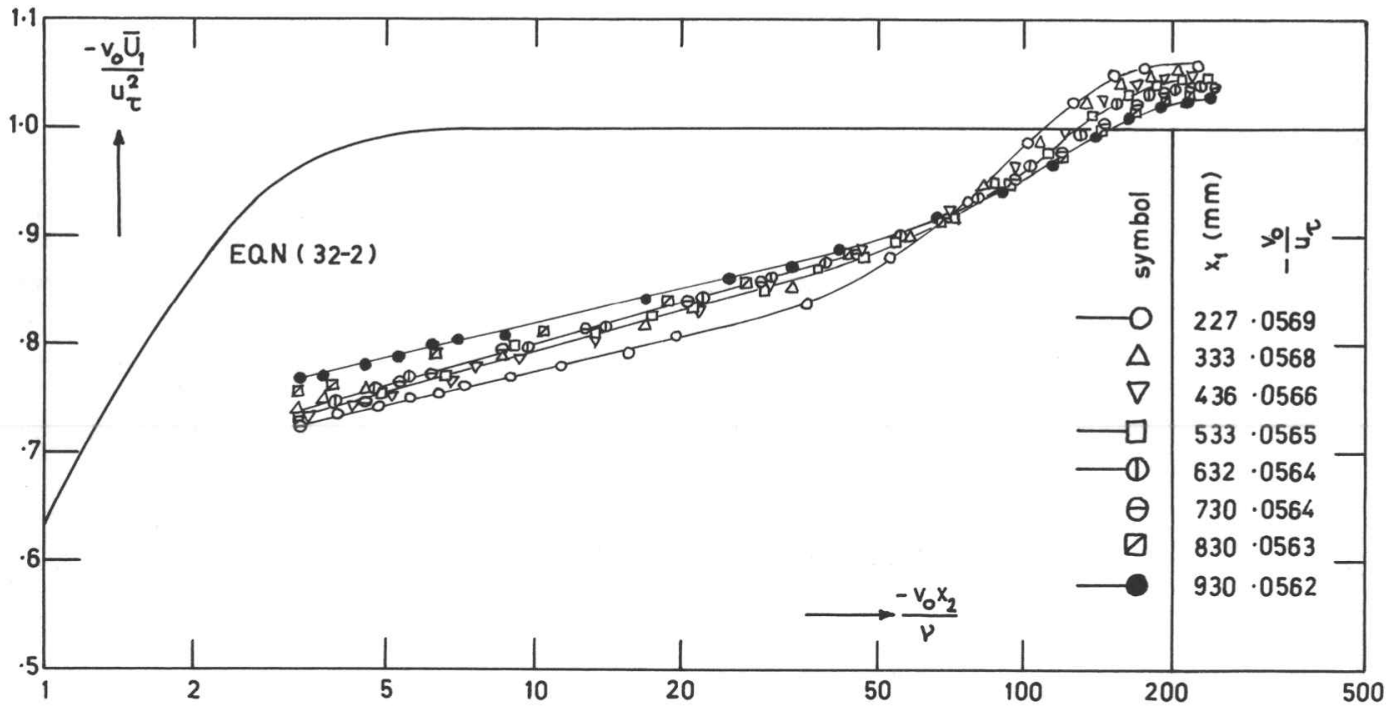

FIG. 8: VELOCITY DISTRIBUTIONS, RUN 1-580

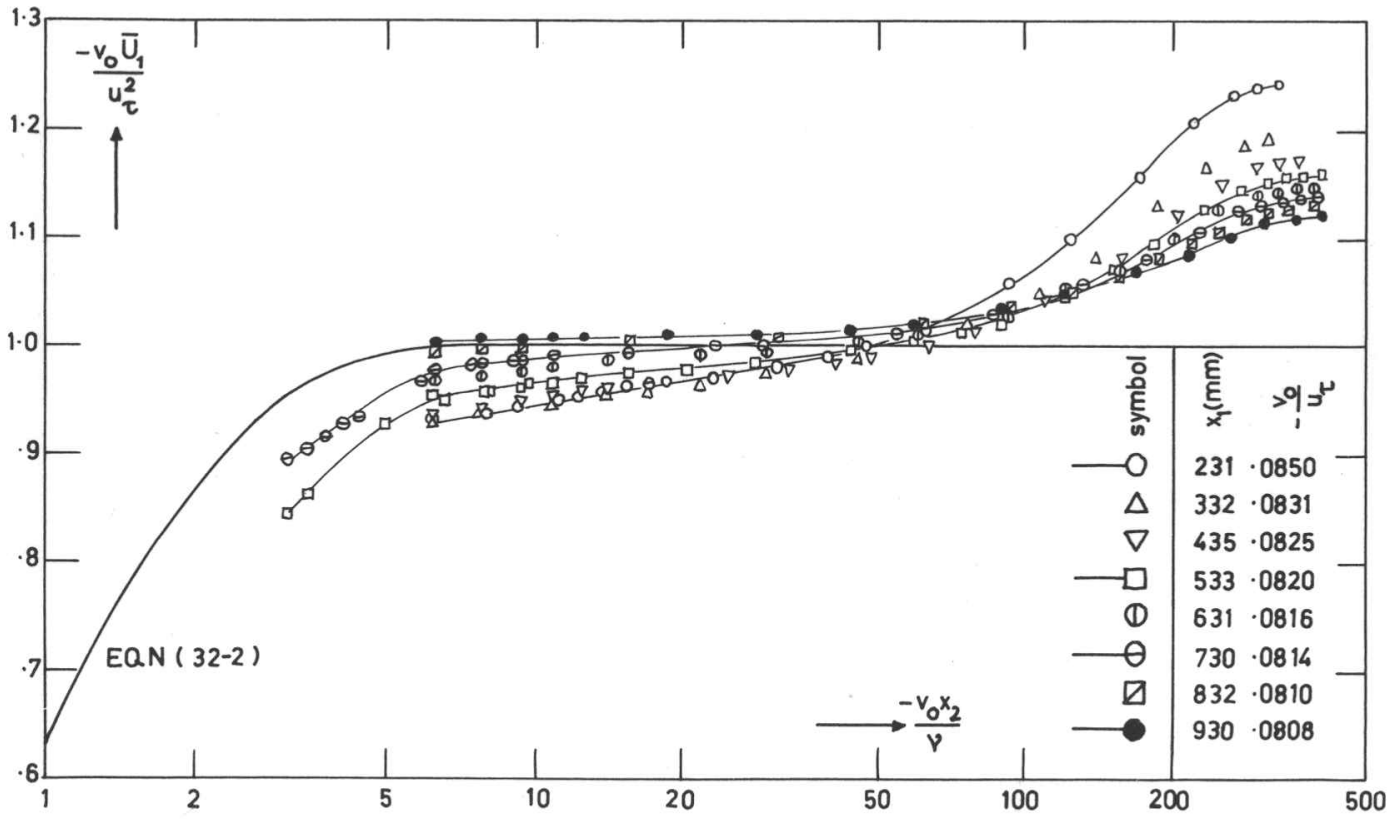


FIG.9 : VELOCITY DISTRIBUTIONS, RUN 2-273

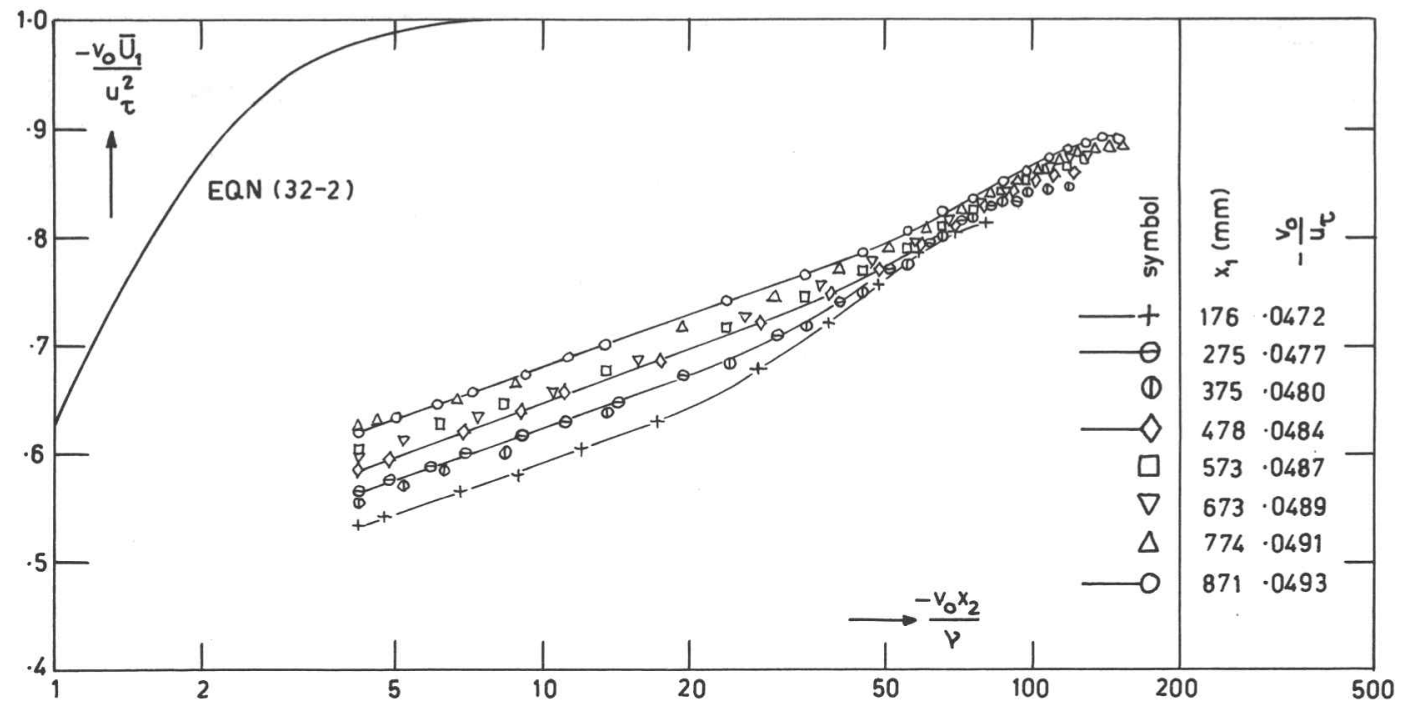

FIG 10 : VELOCITY DISTRIBUTIONS, RUN 2-292

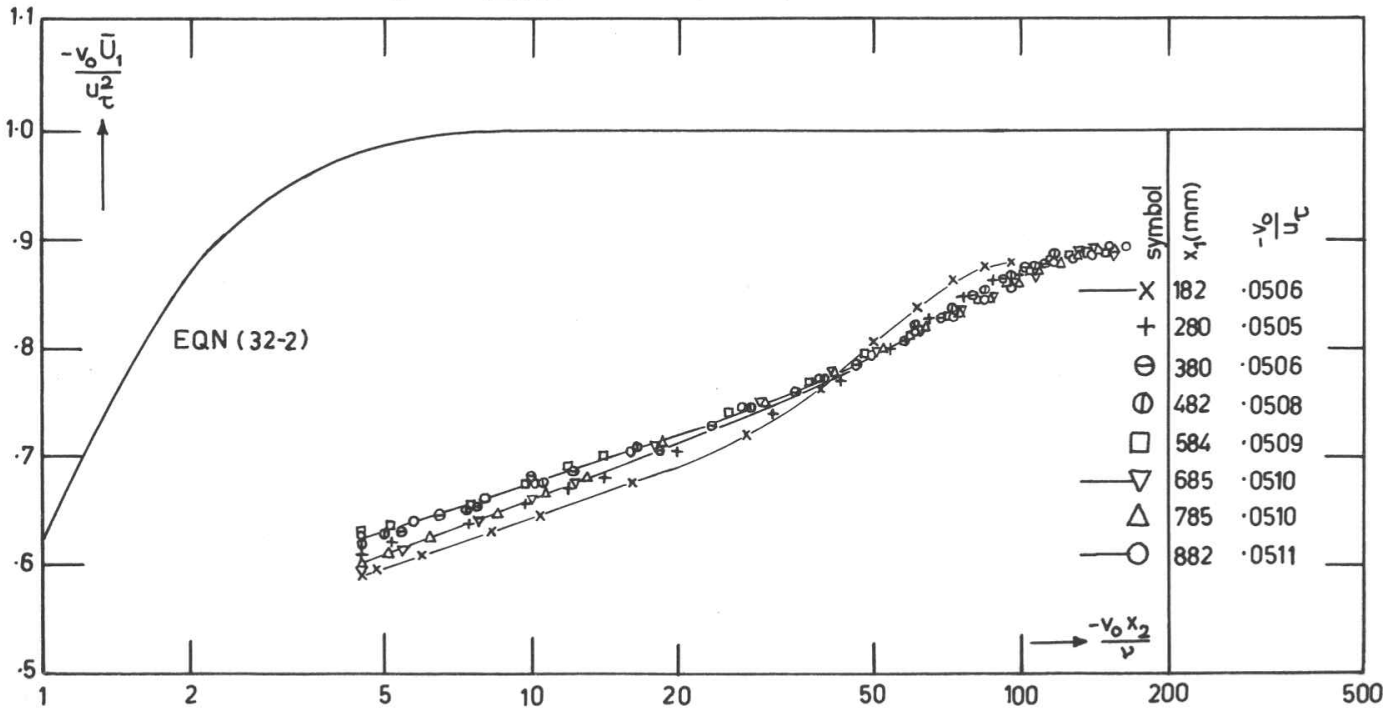


FIG.11: VELOCITY DISTRIBUTIONS, RUN 2-312

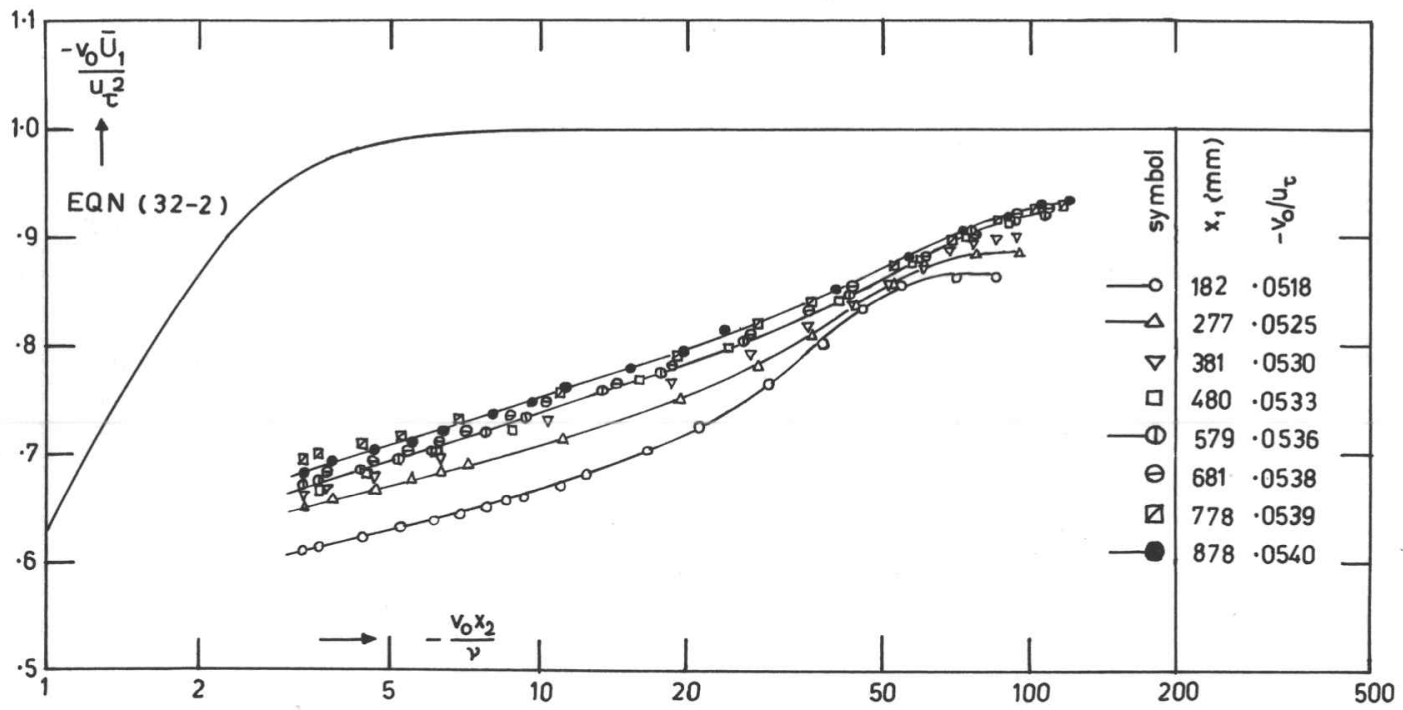

FIG.12 : VELOCITY DISTRIBUTIONS, RUN 2-382

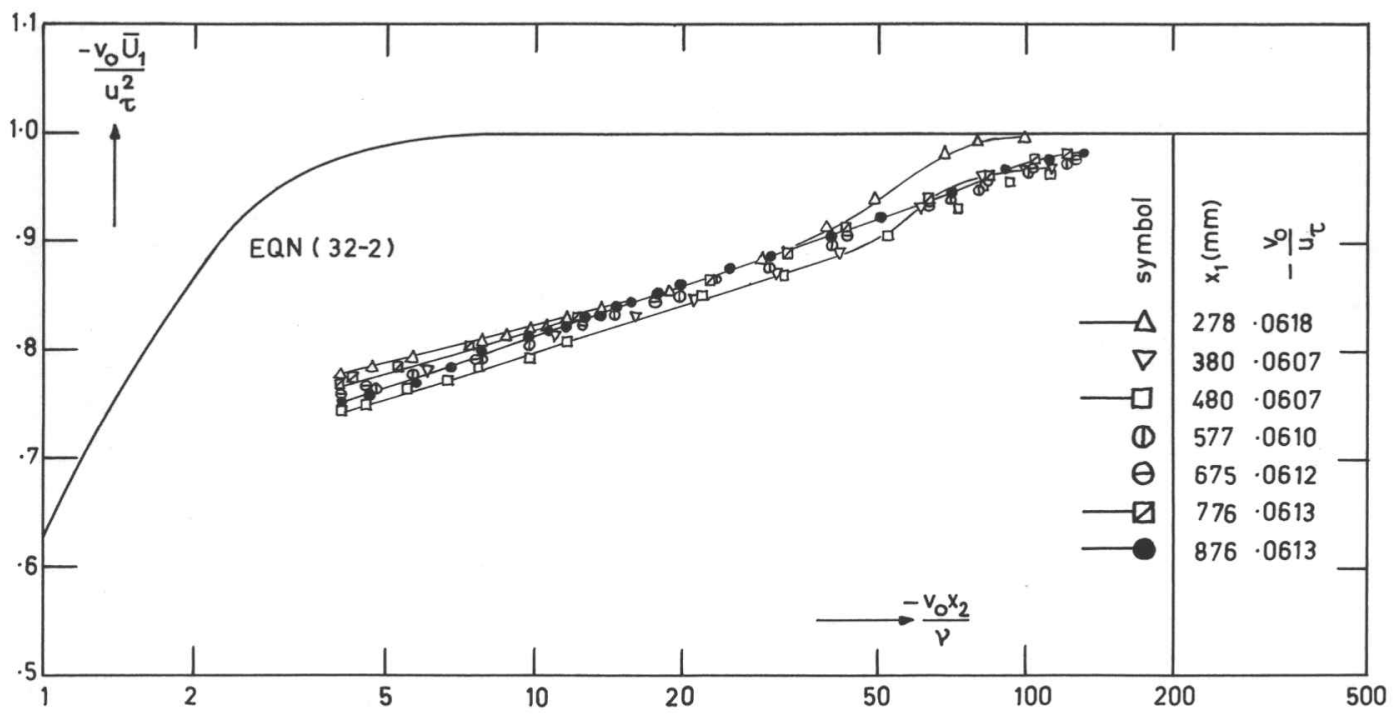


FIG.13 : VELOCITY DISTRIBUTIONS, RUN 2-400

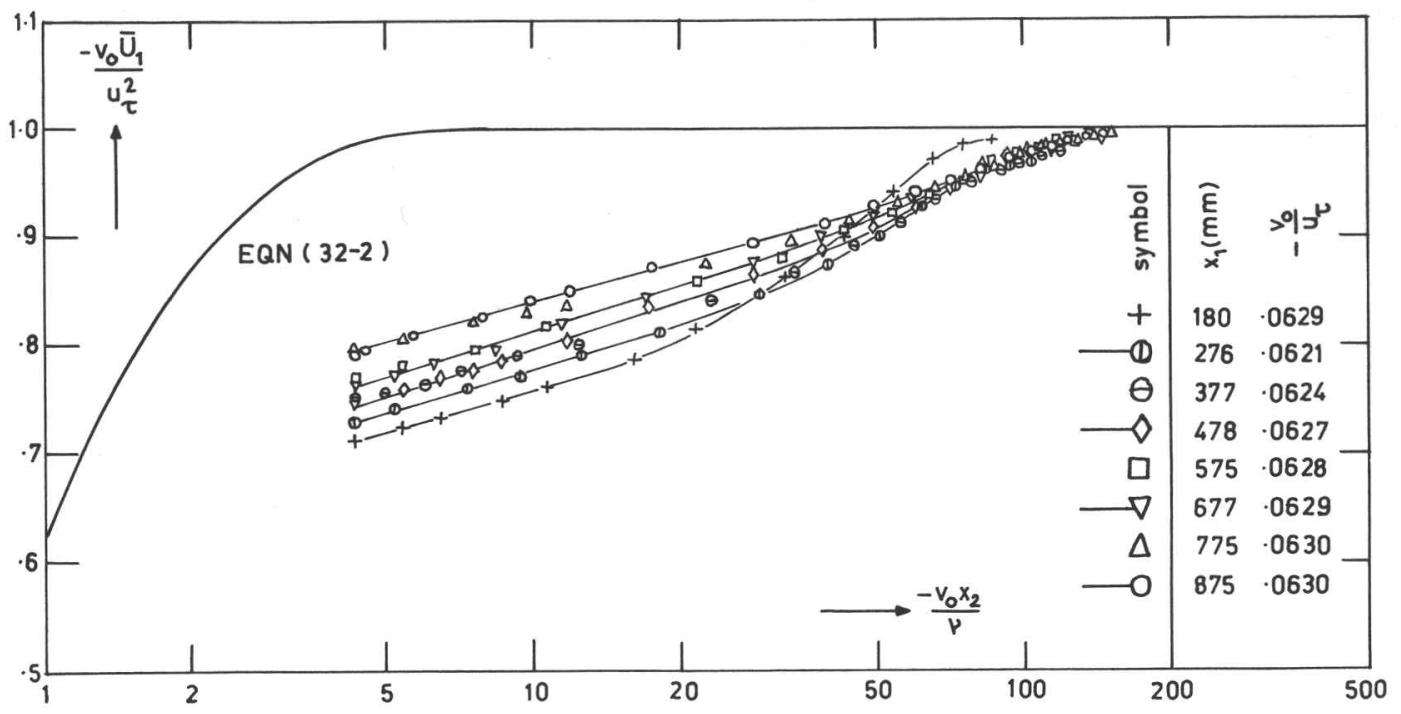

FIG 14: VELOCITY DISTRIBUTIONS, RUN 2-429

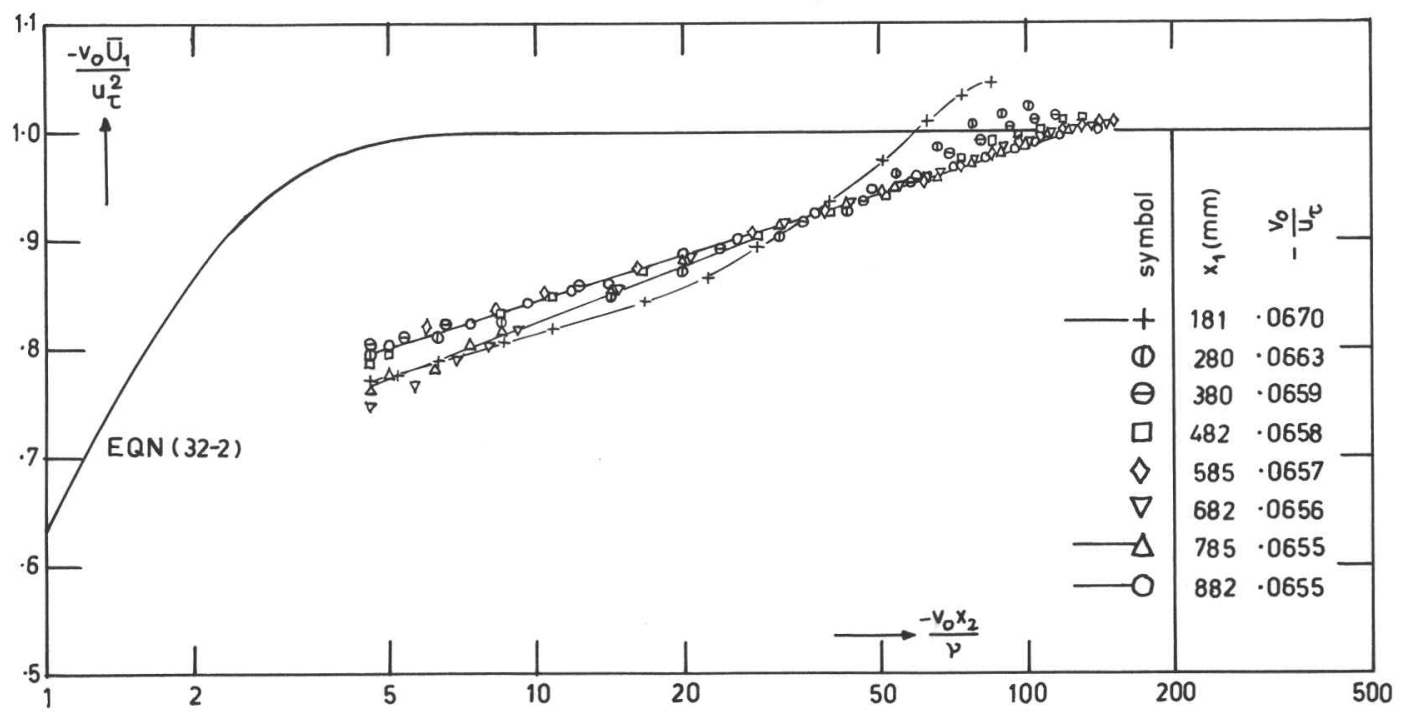


FIG.15: VELOCITY DISTRIBUTIONS, RUN 2-430

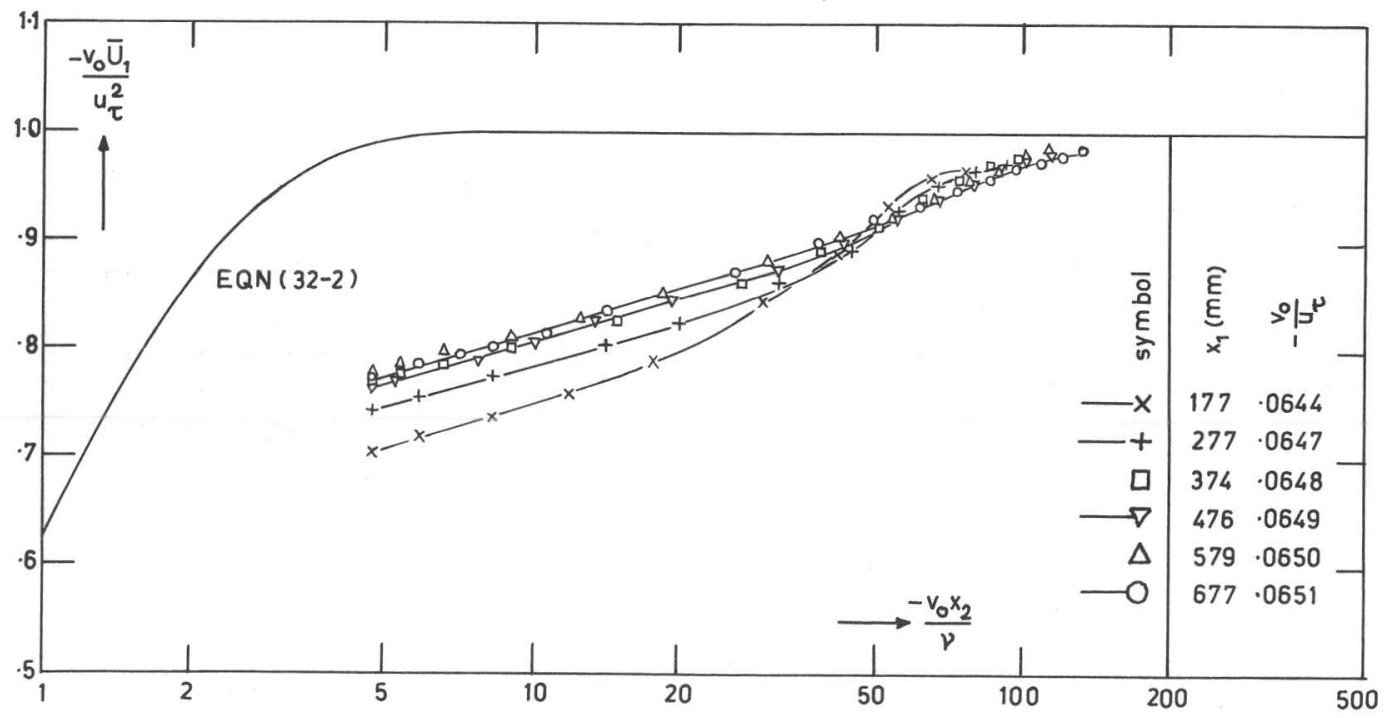

FIG. 16: VELOCITY DISTRIBUTIONS, RUN 2-484

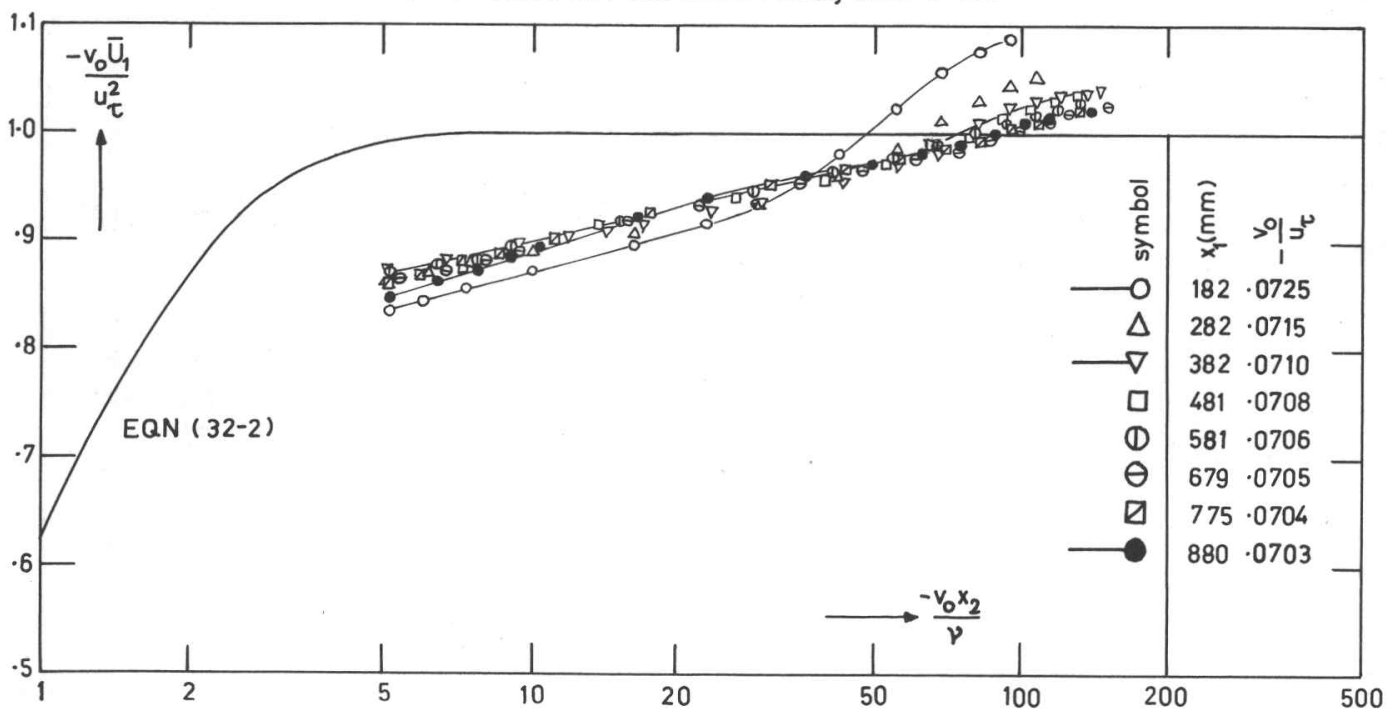


FIG. 17: VELOCITY DISTRIBUTIONS, RUN 2-543

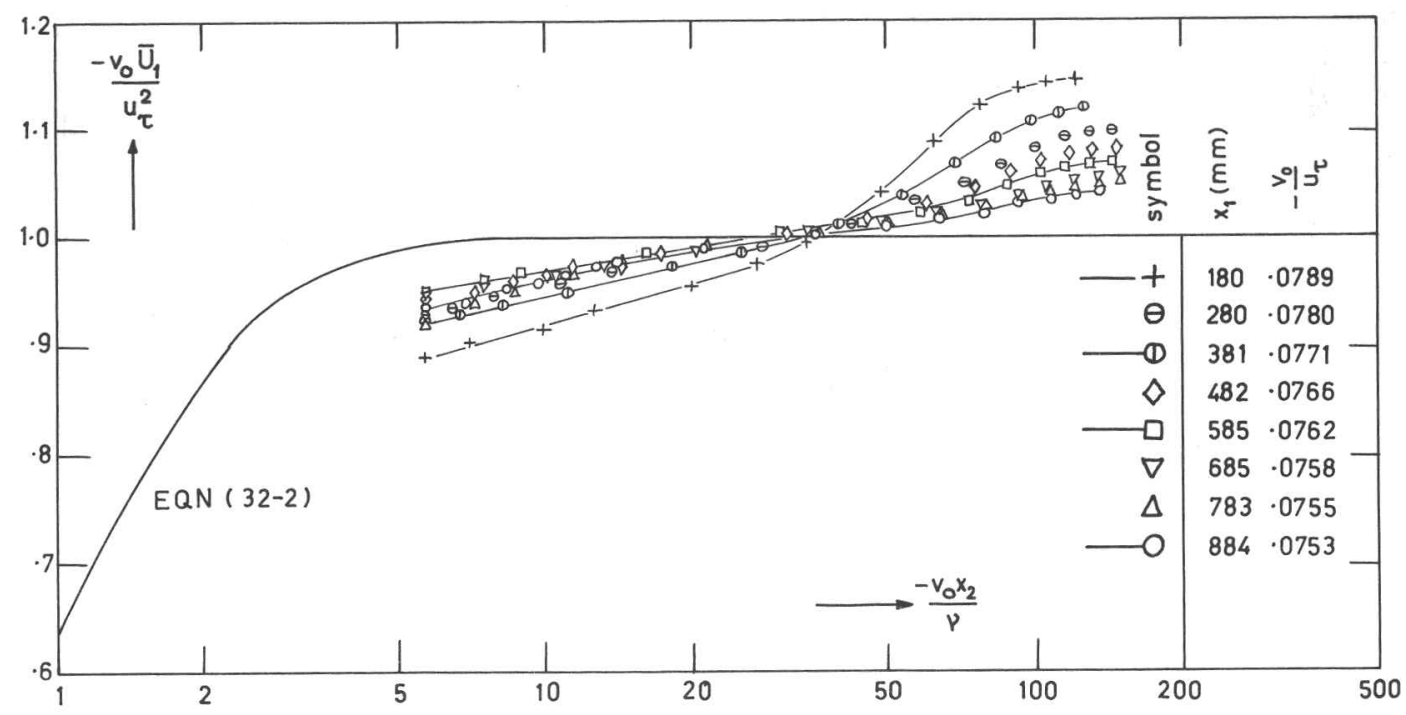

FIG. 18: VELOCITY DISTRIBUTIONS, RUN 3-081

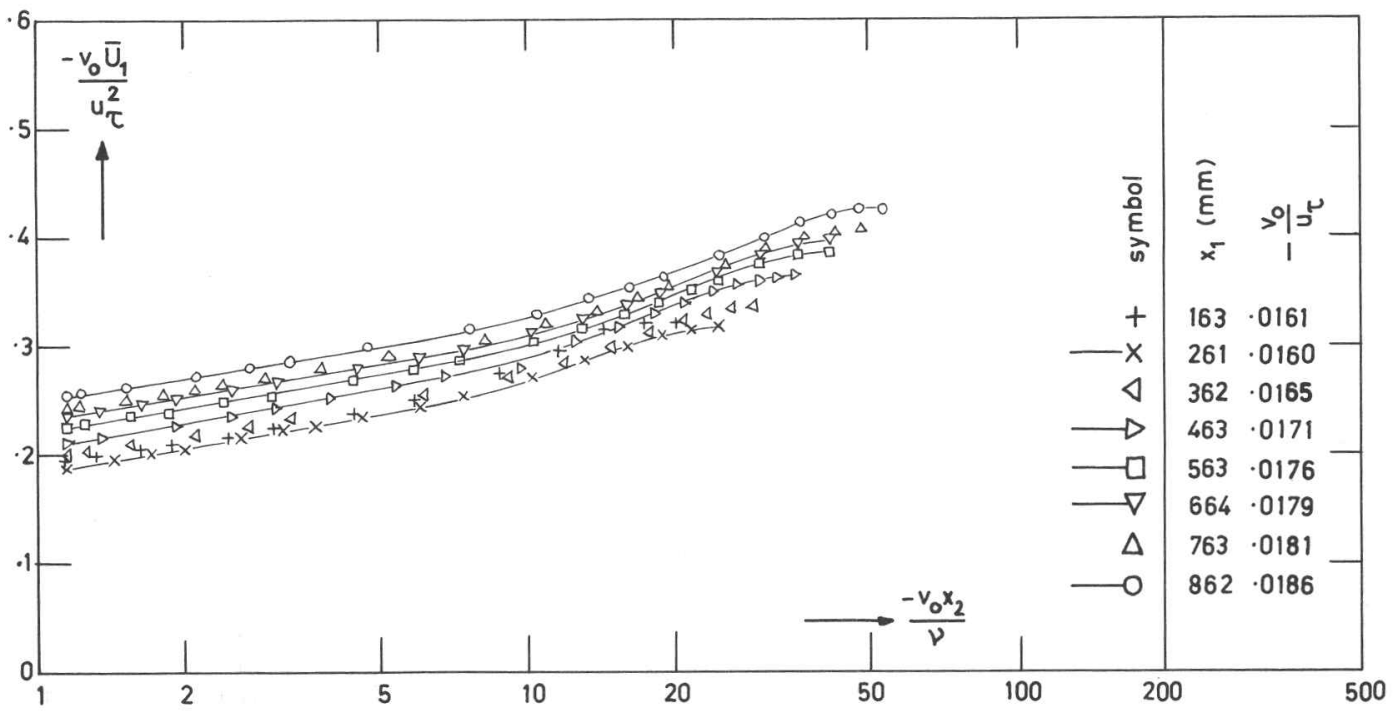


FIG. 19: VELOCITY DISTRIBUTIONS, RUN 3-110

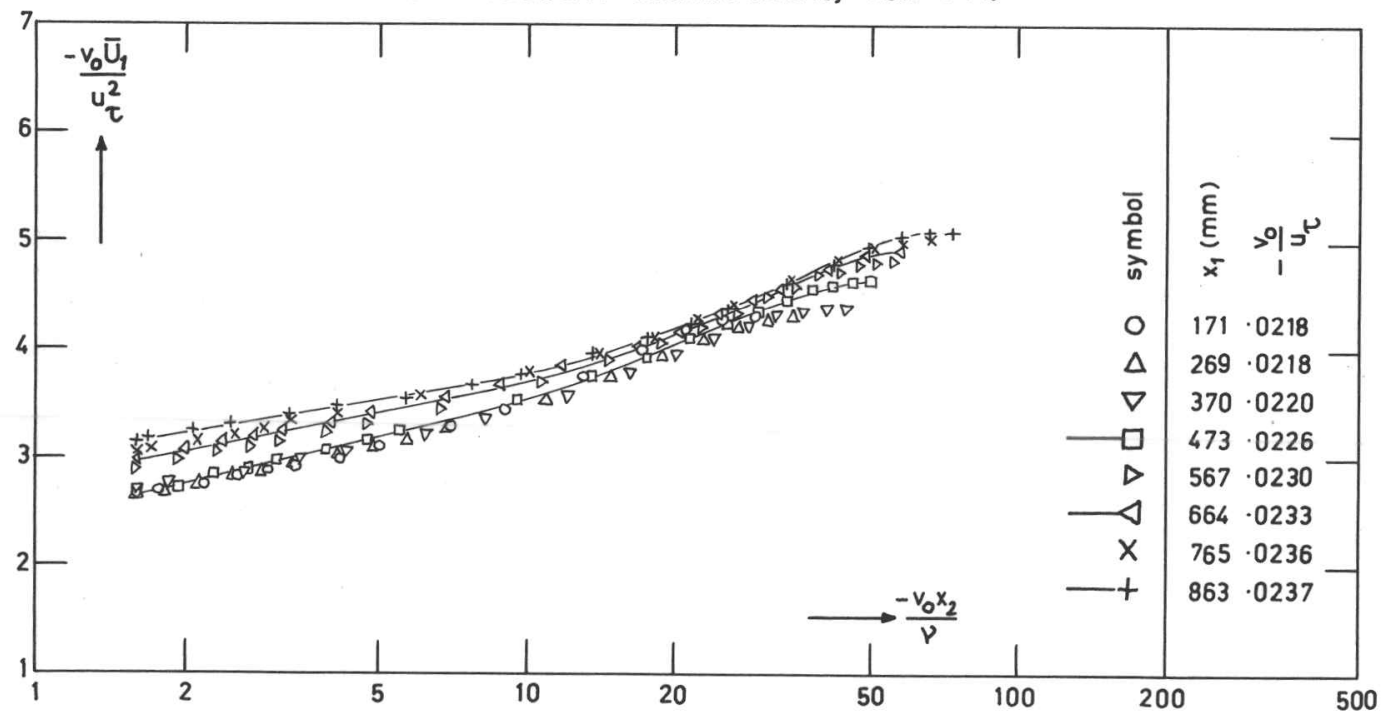

FIG. 20: VELOCITY DISTRIBUTIONS, RUN 3-157

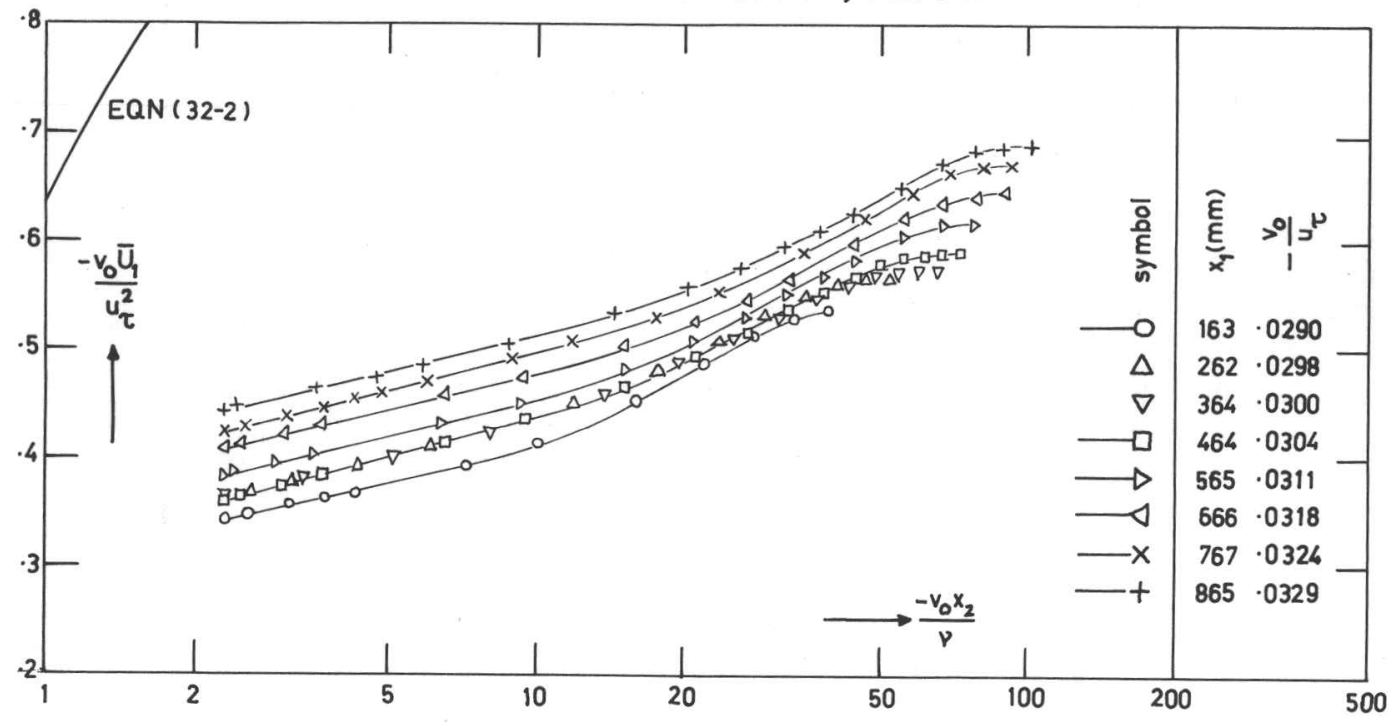


FIG. 21: THE LIMIT LAW OF THE WALL, 5 EXAMPLES

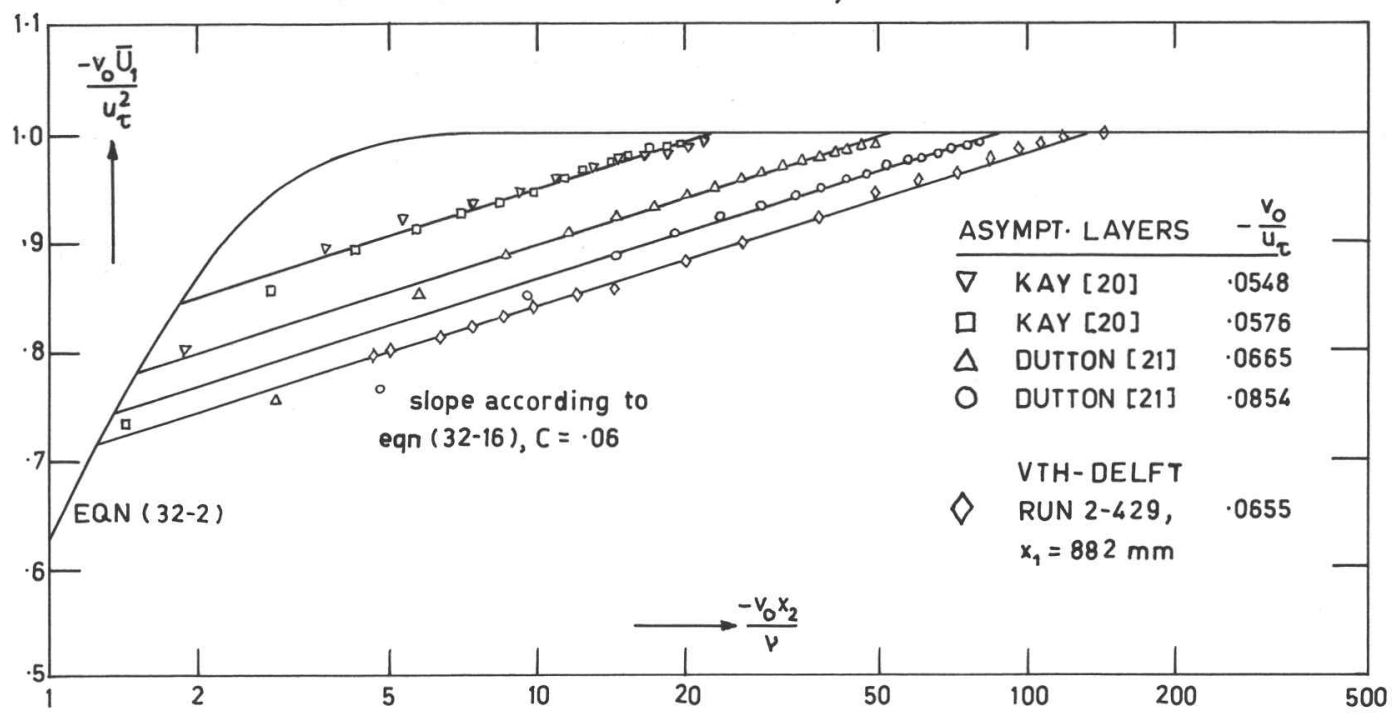

FIG 22: THE LOGARITMIC VELOCITY SCALE

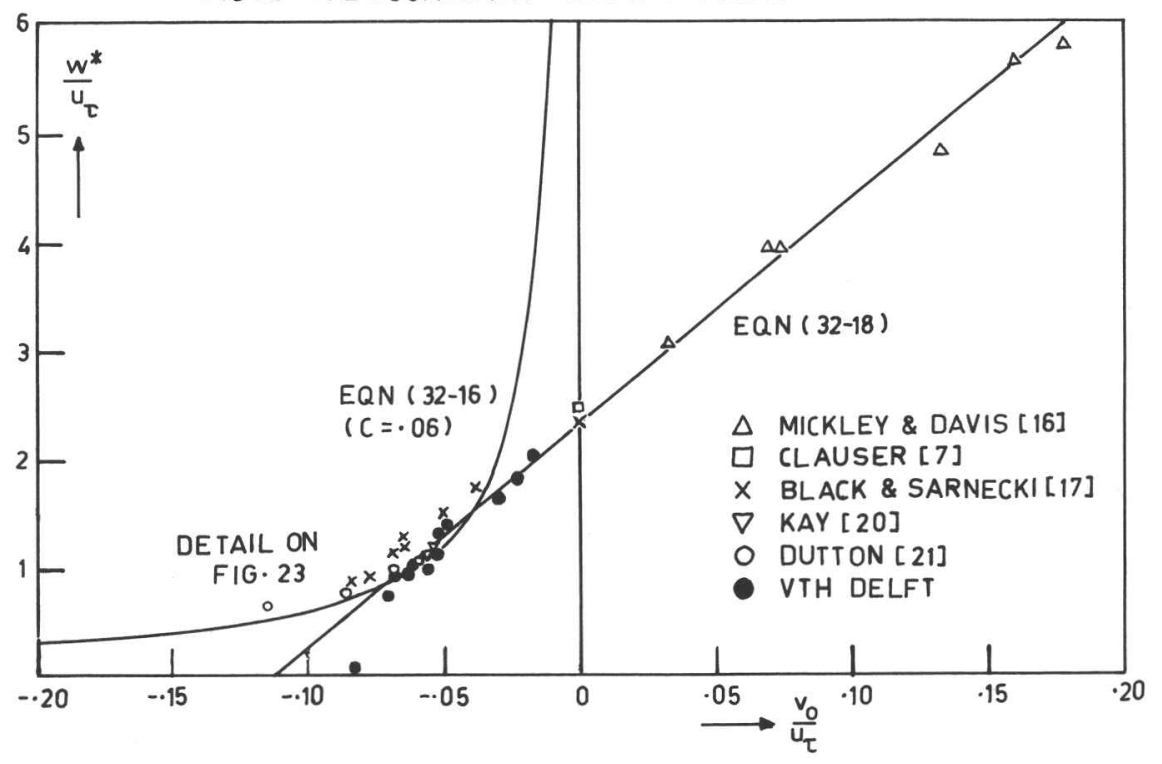




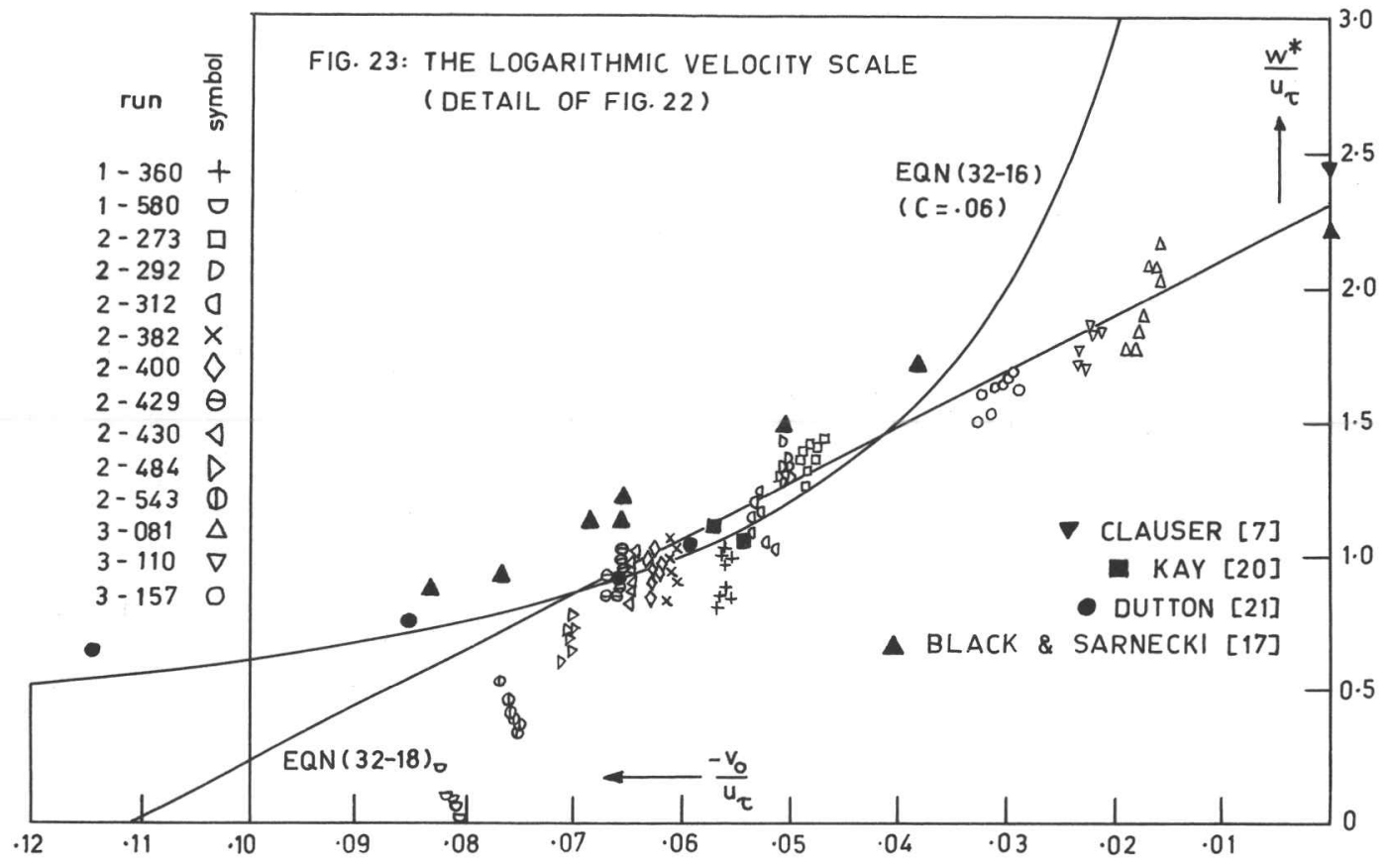

FIG. 24: SHIFT OF LOGARITHMIC VELOCITY DISTRIBUTION

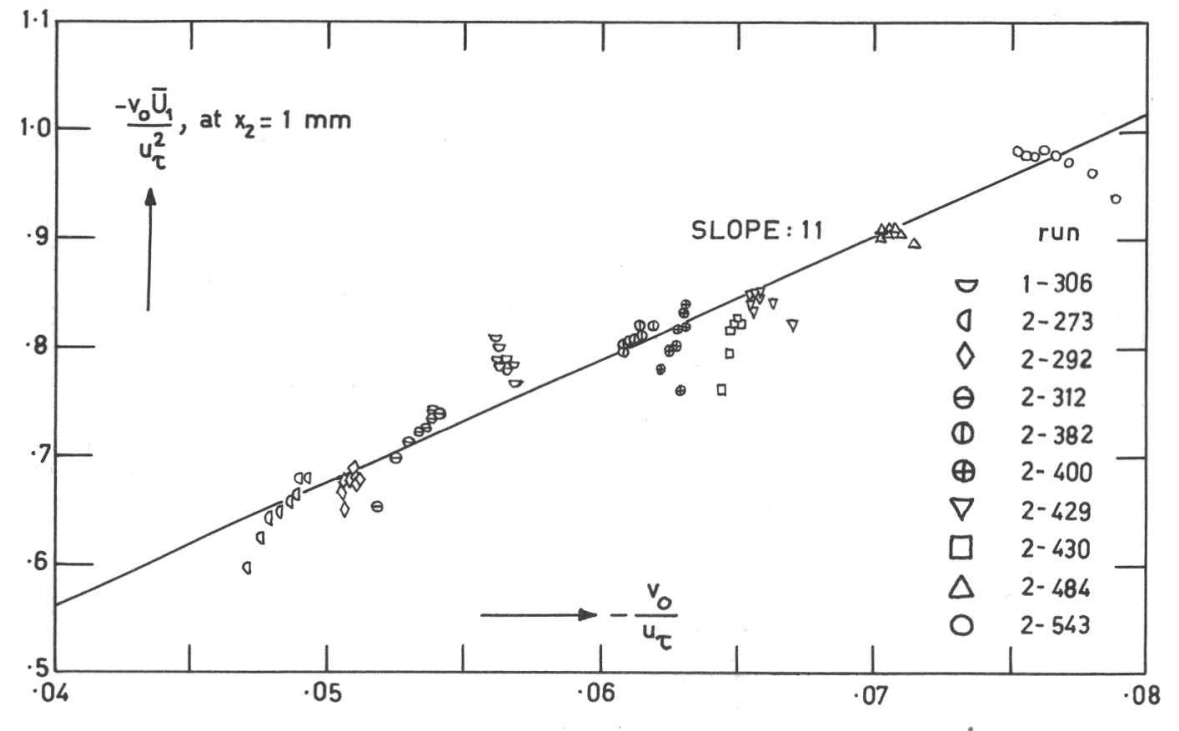


FIG. 25: SHIFT $A^{*}$, FUNCTION OF $-v_{0} / u_{\tau}$

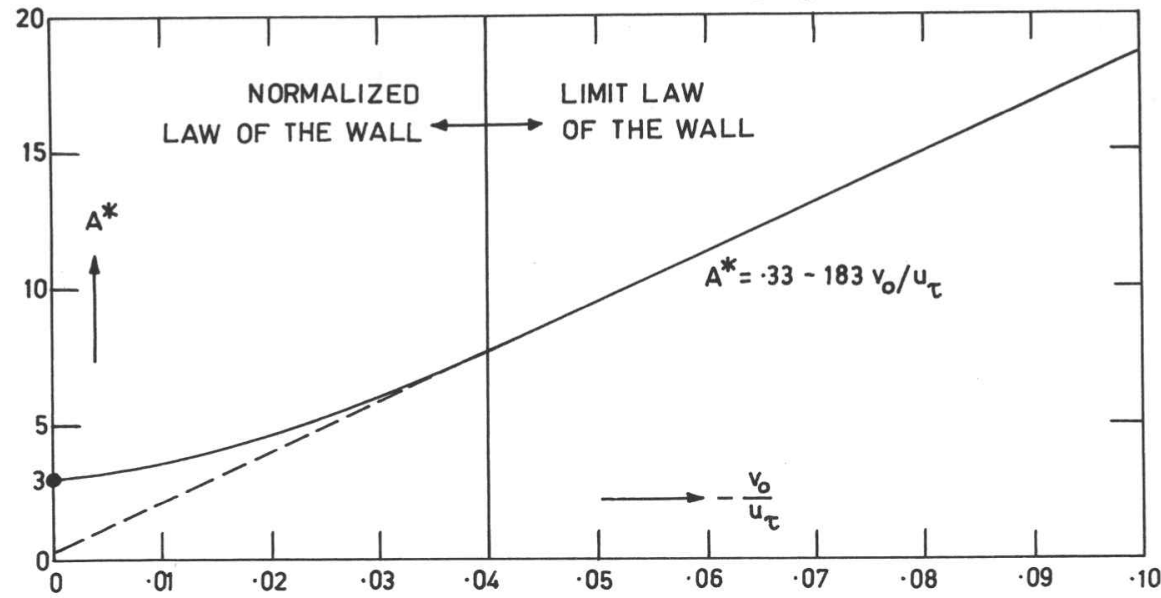

FIG. 26: VELOCITY DISTRIBUTIONS OF ASYMPTOTIC LAYERS

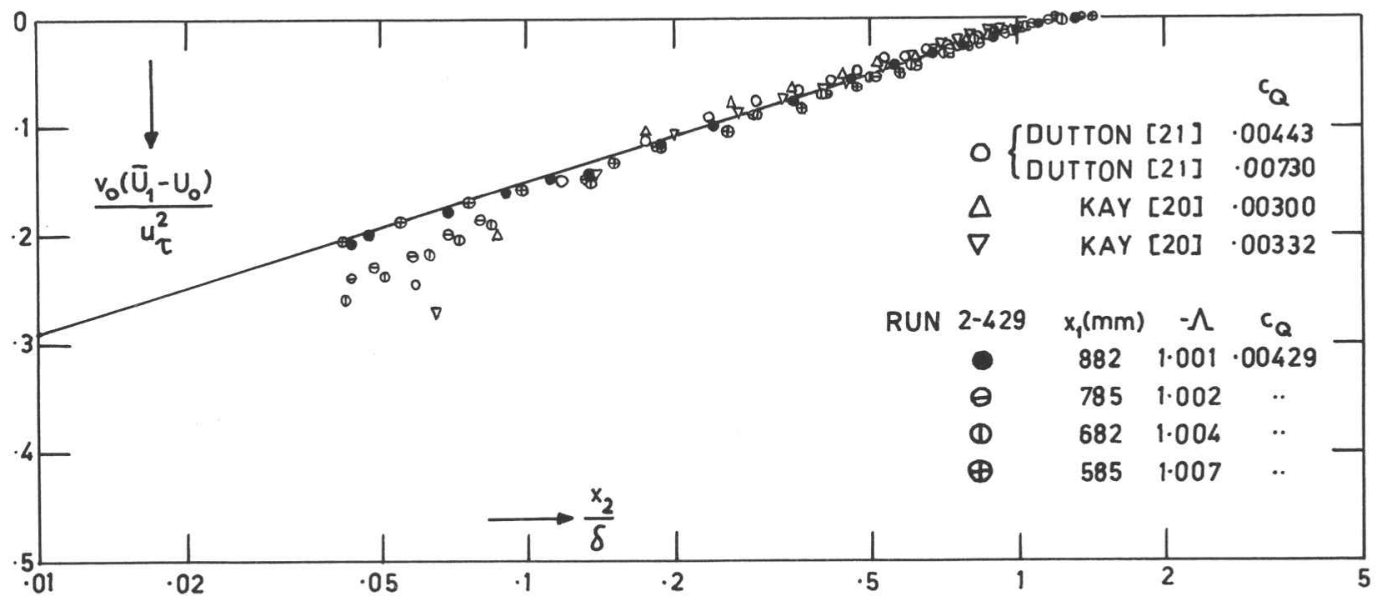


FIG. 27: THE BI-LOGARITHMIC LAW

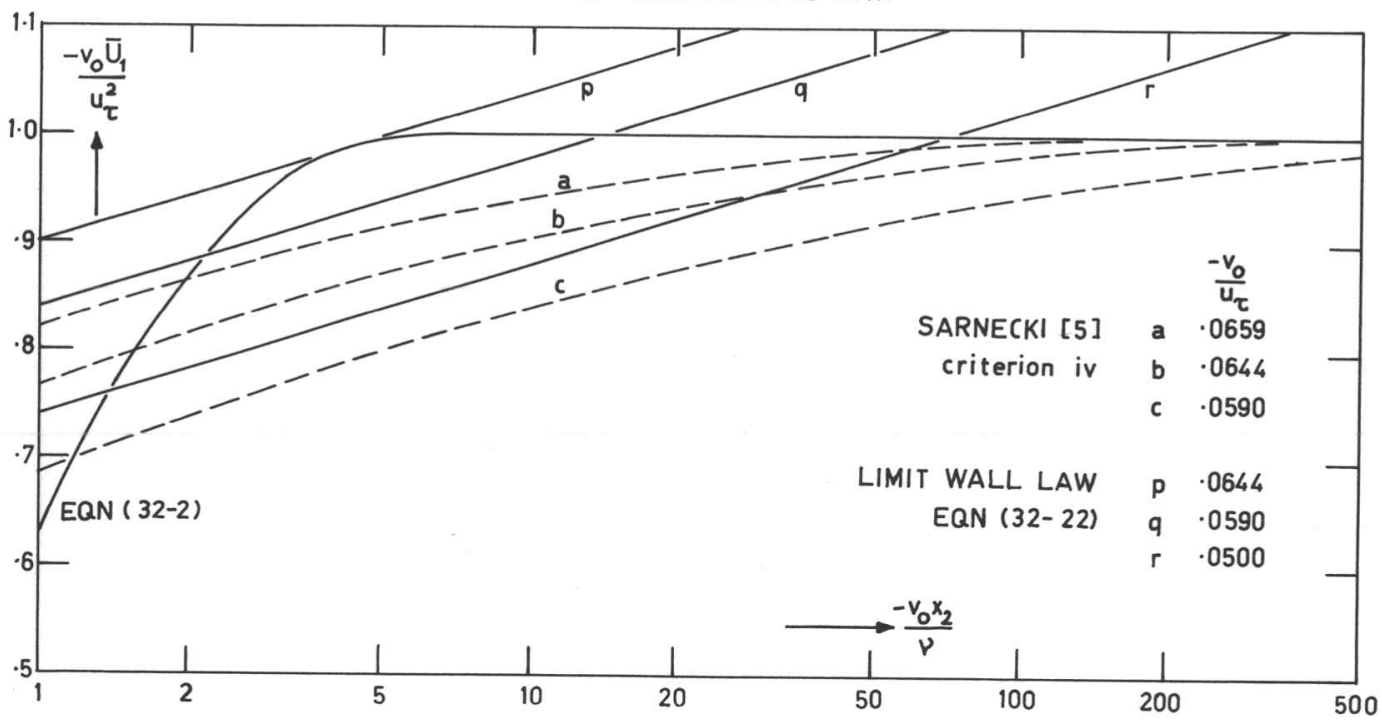

FIG. 28: SARNECKI'S VELOCITY DISTRIBUTIONS, RUNS X-374 AND N-374

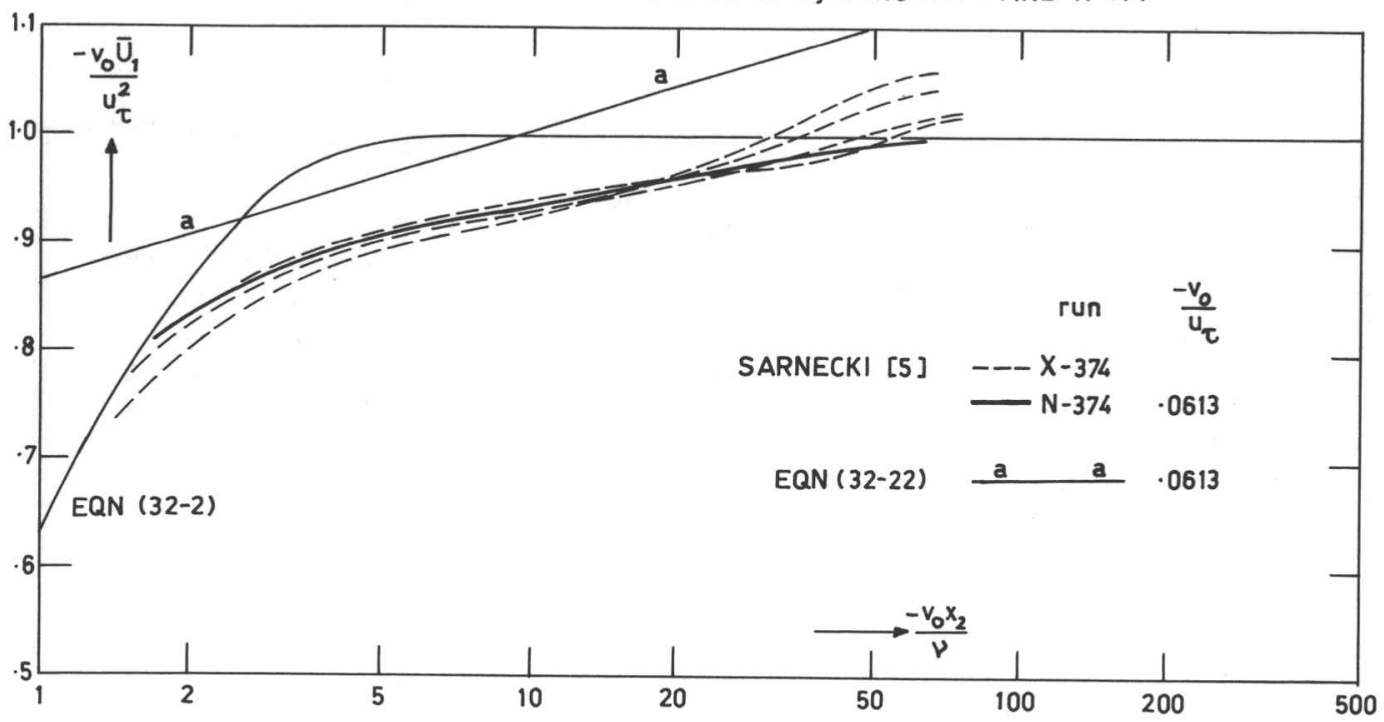


FIG.29: SARNECKI'S VELOCITY DISTRIBUTIONS, RUN P-404

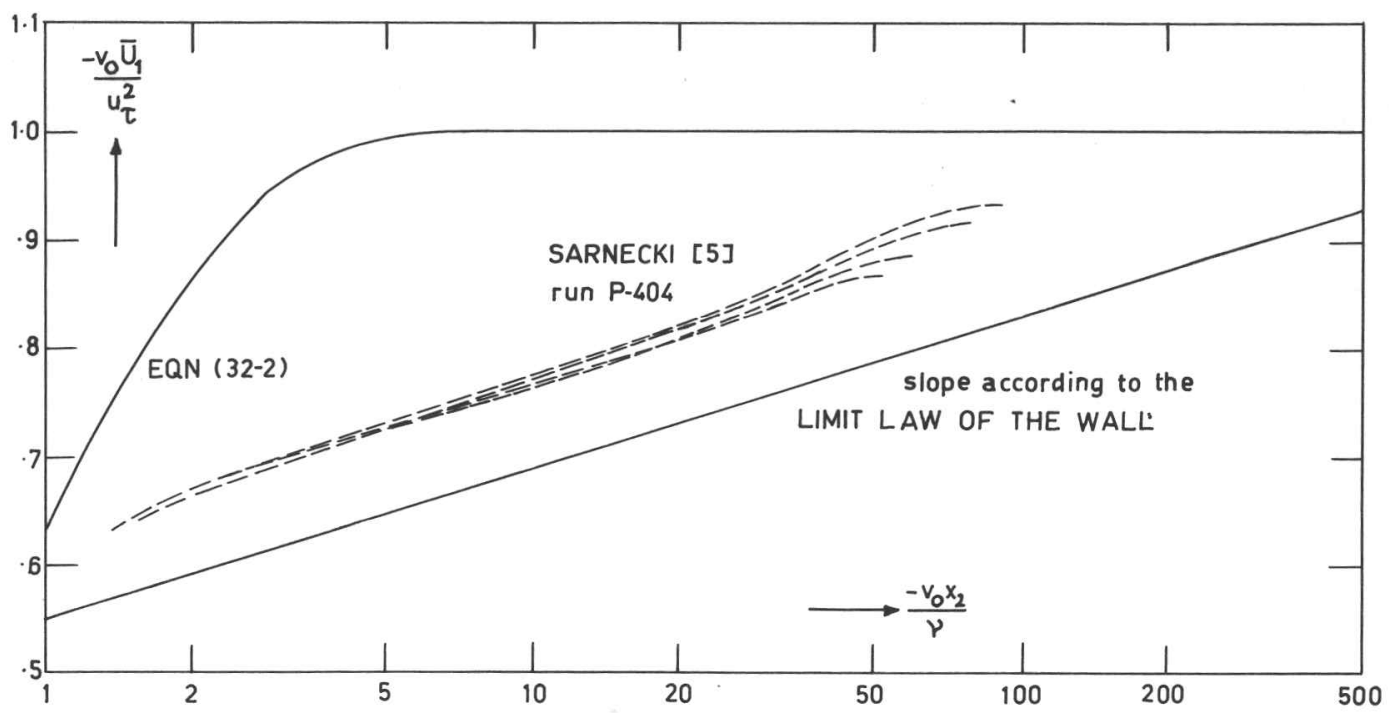

FIG.30: BI-LOGARITMIC LAW AND ASYMPTOTIC LAYERS

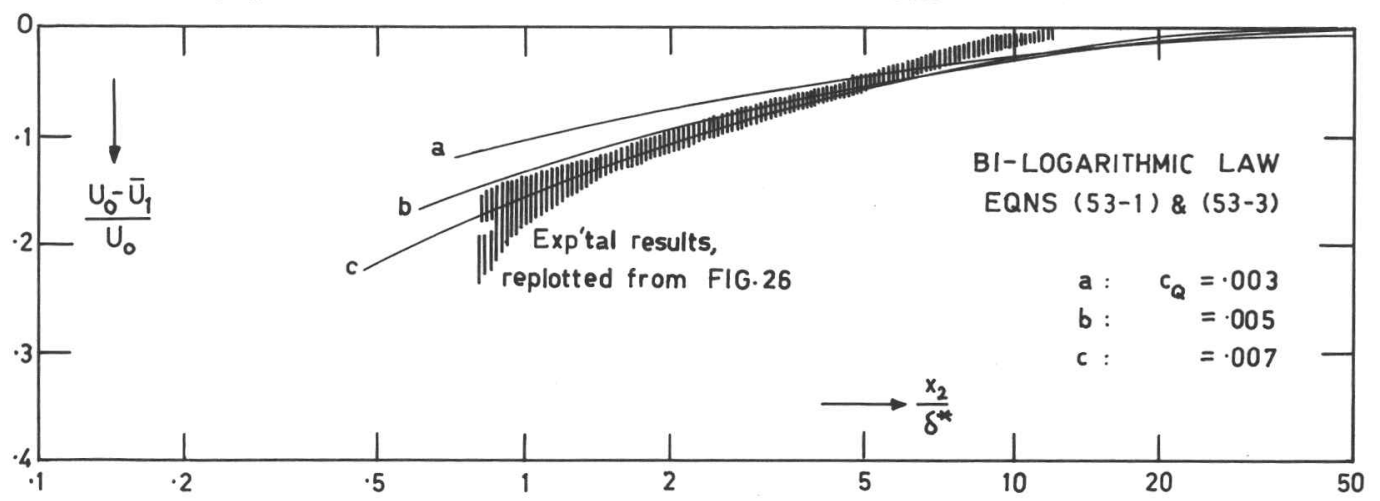

